\title{
Recent Progresses in Electrocatalysts for Water Electrolysis
}

\author{
Muhammad Arif Khan ${ }^{1,2} \cdot$ Hongbin Zhao ${ }^{1}$ (1) $\cdot$ Wenwen Zou ${ }^{1} \cdot$ Zhe Chen $^{1} \cdot$ Wenjuan Cao ${ }^{1}$ Jianhui Fang ${ }^{1}$. \\ Jiaqiang $\mathrm{Xu}^{1} \cdot$ Lei Zhang ${ }^{1,3}$. Jiujun Zhang ${ }^{1,4}$
}

Received: 5 June 2018 / Revised: 26 June 2018 / Accepted: 3 July 2018 / Published online: 28 July 2018

(c) The Author(s) 2019, corrected publication April 2019

\begin{abstract}
The study of hydrogen evolution reaction and oxygen evolution reaction electrocatalysts for water electrolysis is a developing field in which noble metal-based materials are commonly used. However, the associated high cost and low abundance of noble metals limit their practical application. Non-noble metal catalysts, aside from being inexpensive, highly abundant and environmental friendly, can possess high electrical conductivity, good structural tunability and comparable electrocatalytic performances to state-of-the-art noble metals, particularly in alkaline media, making them desirable candidates to reduce or replace noble metals as promising electrocatalysts for water electrolysis. This article will review and provide an overview of the fundamental knowledge related to water electrolysis with a focus on the development and progress of non-noble metal-based electrocatalysts in alkaline, polymer exchange membrane and solid oxide electrolysis. A critical analysis of the various catalysts currently available is also provided with discussions on current challenges and future perspectives. In addition, to facilitate future research and development, several possible research directions to overcome these challenges are provided in this article.
\end{abstract}

Keywords Electrocatalysts · Water electrolysis · Hydrogen generation · Energy storage · Proton exchange membrane · Alkaline media $\cdot$ Solid oxide electrolysis $\cdot$ Oxygen evolution $\cdot$ Hydrogen evolution

PACS 81.16. Hc- Catalytic methods

\section{Introduction}

Energy is a necessity for the economic and social development of the world, and currently, $65 \%$ of the global energy demand is fulfilled by non-renewable fossil fuels [1-3]. This fossil fuel consumption emits harmful greenhouse gasses such as $\mathrm{CO}_{2}$ gas, causing global warming and inducing a series of associated environmental damages. To deal with

Hongbin Zhao

hongbinzhao@shu.edu.cn

$₫$ Jiujun Zhang

jiujun@shaw.ca; jiujun.zhang@i.shu.edu.cn

1 Department of Chemistry, College of Sciences, Shanghai University, Shanghai 200444, China

2 School of Materials Science and Engineering, Shanghai University, Shanghai 200444, China

3 Energy, Mining and Environment, National Research Council of Canada, Vancouver V6T 1W5, Canada

4 Institute for Sustainable Energy, Shanghai University, Shanghai 200444, China the diminishing supply of fossil fuels and the increase in $\mathrm{CO}_{2}$ emissions, at least $10 \mathrm{TW}$ of renewable energy must be produced by 2050 [4-7], with sources from solar, wind, hydroelectricity, biomass, ocean thermal and sea wave/tide, etc. In conjunction to the exploration of renewable energy sources, energy storage technologies must be developed as well. Currently, there are several viable energy storage technologies with electrochemical technology being recognized as the most feasible and effective method in the storage and conversion of renewable energy. Electrochemical technologies include methods such as batteries, electrolysis, compressed air, fly wheels, pumped hydroelectricity, magnetic superconductors. Because $\mathrm{H}_{2}$ is the ultimate energy carrier in which produced $\mathrm{H}_{2}$ can be converted to electricity by using fuel cell technologies, the use of renewable electricity to electrolyse water for the production of hydrogen $\left(\mathrm{H}_{2}\right)$ is the ultimate method of energy storage among the different available electrochemical energy technologies. Therefore, the development of water electrolysis technologies for $\mathrm{H}_{2}$ production is of great urgency and importance [8-10]. 


\subsection{Hydrogen Production from Different Fuel Sources}

Hydrogen, possessing the highest specific energy content of $122 \mathrm{~kJ} \mathrm{~g}^{-1}$, has a 2.5 times higher specific energy content than hydrocarbons. Currently, the total global hydrogen production is about 500 billion cubic metre $\left(\mathrm{b} \mathrm{m}^{3}\right)$, of which the majority is used in ammonia synthesis, petroleum refining and metal refining [11]. Hydrogen can be produced from many sources, and the various sources for hydrogen energy production along with associated advantages and disadvantages are provided in Table 1 [12-16]. The ratio of hydrogen production from various sources are roughly $48 \%$ from natural gas, $30 \%$ from oils, $18 \%$ from coal and only $4 \%$ from electrolysis $[8,9]$.

\subsection{Hydrogen Production from Water Electrolysis}

In terms of environmental impact and sustainability, water electrolysis is the best method of hydrogen production because it utilizes renewable $\mathrm{H}_{2} \mathrm{O}$ and the only by-product is pure oxygen, which has no negative environmental effects. In addition, the consumed electricity in the electrolysis process can come from sustainable sources such as solar, wind, biomass. In electrolysis, water molecules are split into hydrogen and oxygen through the application of electricity and the cost of $\mathrm{H}_{2}$ energy production is mainly determined by the cost of electricity [4, 15, 17]. In Table 2, [17, 18] present and future costs of hydrogen production from electrolysis using different electricity sources are compared, and environmental impacts of the various electrolysis techniques are listed.

From Table 2, it can be seen that electrolysis using hydropower is the most reliable method of hydrogen production with the lowest production costs. Although hydrogen is a sustainable alternative for fossil fuels, challenges associated with this strategy remain. These challenges mainly include the high cost of production and the difficulty in storage due to the impossible liquification of hydrogen at room temperature [8, 18, 19].

Table 1 Hydrogen production from various sources and associated process mechanisms, efficiencies, costs as well as advantages/disadvantages [12-16]

\begin{tabular}{|c|c|c|c|c|c|}
\hline Source & Mechanism & Advantages & Disadvantages & $\begin{array}{l}\text { Hydrogen } \\
\text { cost }(\$ \\
\left.\mathrm{kg}^{-1}\right)\end{array}$ & Efficiency $\%$ \\
\hline $\begin{array}{l}\text { Steam methane } \\
\text { reforming (SMR) }\end{array}$ & $\begin{array}{l}\text { Bio } \\
\quad \text { gas }+ \text { steam } \rightarrow \mathrm{H}_{2}+\mathrm{CO}_{2}\end{array}$ & $\begin{array}{l}\text { Most developed technology } \\
\text { Existing infrastructure }\end{array}$ & $\begin{array}{l}\text { Geopolitical tension } \\
\text { Pollution }\left(\mathrm{CO}, \mathrm{CO}_{2}\right) \\
\text { Unstable supply }\end{array}$ & 2.27 & $74 \sim 85$ \\
\hline $\begin{array}{l}\text { Gasification of } \\
\text { coal }\end{array}$ & $\mathrm{C}_{2} \mathrm{H}_{4}+\mathrm{O}_{2} \rightarrow \mathrm{CO}+\mathrm{H}_{2}$ & & $\begin{array}{l}\text { Along with } \mathrm{H}_{2} \text {, the production of } \\
\text { heavy oils, petroleum and coke can } \\
\text { occur } \\
\mathrm{H}_{2} \text { production depends on season }\end{array}$ & 1.48 & $60 \sim 75$ \\
\hline $\begin{array}{l}\text { Hydrogen from } \\
\text { biomass }\end{array}$ & & $\begin{array}{l}\text { Less expensive } \\
\text { Dependent on renewable } \\
\text { sources } \\
\text { Other useful products can be } \\
\text { obtained such as adhesives, } \\
\text { polymers, fertilizers. }\end{array}$ & $\begin{array}{l}\text { Not entirely clean source because of } \\
\text { methane gas as by-product } \\
\text { Risk of deforestation } \\
\text { Inefficient as compared to fossil fuels }\end{array}$ & 2.05 & $35 \sim 50$ \\
\hline Nuclear energy & & Less carbon production & $\begin{array}{l}\text { Mining and processing of uranium } \\
\text { Disposal of radioactive waste } \\
\text { Potential for accidents }\end{array}$ & $4 \sim 7$ & $45 \sim 50$ \\
\hline Water electrolysis & $2 \mathrm{H}_{2} \mathrm{O} \rightarrow 2 \mathrm{H}_{2}+\mathrm{O}_{2}$ & $\begin{array}{l}\text { Zero emission } \\
\text { Proven technology } \\
\text { Existing infrastructure } \\
\text { By-product is } \mathrm{O}_{2}\end{array}$ & $\begin{array}{l}\text { Transportation problem } \\
\text { Storage problem } \\
\text { Applicable only to special purposes }\end{array}$ & $10 \sim 23$ & $40 \sim 60$ \\
\hline
\end{tabular}

Table 2 Comparison of various electricity sources for water electrolysis [17, 18]

\begin{tabular}{|c|c|c|c|c|}
\hline Electricity source & $\begin{array}{l}\text { Present cost } \\
\left(\$ \mathrm{~kg}^{-1}\right)\end{array}$ & Future cost $\left(\$ \mathrm{~kg}^{-1}\right)$ & Efficiency \% & $\begin{array}{l}\mathrm{CO}_{2} \text { emission } \\
\left(\mathrm{kg} \mathrm{CO}_{2} \mathrm{~kg}^{-1} \mathrm{H}_{2}\right)\end{array}$ \\
\hline Wind & $7 \sim 11$ & $3 \sim 4$ & 21 & 0 \\
\hline Solar & $10 \sim 30$ & $3 \sim 4$ & 20 & 0 \\
\hline Hydro & 1.4 & - & 25 & 0 \\
\hline Nuclear & $4.15 \sim 7$ & $2.45 \sim 2.63$ & 45 & 0 \\
\hline
\end{tabular}




\subsection{Classification of Water Electrolysis Technologies}

Water electrolysis can be classified into three main types depending on the types of electrolyte, operating temperatures and ionic agents. As shown in Fig. 1, the three types of electrolysis technologies are (a) alkaline electrolysis, (b) solid oxide electrolysis and (c) proton exchange membrane electrolysis. Table 3 lists the three types of water electrolysis technologies, their corresponding operation temperature ranges, as well as their advantages and disadvantages.

\subsubsection{Alkaline Electrolysis Cell (AEC)}

Troostwijik and Diemann first discovered the electrolysis phenomenon in 1789 [20, 21], and currently, the most mature hydrogen production technology is alkaline electrolysis (Fig. 1a) [22], which is being used on a global commercial scale. In alkaline electrolysis, two electrodes are immersed in a liquid alkaline solution of $20 \% \sim 30 \% \mathrm{KOH}$ caustic soda. At the anode, water oxidation occurs to produce $\mathrm{O}_{2}$; and at the cathode, water reduction occurs to produce $\mathrm{H}_{2}$. A diaphragm is present in the middle to separate the product gases from each other, avoiding the mixing of hydrogen with oxygen [23]. Alkaline electrolysis possesses several drawbacks such as limited electrolysis current densities, low partial loads and low operating pressures, which can lead to low energy efficiencies [24].

\subsubsection{Solid Oxide Electrolysis Cell (SOEC)}

The first ever solid oxide electrolysis cell (SOEC) was reported in the 1980s by Donitz and Erdle. Currently, the technology is still immature and further research is required. However, SOECs have been demonstrated to possess high hydrogen production efficiencies [25] and scientists believe that they have the potential to be applied on a commercial scale. Currently, the major focus in SOEC development is the exploration of novel, low-cost and durable materials [26].

\subsubsection{Proton Exchange Membrane Electrolysis Cell (PEMEC)}

To address the challenges of alkaline electrolysis cells, polymer membrane electrolysis was developed in 1960 for space applications [27]. This concept was further advanced by the use of solid sulphonated polystyrene membranes as an
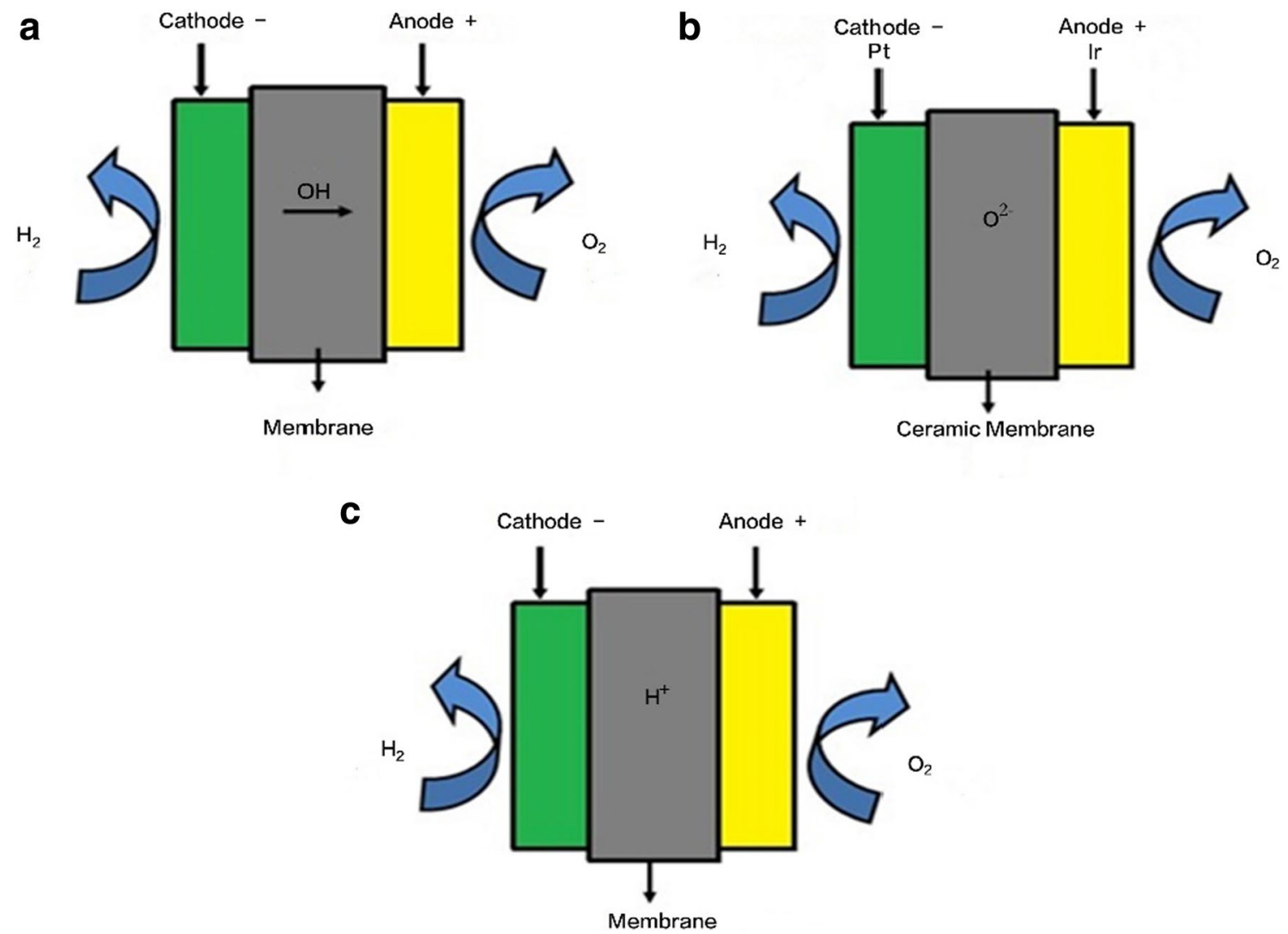

Fig. 1 Schematic illustration of a alkaline electrolysis, $\mathbf{b}$ solid oxide electrolysis, $\mathbf{c}$ proton exchange membrane electrolysis 
Table 3 Comparison of the three types of technology for water electrolysis [27-29]

\begin{tabular}{|c|c|c|c|}
\hline Type of electrolysers & $\begin{array}{l}\text { Operating tempera- } \\
\text { ture }\left({ }^{\circ} \mathrm{C}\right)\end{array}$ & Advantages & Disadvantages \\
\hline Alkaline & 40 90 & $\begin{array}{l}\text { Developed technology } \\
\text { Less expensive catalysts } \\
\text { Long-term stability } \\
\text { Cheap }\end{array}$ & $\begin{array}{l}\text { Current density is low } \\
\text { Low partial load range } \\
\text { Liquid electrolyte can cause corrosion } \\
\text { Crossover of gases }\end{array}$ \\
\hline Solid oxide & $500 \sim 1000$ & $\begin{array}{l}100 \% \text { efficiency } \\
\text { Non-noble catalysts } \\
\text { Possible high-pressure operation }\end{array}$ & $\begin{array}{l}\text { Laboratory-scale production } \\
\text { Bulky system } \\
\text { Brittle system because of ceramic catalysts } \\
\text { Operation at elevated temperatures }\end{array}$ \\
\hline Proton exchange membrane & $20 \sim 100$ & $\begin{array}{l}\text { High current density } \\
\text { High gas purity } \\
\text { High voltage efficiency } \\
\text { Component design } \\
\text { Good partial load range }\end{array}$ & $\begin{array}{l}\text { Mostly precious metal catalysts } \\
\text { Corrosive acidic environment }\end{array}$ \\
\hline
\end{tabular}

electrolyte. These types of membranes, known as polymer electrolyte membranes or solid polymer electrolyte membranes, are used for water electrolysis in PEMECs [27-31] and can be as low as 20 300 $\mu \mathrm{m}$ in thickness, resulting in many advantages such as low gas crossover, high proton conductivity, high-pressure operations and very compact designs.

\subsection{Electrocatalysis of Water Electrolysis Reactions}

In water electrolysis, water reduction at the cathode to produce $\mathrm{H}_{2}$ and water oxidation at the anode to produce $\mathrm{O}_{2}$ are in general kinetically sluggish, leading to low energy efficiencies. Therefore, electrocatalysts are necessary at the electrodes to speed up reaction kinetics. Electrocatalysis in water electrolysis is the biggest challenge for both lowtemperature alkaline electrolysis and proton exchange membrane electrolysis. Although great progress has been made in recent years, catalyst performances are still insufficient in terms of both catalytic activity and stability. To facilitate the research and development of advanced electrocatalysts, this article will review the most recent progresses in catalyst synthesis, characterization and performance [32, 33].

\subsubsection{Electrochemical Reactions in Water Electrolysis}

With regard to the catalytic process of water electrolysis, the overall reaction consists of two electrochemical halfreactions. These two reactions are the oxygen evolution reaction (OER) at the anode and the hydrogen evolution reaction (HER) at the cathode [32-34]. At the anode, water is oxidized to produce $\mathrm{O}_{2}$ as expressed by reactions (1)-(3) for the three types of water electrolysis indicated in Fig. 1:

$$
\begin{aligned}
2 \mathrm{H}_{2} \mathrm{O} \rightarrow & \mathrm{O}_{2}+4 \mathrm{H}^{+} \\
& +4 \mathrm{e}^{-} \text {(Proton exchange membrane electrolysis at low temperatures) } \\
4 \mathrm{OH}^{-} \rightarrow & 2 \mathrm{H}_{2} \mathrm{O}+\mathrm{O}_{2} \\
& \left.+4 \mathrm{e}^{-} \text {(Alkaline electrolysis at low temperatures }\right)
\end{aligned}
$$$$
2 \mathrm{O}^{2-} \rightarrow \mathrm{O}_{2}+4 \mathrm{e}^{-} \text {(Solid oxide electrolysis at high temperatures) }
$$

At the cathode, water is reduced to produce $\mathrm{H}_{2}$ as expressed by reactions (4)-(6) for three types of water electrolysis indicated in Fig. 1:

$2 \mathrm{H}^{+}+2 \mathrm{e}^{-} \rightarrow$

$\mathrm{H}_{2}$ (Proton exchange membrane electrolysis at low temperatures)

$2 \mathrm{H}_{2} \mathrm{O}+2 \mathrm{e}^{-} \rightarrow \mathrm{H}_{2}+2 \mathrm{OH}^{-}$(Alkaline electrolysis at low temperatures)

$\mathrm{H}_{2} \mathrm{O}+2 \mathrm{e}^{-} \rightarrow \mathrm{H}_{2}+\mathrm{O}^{2-}$ (Solid oxide electrolysis at high temperatures)

The overall reaction of the three electrolysis processes can all be expressed as Eq. (7) with a standard cell voltage of $1.23 \mathrm{~V}$ :

$2 \mathrm{H}_{2} \mathrm{O} \rightarrow \mathrm{O}_{2}+2 \mathrm{H}_{2}$

Here, it should be emphasized that the standard cell voltage of $1.23 \mathrm{~V}$ is in the case of standard thermodynamic conditions (1.0 atm and $25^{\circ} \mathrm{C}$ ), and not for other conditions.

Regarding the OER and HER kinetics, the OER is normally much slower than the HER, as indicated by the higher overpotential of the OER at the anode than that of the HER at the cathode. However, the overpotentials of the OER and the HER can both contribute to the limitations of overall energy efficiency for water electrolysis [35-37]. 
To reduce overpotentials and improve energy efficiencies, both OER and HER kinetics must be increased by using electrocatalysts in the electrolysis process, and in general, both OER and HER electrocatalysts are applied onto their corresponding electrodes. In latter sections of this article, these electrocatalysts will be reviewed in detail, and their properties and performance will be discussed.

\subsubsection{Requirements for Electrocatalysts for Water Electrolysis}

As discussed above, although the energy efficiency of water electrolysis is based on both the OER and the HER, the contribution of the OER is much greater than that of the HER. This is because the reaction overpotential of the OER is much higher than that of the HER. This higher overpotential is mainly caused by the multi-electron transfer reaction of the OER, involving several multi-step element reactions in which one rate-determining step dominates the overall reaction rate. Therefore, the role of an electrocatalyst is to speed up this rate-determining step, resulting in higher OER or HER rates and, subsequently, higher energy efficiencies [35, 36, 38-40].

In general, electrocatalysts for water electrolysis should possess several properties: (1) a highly active surface that provides good accessibility to reactants and can assist in the fast removal of products; (2) a high electrical conductivity; (3) be chemically/electrochemically/mechanically stable; and (4) provide low intrinsic overpotentials for OERs and/or HERs [41, 42].

For alkaline electrolyte electrolysis, the need for catalysts is not as critical as those of acidic electrolyte electrolysis (proton exchange membrane electrolysis) or solid oxide electrolysis. For example, less expensive transition metal oxides can be extensively used as catalysts for alkaline electrolysis, but expensive noble metal catalysts are required for proton exchange membrane electrolysis.

\section{Electrocatalysts for OER in Alkaline Electrolysis}

\subsection{Noble Metal Catalysts}

The most commonly used metals for noble metal catalysts are Ir and Ru because of their high stability, low Tafel value and small overpotential. Pt and Pd have also been used but their performance is lower in which the order of performance for these metals are as follows: $\mathrm{Ru}>\mathrm{Ir}>\mathrm{Pt}>\mathrm{Pd}$. Although $\mathrm{Ru}$ demonstrates superior performance, its practical applicability is hindered by its lower stability as compared with the other catalysts [43, 44]. In addition, $\mathrm{Ir}$ and $\mathrm{Ru}$ oxides $\left(\mathrm{RuO}_{2}\right.$ and $\left.\mathrm{IrO}_{2}\right)$ are much more active and stable in basic media than their pure metal counterparts because pure Ir and $\mathrm{Ru}$ are more soluble than oxides in basic electrolytes, leading to decreased stability and potential in basic electrolytes for commercial scale applications [45-49].

In general, porous structures with extremely large specific surface areas can offer numerous benefits for charge and mass transport in electrochemistry. Therefore, noble metal catalysts, possessing porous structures, demonstrate good catalytic activities for OERs [50-52]. To synthesize porous noble metal catalysts, template synthesis routes have been adopted by researchers and the most commonly used templates are polymeric or inorganic beads such as polystyrene (PS), and poly (methyl methacrylate) or silica spheres. For example, in a study conducted by Lee et al. [53], catalytic performances were increased by decorating Ir onto the surface of carbon with Ir and graphene oxide (GO) as precursors and polystyrene (PS) as the template (Fig. 2a-e). In this process, the GO was deposited onto the surface of the PS, and Ir ions were adsorbed onto the surface of the GO. And in addition to the intrinsically high conductivity of the GO, the addition of the GO increased the electrochemical surface area of the resulting catalyst by 6 orders of magnitude, resulting in enhanced catalytic performances in which a current density of $89.99 \mathrm{~mA} \mathrm{~cm}^{-2}$ was obtained at a potential of $1.6 \mathrm{~V}$ in their testing.

Because the use of noble metals can increase the cost of hydrogen energy production, reducing the usage quantity of such noble metal-based catalysts is necessary for OER processes to become more economical. Based on this, an effective strategy is to use metal nanoparticles (NPs), such as $\mathrm{Ag}, \mathrm{Au}, \mathrm{Pt}, \mathrm{Ru}, \mathrm{RuO}_{2}$, Ir, $\mathrm{IrO}_{2}$ and NiRuP, to coat the surface of carbon. The reason for this is because researchers have found that the electrocatalytic properties of NPs are far more superior to bulk systems. Furthermore, performances can be further improved if bimetallic NPs were formed on carbon surfaces, in which the catalytic performance improvements can be attributed to the generation of NPs forming active sites for rapid water dissociation and fast electron transfer [54-57].

In a recent study by $\mathrm{Li}$ et al. [58], efforts were made to enhance the intrinsic activity and durability of an Ir and $\mathrm{Ru}$ oxide-based catalyst in which a discontinuous $\mathrm{IrO}_{2}$ layer was supported on the surface of $\mathrm{RuO}_{2} @ \mathrm{Ru}$. Here, outstanding OER activities were observed because of a combination of high activities from both $\mathrm{RuO}_{2}$ and $\mathrm{IrO}_{2}$. In this study, as shown in Fig. 3a, $\mathrm{RuCl}_{3}$ was reduced to metallic $\mathrm{Ru}$, which initiated the synthesis process, acting as a support for the $\mathrm{H}_{2} \mathrm{IrCl}_{6}$ precursor. The supported $\mathrm{IrO}_{2}-\mathrm{RuO}_{2} @ \mathrm{Ru}$ was subsequently obtained through hydrolysis and thermal treatment and in electrochemical testing, achieved a current density of $10 \mathrm{~mA} \mathrm{~cm}{ }^{-2}$ with an overpotential of only $281 \mathrm{mV}$, which was superior to alloyed $\mathrm{Ir}_{3} \mathrm{RuO}_{2}$ and $\mathrm{IrO}_{2}$ crystals.

In another example, Liyanage et al. [59] developed a synthesis process to prepare ternary metal phosphide 
a

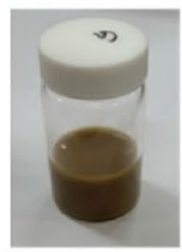

Solution 1 $\mathrm{GO} / \mathrm{PS} / \mathrm{IrCl}_{3}$

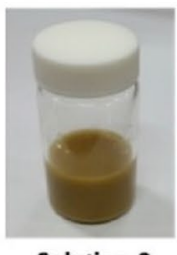

Solution 2 $\mathrm{PS} / \mathrm{IrCl}$
Coating

b

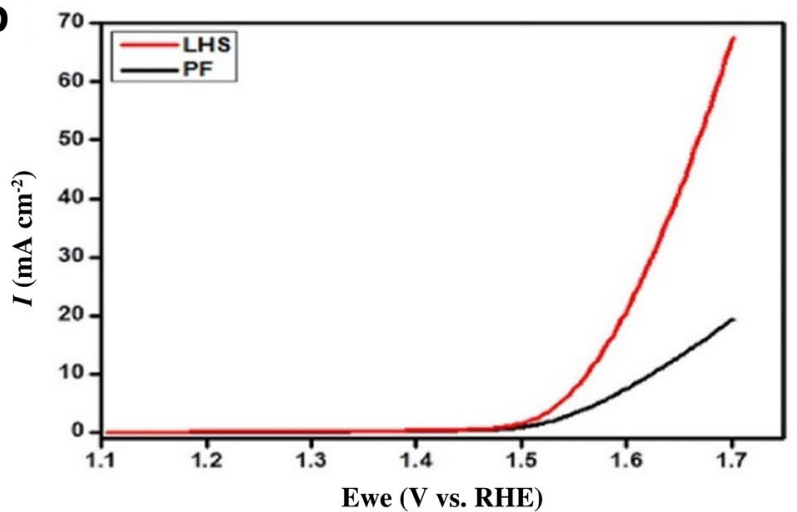

d

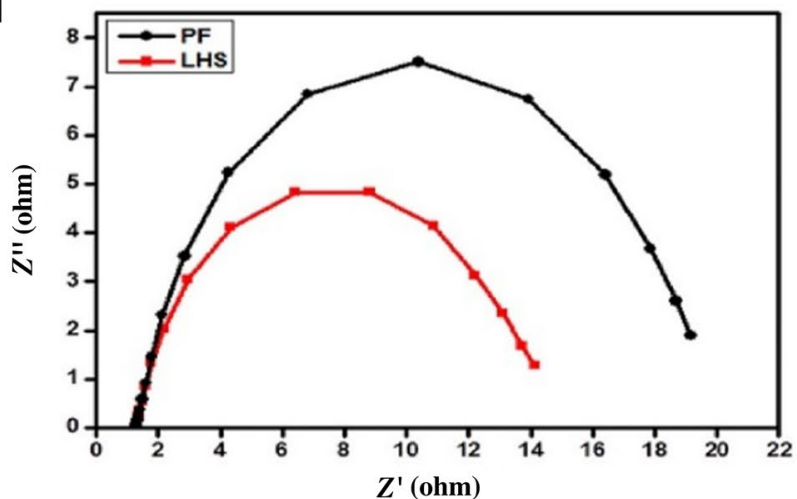

Fig. 2 a Schematic illustration of the formation of a layered hollow sphere electrode and a porous film electrode. b OER activity comparison between layered hollow spheres (LHS) and porous film (PF)

nanoparticles $\left(\mathrm{Ni}_{2-x} \mathrm{Ru}_{x} \mathrm{P}\right)$ to create an efficient, low-cost noble metal catalyst for the OER. This composite of Ru and highly active but inexpensive Ni metal was considered by the researchers to be a state-of-the-art catalyst for the OER and its morphology was evaluated by using the TEM. The corresponding images of each composition are shown in Fig. 3b. In the evaluations of this catalyst, the Ni-rich composite was found to possess a spherical morphology that shifted

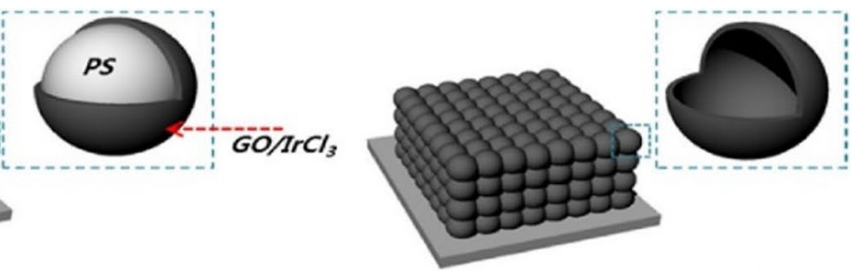

Pyrolysis

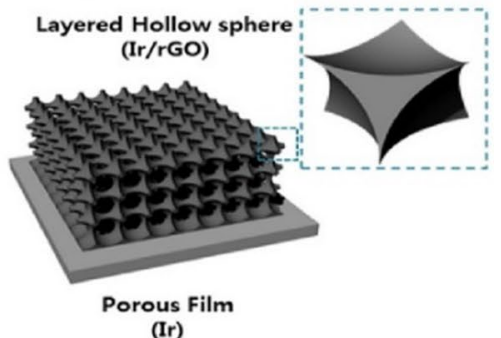

(Ir)
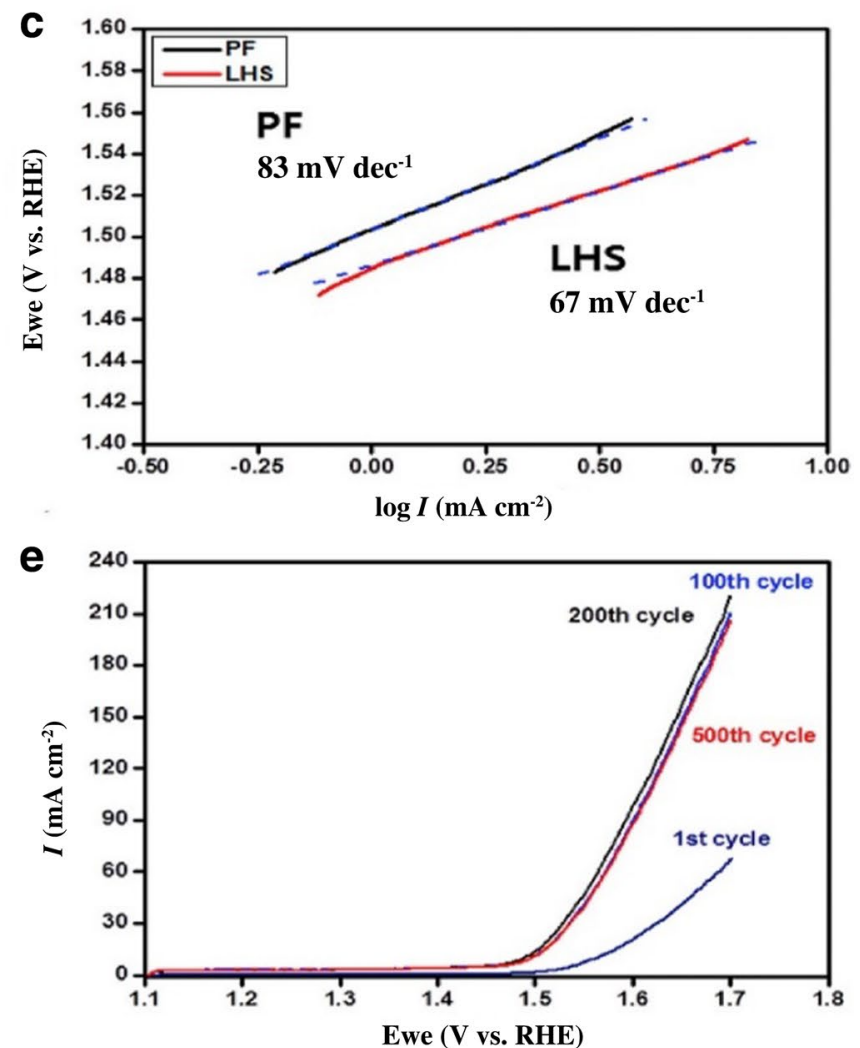

electrodes. c Tafel plots. d Electrochemical impedance spectroscopy (EIS) of the LHS and PF electrodes. e OER activity of the LHS electrode according to cycle numbers [53]

from spherical to elongated nanoparticles with increasing $\mathrm{Ru}$ amounts. The catalyst also demonstrated an OER activity comparable to that of $\mathrm{RuO}_{2}$ and $\mathrm{IrO}_{2}$ (an overpotential of $340 \mathrm{mV}$ at a current density of $10 \mathrm{~mA} \mathrm{~cm}^{-2}$ ) (Fig. 3c).

Although the various strategies of decreasing noble metal loading and changing morphologies by using templates are shown to provide improvements, they are still not effective enough because the cost of noble metals are ever-increasing. 


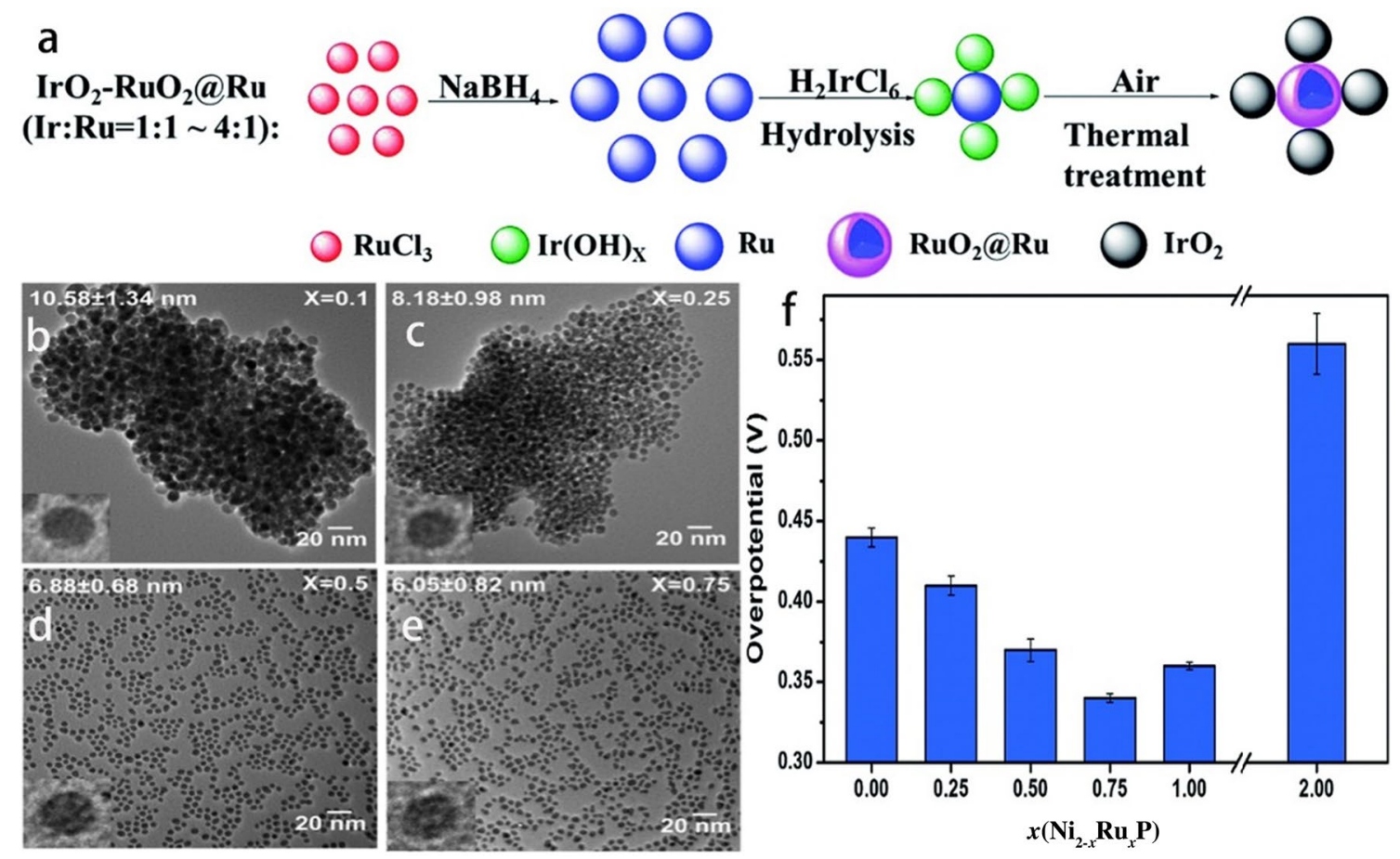

Fig. 3 a Schematic illustration of the synthesis of $\mathrm{IrO}_{2}-\mathrm{RuO}_{2} @ \mathrm{Ru}$ nanocatalysts [58]. b-e TEM images for $\mathrm{Ni}_{2-x} \mathrm{Ru}_{x} \mathrm{P}$ nanoparticles. f Changes in overpotential (at $10 \mathrm{~mA} \mathrm{~cm}{ }^{-2}$ ) for different compositions of $\mathrm{Ni}_{2-x} \mathrm{Ru}_{x} \mathrm{P}$ in $1.0 \mathrm{M} \mathrm{KOH} \mathrm{[59]}$

As an alternative to address the issue of cost, non-noble metal catalysts need to be explored as OER catalysts for alkaline water electrolysis.

\subsection{Non-noble Metal Catalysts}

Although noble metal compounds are the most efficient catalysts for the OER, their high cost is a major obstacle towards commercialization and widespread application. The shortterm solutions such as the lowering of noble metal loading have shown promise, they are not effective because the price of noble metals is ever-increasing, essentially nullifying the improvements of decreased metal loading. Alternatively, an effective approach towards this problem is the replacement of noble metals with non-noble metals. And in recent years, transition metal compounds such as $\mathrm{Ni}, \mathrm{Co}$, and $\mathrm{Fe}$ compounds, being highly abundant, inexpensive, corrosion resistant and highly active in alkaline environments, have been extensively explored as OER catalysts and are steadily replacing noble metals. In 2017, a comparative study by Huang et al. [59] revealed that $\mathrm{Ni}$-based compounds are more promising as non-noble metal OER catalysts, and in 2008, Jiang et al. [60] found that the order of the electrocatalytic performances of transition metal compounds was in the order of $\mathrm{Ni}>\mathrm{Co}>\mathrm{Fe}[60,61]$.

Transition metal compounds are also promising in OER catalyst applications because of their variable oxidation states, presence of $3 d$ electrons and morphological properties. In addition, the performance of these compounds can be further enhanced by changing their particle sizes, surface areas and microstructures. As for Ni-based OER catalysts, they are in the form of oxides, hydroxides and double hydroxides and the various compounds studied recently are $\mathrm{NiP}, \mathrm{Ni}_{3} \mathrm{Fe}, \mathrm{NiFe}(\mathrm{OH})_{2}, \mathrm{~N}$-doped $\mathrm{NiFe}, \mathrm{NiS}, \mathrm{NiFe}-\mathrm{LDHs}$, $\mathrm{NiFe}$ oxide, $\mathrm{NiCo}_{2} \mathrm{O}_{4}$, Fe-doped $\mathrm{NiCo}_{2} \mathrm{O}_{4}$ and $\mathrm{NiCoO}_{2}$. Some of these catalysts with their performance values are provided in Table 4 . In addition to $\mathrm{Ni}$, this article will also discuss cobalt (Co)- and manganese (Mn)-based compounds.

\subsubsection{Nickel Oxides}

Nickel oxides are good candidates for the OER [62-65] because these catalysts are resistant to corrosion in alkaline media. In addition, enhancements in the performance of these catalysts can be made by changing their particle size, surface area and microstructure, which motivated researchers to discover new methods to enhance electrocatalytic OER activities as well.

As an example, Arciga-Duran et al. [61] obtained NiO films for testing through the electrodeposition of $\mathrm{Ni}$ using an electrolyte solution containing glycine at different $\mathrm{pH}$ levels. In their resulting SEM images, the researchers found that by increasing the $\mathrm{pH}$ level of the electrolyte solution through the addition of glycine, the grain size of the $\mathrm{NiO}$ 
film decreased from 170 to $70 \mathrm{~nm}$, and that oxygen vacancies increased from $25 \%$ to $36 \%$. The researchers attributed this to the combustion of occluded glycine. The researchers also obtained the best OER performances from the $\mathrm{NiO}$ film catalysts that were obtained at $\mathrm{pH}$ levels greater than 5, achieving a current density of $1 \mathrm{~mA} \mathrm{~cm}{ }^{-2}$ with an overpotential of $450 \mathrm{mV}$.

Electrodes possessing 3D structures can also provide high electrical conductivities, large surface areas and high stability. Because of this, nickel foam (NF), a 3D electrode substrate with a long-range porous structure, can potentially facilitate the enhancement of charge transfer and mass transport. Based on this, Babar et al. [62] developed a novel thermal oxidation method to produce a $3 \mathrm{D}$ porous $\mathrm{NiO}$ electrocatalyst on a nickel foam (NF) substrate that achieved a high electrocatalytic activity with a low Tafel slope value of $54 \mathrm{mV} \mathrm{dec}^{-1}$ and an overpotential value of $310 \mathrm{mV}$ to reach a current density of $10 \mathrm{~mA} \mathrm{~cm}{ }^{-2}$ (Fig. $4 \mathrm{~g}-\mathrm{h}$ ). In this study, XRD analysis revealed that the degree of crystallinity on the 3D porous electrocatalyst can increase with increasing thermal oxidation temperatures. Furthermore, the interconnected nanowalled structure of the catalyst, as confirmed by the FESEM shown in Fig. 4a-f, was found to thicken with increasing thermal oxidation temperatures.

For nickel oxide electrocatalysts, the use of nickel in higher electronic states, such as $\mathrm{Ni}^{3+}$, usually resulted in optimal OER performances [62]. Based on this, Zhang et al. [63] assembled Fe-doped $\mathrm{NiO}_{x}$ catalysts from ultrathin nanosheets containing trivalent $\left(\mathrm{Ni}^{3+}\right)$ active centres. Here, XPS analysis confirmed the presence of $\mathrm{Ni}^{3+}$ active sites and the incorporation of $\mathrm{Fe}$ and $\mathrm{Ni}$ was found to result in an increase in oxygen vacancies. And because of this, the OER activity of the assembled $\mathrm{Fe}$-doped $\mathrm{NiO}_{x}$ catalyst was found to be superior to $\mathrm{NiO}_{x}$ catalysts without Fe doping. The effects of Fe doping were also reported by Wu et al. [64] based on a Fe-doped mesoporous $\mathrm{NiO}$ catalyst synthesized through a facile solvothermal method. Here, the well-connected 3D porous nanosheet array structure of the prepared catalyst provided many active sites and Fe doping resulted in the modification of the $\mathrm{NiO}$ electronic structure through activating Ni centres (Fig. 5a-c). The resulting catalyst demonstrated enhanced OER activities with a low overpotential value of $206 \mathrm{mV}$ and a Tafel slope $49.4 \mathrm{mV} \mathrm{dec}^{-1}$ to reach a current density of $10 \mathrm{~mA} \mathrm{~cm}^{-2}$.

The OER performance of nickel oxides can be further improved by the introduction of other metals $(\mathrm{Co}, \mathrm{Fe}$ or $\mathrm{Mn}$ ) to form binary metal oxides and their composites (e.g. $\mathrm{NiCoO}_{2}, \mathrm{NiCo}_{2} \mathrm{O}_{4}$ [66-77], $\mathrm{NiMnO}_{4}[78]$ and $\mathrm{NiFe}$ oxides) [79-86]. These materials are referred to by researchers as spinel oxides and can demonstrate superior performances as OER catalysts. And of these spinel oxides, the effects of synthesis routes and calcination temperatures have been extensively studied for $\mathrm{NiCo}_{2} \mathrm{O}_{4}$ [65-76], in which several synthesis methods, including coprecipitation by using $\mathrm{NaOH}$, thermal decomposition of hydroxides, microemulsion, and sol-gel, have been evaluated. Here, it was found that optimal catalytic performances can be obtained from catalysts obtained through the coprecipitation method under an optimal temperature of $325^{\circ} \mathrm{C}$. The reason calcination temperatures have such significant effects on performance is that at insufficient temperatures, samples remain as a mixture of two individual oxides and at high temperatures, sintering occurs, causing a decrease in active surface areas [72]. For example, Chen et al. [66] fabricated $3 \mathrm{D} \mathrm{NiCo}_{2} \mathrm{O}_{4}$ core-shell nanowires using a simple two-step wet chemical method on a flexible conductive carbon cloth substrate and obtained a catalyst with high surface areas, enhanced charge transfers and 3D conductive pathways, all of which collectively contributed towards a high OER performance [67].

Numerous studies have provided evidence that catalyst morphology is a crucial factor for performance enhancement $[66,67,70,71,73]$. Based on this, Yan et al. [76] fabricated a $\mathrm{MnO}_{2} / \mathrm{NiCo}_{2} \mathrm{O}_{4}$ catalyst supported on the nickel foam (NF) through the hydrothermal method which provided high catalytic activities and found that the NF support can provide a 3D skeleton, facilitating the utilization of active surface areas and mass transfers of the electrolyte. The researchers also found that the synergetic effect between $\mathrm{MnO}_{2}$ and $\mathrm{NiCo}_{2} \mathrm{O}_{4}$ is another factor contributing towards high catalytic activities in which the vertically aligned $\mathrm{NiCo}_{2} \mathrm{O}_{4}$ nanoflakes on the surface of the $\mathrm{Ni}$ foam can provide more exposed active sites, further interconnecting with each other to form a hierarchical structure which can act as a precursor for the dispersion of $\mathrm{MnO}_{2}$ layers (Fig. $5 \mathrm{~d}-\mathrm{g}$ ). And because of these beneficial morphological properties, the OER performance of this catalyst in alkaline media was found to be superior with an overpotential value of $340 \mathrm{mV}$ at a current density of $10 \mathrm{~mA} \mathrm{~cm}^{-2}$. Figure 6 shows the SEM images of $\mathrm{NiCo}_{2} \mathrm{O}_{4}$ with different morphologies.

In conclusion, through extensive research, mono-oxides, bimetallic oxides (spinal oxides), ternary oxides and other composites/hybrids of nickel have been proven to be promising materials for OERs in alkaline electrolyte solutions (Table 4).

\subsubsection{Ni-Based LDHs}

Ni-based layered double hydroxides (LDHs) have also been explored as suitable candidates for catalysing the OER in water-splitting applications [87-94]. Despite having low electric conductivities, LDHs possess special structures that are helpful in the enhancement of OER performances, and among all LDHs catalysts, NiFe-LDH catalysts have been found to possess the best performances. For example, Yan et al. [87] synthesized a high-performing NiFe-layered double hydroxide using a cost-effective method which contained coprecipitation followed by delamination (Fig. 7d). 
Table 4 Non-noble metal OER catalysts in alkaline media

\begin{tabular}{|c|c|c|c|c|c|}
\hline Material & Electrolyte & $\begin{array}{l}\text { Overpotential } \\
(\mathrm{mV})\end{array}$ & $\begin{array}{l}\text { Tafel value } \\
\left(\mathrm{mV} \mathrm{dec}^{-1}\right)\end{array}$ & $\begin{array}{l}\text { Current density } \\
\left(\mathrm{mA} \mathrm{cm}^{-2}\right)\end{array}$ & References \\
\hline $\mathrm{NiO}$ film & $1 \mathrm{M} \mathrm{NaOH}$ & 450 & 96 & 1 & {$[62]$} \\
\hline $\mathrm{NiO} / \mathrm{NF}$ & $1 \mathrm{M} \mathrm{KOH}$ & 310 & 54 & 10 & {$[63]$} \\
\hline $\mathrm{Fe}-\mathrm{NiO}$ & $1 \mathrm{M} \mathrm{KOH}$ & 310 & 49 & 10 & {$[64]$} \\
\hline $\mathrm{Fe}-\mathrm{NiO} / \mathrm{NF}$ & $1 \mathrm{M} \mathrm{KOH}$ & 206 & 49.4 & 10 & {$[65]$} \\
\hline $\mathrm{NiCo}_{2} \mathrm{O}_{4} / \mathrm{Ti}_{4} \mathrm{O}_{7}$ & $1 \mathrm{M} \mathrm{KOH}$ & - & 64 & 10 & {$[66]$} \\
\hline $\mathrm{NiFeO}_{2}$ & $0.1 \mathrm{M} \mathrm{KOH}$ & 329 & - & 2 & [79] \\
\hline $\mathrm{NiCoO}_{2}$ nanowires & $1 \mathrm{M} \mathrm{KOH}$ & 303 & 57 & 10 & {$[75]$} \\
\hline $\mathrm{Fe}-\mathrm{NiCo}_{2} \mathrm{O}_{4}$ & $0.1 \mathrm{M} \mathrm{KOH}$ & 350 & 27 & 10 & {$[68]$} \\
\hline $\mathrm{NiFeO}$ & $1 \mathrm{M} \mathrm{KOH}$ & 300 & - & 10 & {$[85]$} \\
\hline $\mathrm{MnO}_{2} / \mathrm{NiCo}_{2} \mathrm{O}_{4}$ & $1 \mathrm{M} \mathrm{KOH}$ & 340 & - & 10 & {$[77]$} \\
\hline $\mathrm{NiO} / \mathrm{NiFe}_{2} \mathrm{O}_{4}$ & $1 \mathrm{M} \mathrm{KOH}$ & 302 & 42 & 10 & {$[80]$} \\
\hline $\mathrm{Ni}_{3} \mathrm{Fe}$ & $1 \mathrm{M} \mathrm{KOH}$ & 248 & 98 & 10 & {$[105]$} \\
\hline $\mathrm{NiFe}$ & $1 \mathrm{M} \mathrm{KOH}$ & - & 90 & 10 & [106] \\
\hline Boron-doped $\mathrm{NiFe}$ & $1 \mathrm{M} \mathrm{KOH}$ & 350 & 40 & 10 & {$[107]$} \\
\hline $\mathrm{NiFe}$ & $1 \mathrm{M} \mathrm{KOH}$ & 257 & - & 10 & {$[108]$} \\
\hline $\mathrm{N}$-doped NiFe & $1 \mathrm{M} \mathrm{KOH}$ & 360 & - & 10 & [110] \\
\hline NiCo@NC & $1 \mathrm{M} \mathrm{KOH}$ & - & 100 & 10 & [109] \\
\hline NiFe-LDHs & $1 \mathrm{M} \mathrm{KOH}$ & 350 & 47 & 12.8 & [88] \\
\hline NiFe-LDHs & $1 \mathrm{M} \mathrm{KOH}$ & 240 & - & 20 & {$[90]$} \\
\hline 3D NiFe-LDHs & $0.1 \mathrm{M} \mathrm{KOH}$ & 435 & - & 10 & [89] \\
\hline $\mathrm{NiFe} / \mathrm{RGO}$ & $1 \mathrm{M} \mathrm{KOH}$ & 245 & - & 10 & {$[92]$} \\
\hline $\mathrm{NiFeAl} \mathrm{LDHs}$ & $1 \mathrm{M} \mathrm{KOH}$ & 304 & 57 & 20 & [87] \\
\hline NiFe-LDHs & $1 \mathrm{M} \mathrm{KOH}$ & 210 & 39 & 10 & [91] \\
\hline $\mathrm{Ni}-\mathrm{P}$ foam & $1 \mathrm{M} \mathrm{KOH}$ & 350 & - & 10 & [98] \\
\hline $\mathrm{Ni}_{2} \mathrm{P}$ & $1 \mathrm{M} \mathrm{KOH}$ & 290 & - & 10 & {$[95]$} \\
\hline $\mathrm{Fe}-\mathrm{NiP} / \mathrm{NF}$ & $1 \mathrm{M} \mathrm{KOH}$ & 192 & 50 & 10 & {$[103]$} \\
\hline $\mathrm{NiP}_{2} / \mathrm{CC}$ & $1 \mathrm{M} \mathrm{KOH}$ & 310 & - & 20 & [97] \\
\hline FeNiP & $1 \mathrm{M} \mathrm{KOH}$ & 156 & 66 & 10 & {$[100]$} \\
\hline $\mathrm{Co}_{3} \mathrm{O}_{4}$ nanostructure & $1 \mathrm{M} \mathrm{KOH}$ & 356 & - & 10 & {$[130]$} \\
\hline $\mathrm{Co}_{3} \mathrm{O}_{4}$ crystalline & $1 \mathrm{M} \mathrm{KOH}$ & - & 49 & 10 & {$[127]$} \\
\hline $\mathrm{Co}_{3} \mathrm{O}_{4}$ nanosheet & $1 \mathrm{M} \mathrm{KOH}$ & 330 & 72 & 20 & [131] \\
\hline $\mathrm{Fe}-\mathrm{Co}_{3} \mathrm{O}_{4}$ & $0.1 \mathrm{M} \mathrm{KOH}$ & 420 & - & 10 & [135] \\
\hline $\mathrm{CoFe}_{2} \mathrm{O}_{4}$ & $1 \mathrm{M} \mathrm{KOH}$ & 490 & 54.2 & 10 & [133] \\
\hline Porous $\mathrm{Co}_{3} \mathrm{O}_{4}$ & $0.1 \mathrm{M} \mathrm{KOH}$ & 306 & 65 & 10 & [137] \\
\hline $\mathrm{ZnCo}_{2} \mathrm{O}_{4}$ & $0.1 \mathrm{M} \mathrm{KOH}$ & 306 & 65 & 10 & [139] \\
\hline $\mathrm{CoWO}_{4}$ & $1 \mathrm{M} \mathrm{KOH}$ & 389 & 59.4 & 10 & [134] \\
\hline $\mathrm{Co} @ \mathrm{Co}_{3} \mathrm{O}_{4}$ & $1 \mathrm{M} \mathrm{KOH}$ & 309 & 51 & 10 & {$[145]$} \\
\hline $\mathrm{Co}_{3} \mathrm{O}_{4} \mathrm{NPs} / \mathrm{G}$ & $0.1 \mathrm{M} \mathrm{KOH}$ & 435 & - & 10 & [140] \\
\hline $\mathrm{Co}_{3} \mathrm{O}_{4} / \mathrm{CoMoO}_{4}$ & $0.1 \mathrm{M} \mathrm{KOH}$ & 375 & 67 & 10 & {$[143]$} \\
\hline $\mathrm{Co}-\mathrm{N} / \mathrm{C} \mathrm{Co}_{3} \mathrm{O}_{4}$ & $0.1 \mathrm{M} \mathrm{KOH}$ & 318 & 63 & 10 & [142] \\
\hline CoP polyhedron & $0.1 \mathrm{M} \mathrm{KOH}$ & 300 & 57 & 10 & [148] \\
\hline $\mathrm{Co}_{2} \mathrm{P}$ needles & $1 \mathrm{M} \mathrm{KOH}$ & - & 127 & 10 & [149] \\
\hline $\mathrm{Co}_{2} \mathrm{P} \mathrm{NWs}$ & $1 \mathrm{M} \mathrm{KOH}$ & 400 & 57 & 10 & {$[150]$} \\
\hline $\mathrm{CoFeP}$ & $1 \mathrm{M} \mathrm{KOH}$ & 267 & 30 & 10 & [156] \\
\hline $\mathrm{CoP}_{2} / \mathrm{RGO}$ & $1 \mathrm{M} \mathrm{KOH}$ & - & 25.6 & 10 & {$[158]$} \\
\hline $\mathrm{CoS}$ & $1 \mathrm{M} \mathrm{KOH}$ & 267 & 30 & 10 & [163] \\
\hline $\mathrm{Co}_{9} \mathrm{~S}_{8} / \mathrm{NS}-\mathrm{CN}$ & $0.1 \mathrm{M} \mathrm{KOH}$ & 271 & 64.8 & 10 & [165] \\
\hline $\mathrm{Fe}-\mathrm{CoSe}_{2}$ & $1 \mathrm{M} \mathrm{KOH}$ & 330 & 82 & 10 & {$[170]$} \\
\hline $\mathrm{Mn}-\mathrm{CoN}$ & $1 \mathrm{M} \mathrm{KOH}$ & 265 & - & 10 & [168] \\
\hline $\mathrm{Mn}_{2} \mathrm{O}_{3}$ & $1 \mathrm{M} \mathrm{KOH}$ & 427 & - & 10 & {$[177]$} \\
\hline
\end{tabular}


Table 4 (continued)

\begin{tabular}{llllll}
\hline Material & Electrolyte & $\begin{array}{l}\text { Overpotential } \\
(\mathrm{mV})\end{array}$ & $\begin{array}{l}\text { Tafel value } \\
\left.(\mathrm{mV} \mathrm{dec})^{-1}\right)\end{array}$ & $\begin{array}{l}\text { Current density } \\
\left.(\mathrm{mA} \mathrm{cm})^{-2}\right)\end{array}$ & References \\
\hline $\mathrm{Ni}-\mathrm{Mn}_{3} \mathrm{O}_{4}$ & $1 \mathrm{M} \mathrm{KOH}$ & 283 & 165 & 10 & {$[180]$} \\
\hline
\end{tabular}
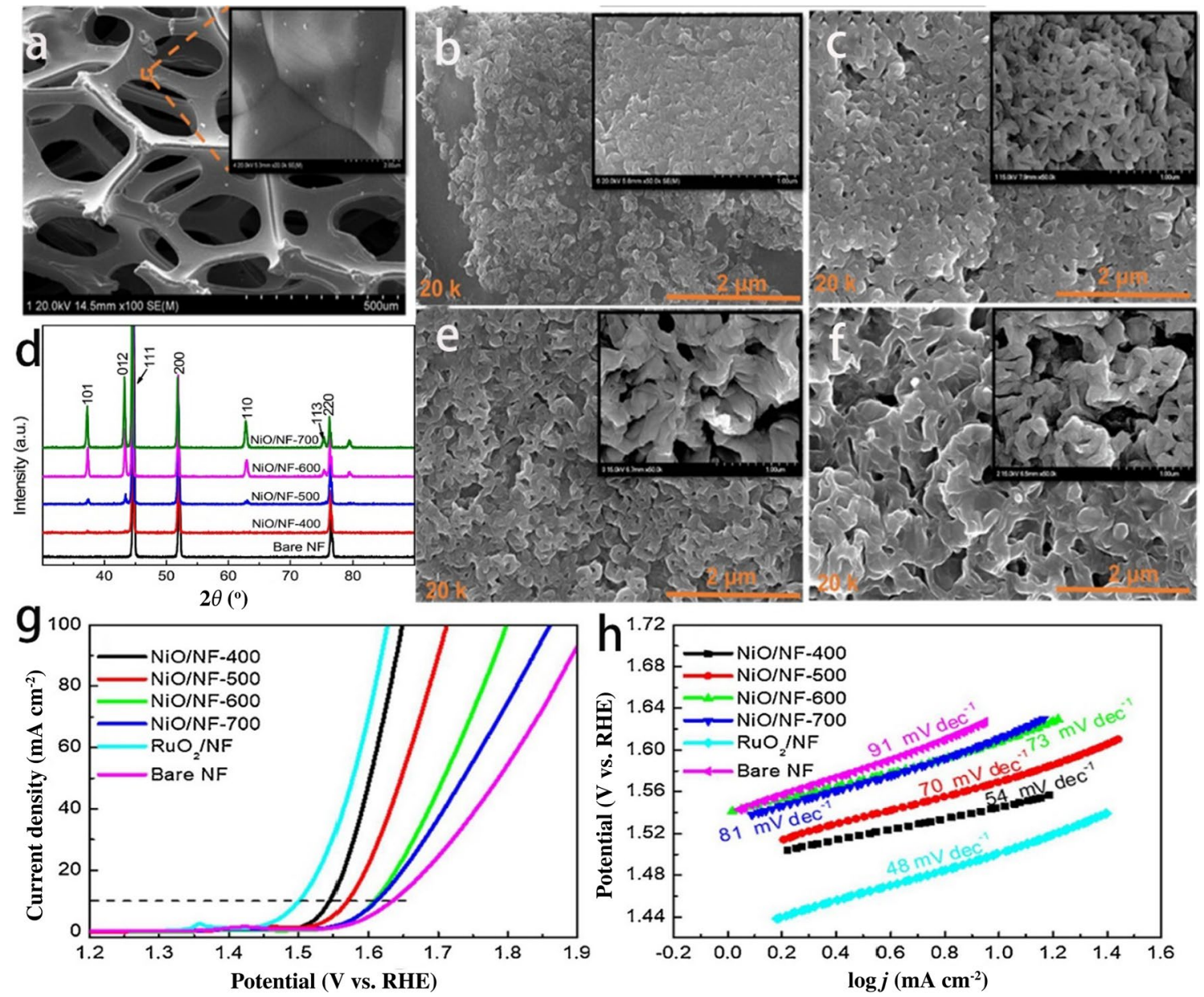

Fig. 4 a-f XRD pattern of NiO/NF and SEM images at different temperatures. $\mathbf{g}$ OER polarization curves. $\mathbf{h}$ Tafel plots [63]

The observed high electrocatalytic activity of this LDH was attributed to its nanosheet array structure in which the delamination step can prevent the agglomeration of the nanosheets. In this study, a comparative analysis was also made between four different LDHs, namely NiFe-LDH, CuFe-LDH, CoFe-LDH and ZnFe-LDH, among which, $\mathrm{NiFe}-\mathrm{LDH}$ demonstrated the highest OER performance with a Tafel slope value of $47 \mathrm{mV} \mathrm{dec}^{-1}$ (Fig. 7b, c) [88]. Another drawback of LDHs is that they possess significantly higher charge densities because of the barriers between layers of nanosheets. To modify this, Li et al. [88] designed an atomically thin layered $\mathrm{NiFe}-\mathrm{LDH}$ to synergistically incorporate the effects of released carbonate anions and butanol. Based on this, the obtained catalyst gained a $3 \mathrm{D}$ porous structure which in combination with the atomically thin layered LDHs nanosheets, enhanced electrocatalytic activities.

In general, graphene-based electrocatalysts possess desired activities for OER applications but is hindered because of their chemical inertness. However, if combined with LDHs, the properties of graphene and LDHs complement each other, increasing performances [94]. And because the chemical reactivity of graphene can be improved by combining with LDHs that possess high chemical reactivity, a new field of hybrid compounds as OER catalysts is emerging. Xia et al. [93] suggested that this enhanced catalytic activity can be attributed to the promising synergetic effects between $\mathrm{NiFe}$ and the reduced graphene oxide (RGO), in which the RGO layer can facilitate the uniform deposition of $\mathrm{NiFe}$, providing electrochemical pathways and high surface 


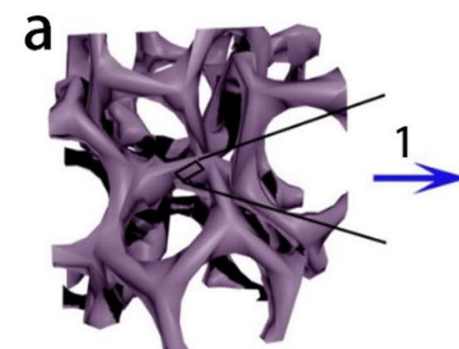

$\mathrm{Ni}$ foam
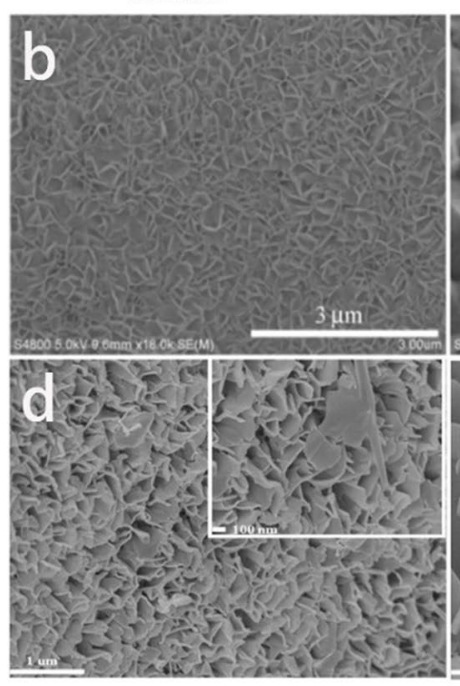

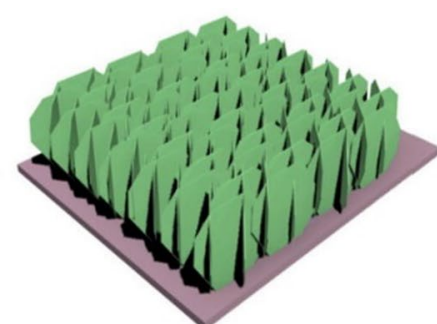

Fe-doped $\beta-\mathrm{Ni}(\mathrm{OH})_{2}$ array

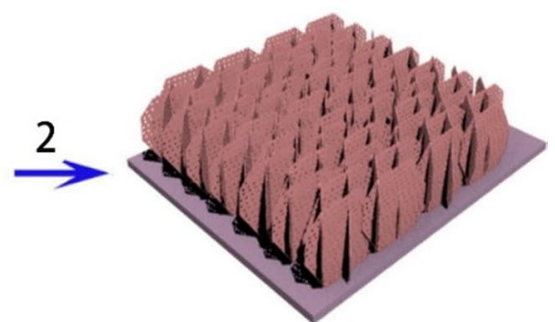

Fe-doped mesoporous $\mathrm{NiO}$ array
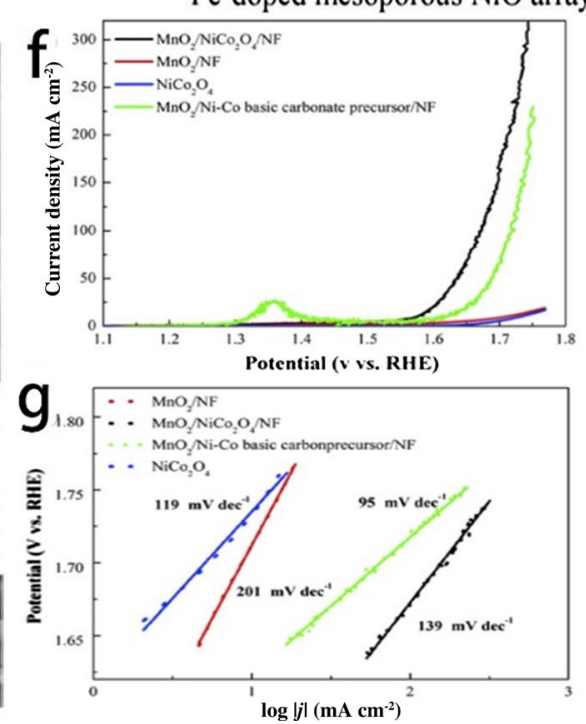

Fig. 5 a Graphical representation of the formation process of the $\mathrm{Fe}$-doped $\mathrm{NiO}$ mesoporous nanosheets array. b-c FESEM images of $\mathrm{Fe}_{11 \%}-\mathrm{NiO} / \mathrm{NF}$ with low and high magnifications [65]. d SEM

areas to the loaded NiFe. The researchers here demonstrated this by synthesizing a graphene-/Ni-Fe-layered doublehydroxide composite and found that the obtained catalyst provided good stability (up to 1000 cycles), satisfactory electrocatalytic property (overpotential of $245 \mathrm{mV}$ at a current density of $10 \mathrm{~mA} \mathrm{~cm}^{-2}$ ) and a high faradic efficiency of 97\% [93]. Based on these results, this composite shows promise in future commercial scale applications because of its high stability, activity and low cost. The synthesis process of the composite is illustrated in Fig. 7a.

Despite promising performances, Ni-based LDHs still face challenges such as low electrical conductivities for electron transportation. This problem can be reduced, however, through coupling with carbon nanotubes, graphene-like networks or exfoliation. Nevertheless, there is much need for further developments in LDHs to achieve desirable electrocatalytic performances.

\subsubsection{Ni Phosphides}

Ni-based phosphides are generally employed as HER catalysts in alkaline water electrolysis; however, inspired by the promising HER activities of these catalysts, researchers image of Ni-Co basic carbonate precursor. e SEM image of $\mathrm{MnO}_{2} /$ $\mathrm{NiCo}_{2} \mathrm{O}_{4} / \mathrm{NF}$. f-g Linear sweep voltammetry (LSV) and Tafel slopes of $\mathrm{NiCo}_{2} \mathrm{O}_{4} / \mathrm{NF}$ [77]

have started to investigate their OER activities as well and have obtained promising results demonstrating that these $\mathrm{Ni}$ based phosphides have potential as OER catalysts [95-99]. In one example, Stern et al. [94] reported $\mathrm{Ni}_{2} \mathrm{P}$ as an OER catalyst in alkaline media in which the researchers adopted two separate synthesis routes. One route involved a thermal reaction between $\mathrm{NaH}_{2} \mathrm{PO}_{2}$ and $\mathrm{NiCl}_{2} \cdot 6 \mathrm{H}_{2} \mathrm{O}$ at $250{ }^{\circ} \mathrm{C}$ resulting in poly-dispersed nanoparticles of about $50 \mathrm{~nm}$ in size. The other route resulted in $\mathrm{Ni}_{2} \mathrm{P}$ nanowires which were with an average of $11 \mathrm{~nm}$ in size fabricated by heating nickel acetylacetone in a solution of oleic acid, trioctylamine and tri- $n$-octylphosphine at $320^{\circ} \mathrm{C}$. The second method proved to be more suitable for the synthesis of $\mathrm{Ni}_{2} \mathrm{P}$ giving more uniform particle size. In this study, the researchers found that as an OER catalyst, $\mathrm{Ni}_{2} \mathrm{P}$ provided superior performances comparable with state-of-the-art catalysts such as nickel oxides and spinal oxides with an overpotential of only $290 \mathrm{mV}$ being required to reach a current density of $10 \mathrm{~mA} \mathrm{~cm}^{-2}$.

Further enhancements in the electrocatalytic activity of Ni phosphides can be made by the introduction of doping elements. For example, a facile and safe sol-gel method was developed by Liu et al. [95] for the synthesis of $\mathrm{Ni}_{2} \mathrm{P}$ 

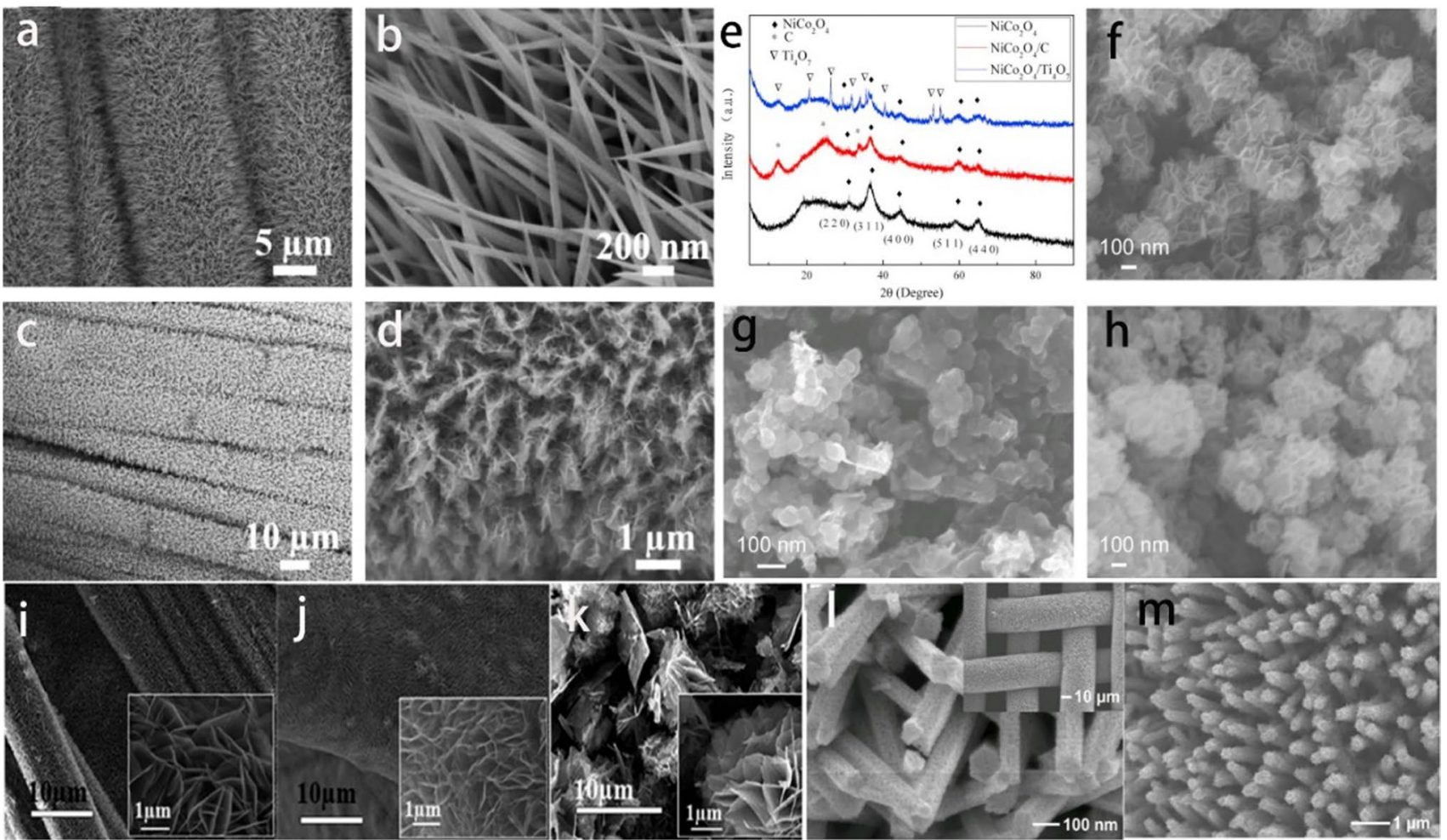

Fig. 6 a-d SEM images of $\mathrm{NiCo}_{2} \mathrm{O}_{4}$ nanowire arrays [67]. e-h XRD patterns and SEM images of $\mathrm{NiCo}_{2} \mathrm{O}_{4}, \mathrm{NiCo}_{2} \mathrm{O}_{4} / \mathrm{C}$ and $\mathrm{NiCo}_{2} \mathrm{O}_{4} / \mathrm{Ti}_{4} \mathrm{O}_{7}$ [66]. i-k SEM images of $\mathrm{NiCo}_{2} \mathrm{O}_{4} / \mathrm{CP}, \mathrm{NiCo}_{2} \mathrm{O}_{4} / \mathrm{NF}$ and $\mathrm{NiCo}_{2} \mathrm{O}_{4}$ nanosheets [70]. $\mathbf{l}-\mathbf{m}$ SEM and TEM images of $\mathrm{NiCo}_{2} \mathrm{O}_{4} / \mathrm{SSL}_{\text {[71] }}$

a

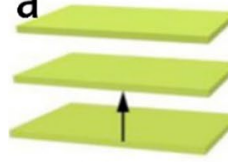

GO nanosheet

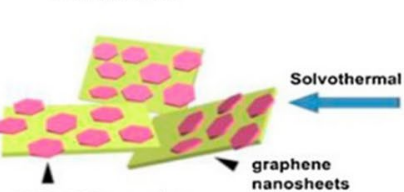

Ni-Fe LDH nanoplates

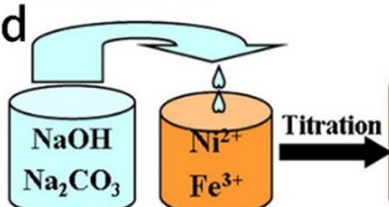

Exfoliation

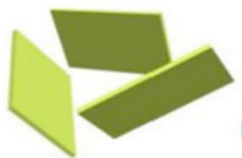

$\int$

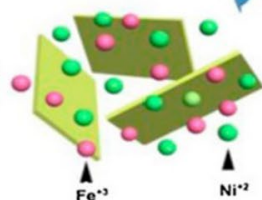

b

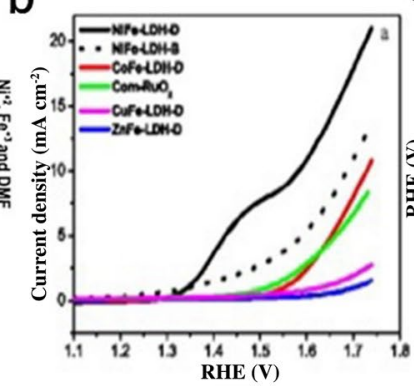

C
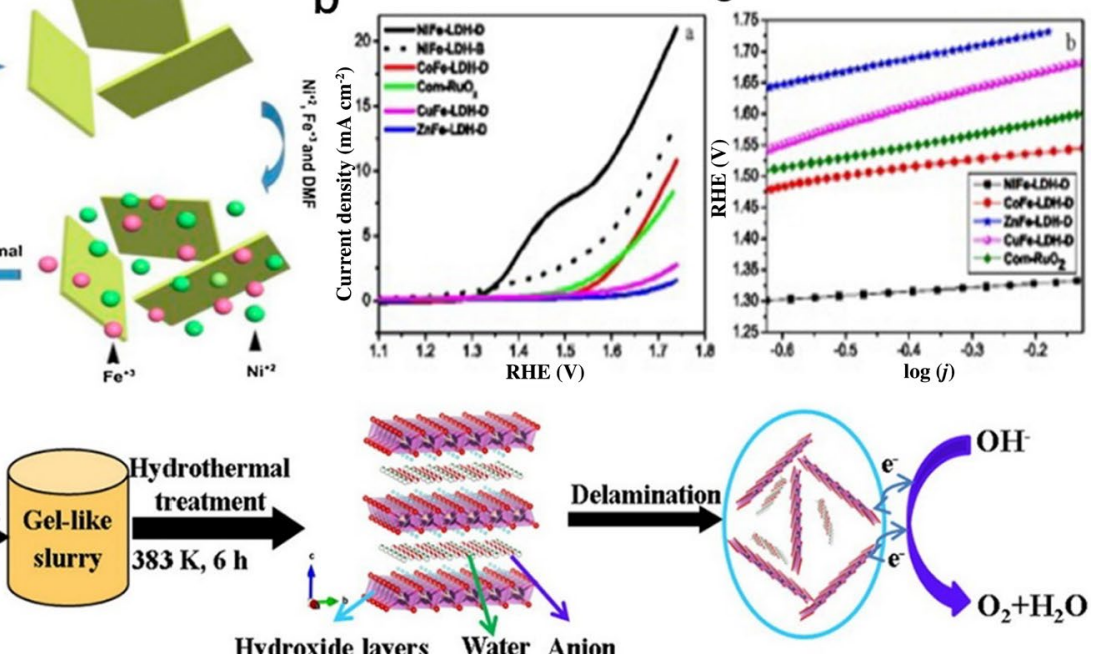

Hydroxide layers Water Anion

Fig. 7 a Schematic illustration of the formation of the RGO-Ni-Fe LDH [94]. b LSV of the as-prepared LDHs, the NiFe-LDH-D (NiFeLDHs after delamination), the NiFe-LDH-B (bulk NiFe-LDHs with-

nanocatalyst. Here, Fe doping was conducted to enhance the catalytic activity of the Ni phosphide and the resulting Fedoped $\mathrm{Ni}_{2} \mathrm{P}$ catalyst outperformed the catalytic performances of simple $\mathrm{Ni}$ phosphides, and commercial $\mathrm{RuO}_{2}$, producing a out delamination) and commercial $\mathrm{RuO}_{2}$. c Tafel plot of the NiFeLDHs and commercial $\mathrm{RuO}_{2}$. d Schematic procedure of the facile and cost-effective synthesis of NiFe-LDH nanosheets [88]

small Tafel slope value of $50 \mathrm{mV} \mathrm{dec}{ }^{-1}$ and an overpotential of only $292 \mathrm{mV}$. These findings may provide a new pathway for the development of new OER materials [96]. 
Despite these promising results, however, further improvements in catalytic activity and the development of cost-effective methods for $\mathrm{Ni}$ phosphides synthesis are still required. Wang et al. [97] attempted to tackle these issues by synthesizing a novel 3D porous self-supported $\mathrm{Ni}-\mathrm{P}$ foam as an efficient OER catalyst. In their study, binder-free and P-enriched nickel diphosphide nanosheet arrays were fabricated on the surface of carbon cloth. Here, obtained SEM images revealed a well-preserved 3D structure for the $\mathrm{NiP}_{2} /$ CC (Fig. 8a-f) that resulted in high OER performances because of the considerable number of exposed active sites (Fig. 81, m).

Research has shown that a combination of two metals in a compound can enhance catalytic activities because of the synergetic effects between them. Based on this, bimetallic Ni phosphides (FeNiP, NiCo, FeNiP) are gaining increasing attention as efficient OER catalysts [60, 100-104]. For example, Xiao et al. [103] studied a bimetallic iron nickel phosphide (FeNiP/NF) on Ni foam as a potential OER catalyst, in which the role of the $\mathrm{Ni}$ foam was not only to act as a substrate but also as a slow releasing Ni source. In the obtained SEM micrographs shown in Fig. 8, the formation of nanosheets can be clearly seen and the colour changes indicate the successful modification of the catalyst. In this study, the researchers found that the combined effects of the bimetallic composite, the metallic phosphide and the electrode fabrication method collectively contributed to a high OER activity with an overpotential of just $192 \mathrm{mV}$ to reach a current density of $10 \mathrm{~mA} \mathrm{~cm}^{-2}$. The schematic illustration of this synthesis process is shown in Fig. 8k.

\subsubsection{Ni-Based Alloys}

The alloying of $\mathrm{Ni}$ with other transition metals can enhance OER performances, and various alloys have been synthesized and studied in which $\mathrm{Ni}$ alloys with $\mathrm{Co}$ and $\mathrm{Fe}$ were found to be particularly effective in enhancing OER performances [105-120]. The reason for this enhancement is the combination of two transition metals that can synergistically provide better electrocatalytic properties than their individual components. Based on this, Bandal et al. [104] developed a facile method to synthesize $\mathrm{Ni}_{3} \mathrm{Fe}$ alloy catalysts with a bicontinuous (BC) structure [105] through the coprecipitation of metal salts with EDA. In this study, SEM micrographs revealed the uniform formation of a highly porous and bicontinuous structure with interconnected pores which are helpful in reducing mass transfer resistances (Fig. 9f-h). The obtained $\mathrm{Ni}_{3} \mathrm{Fe}-\mathrm{BC}$ also possessed a high BET surface area of $62 \mathrm{mg} \mathrm{cm}^{-2}$, allowing it to provide greater numbers of active sites. These factors subsequently were found to contribute to a high catalytic activity with an overpotential value of only $248 \mathrm{mV}$ to achieve a current density of $10 \mathrm{~mA} \mathrm{~cm}^{-2}$. A schematic illustration of the synthesis process is shown in Fig. 9e.

Further catalytic performance improvements of these $\mathrm{Ni}$ alloys can also be achieved by metallic or non-metallic elemental doping. In one example, Yang et al. [107] developed
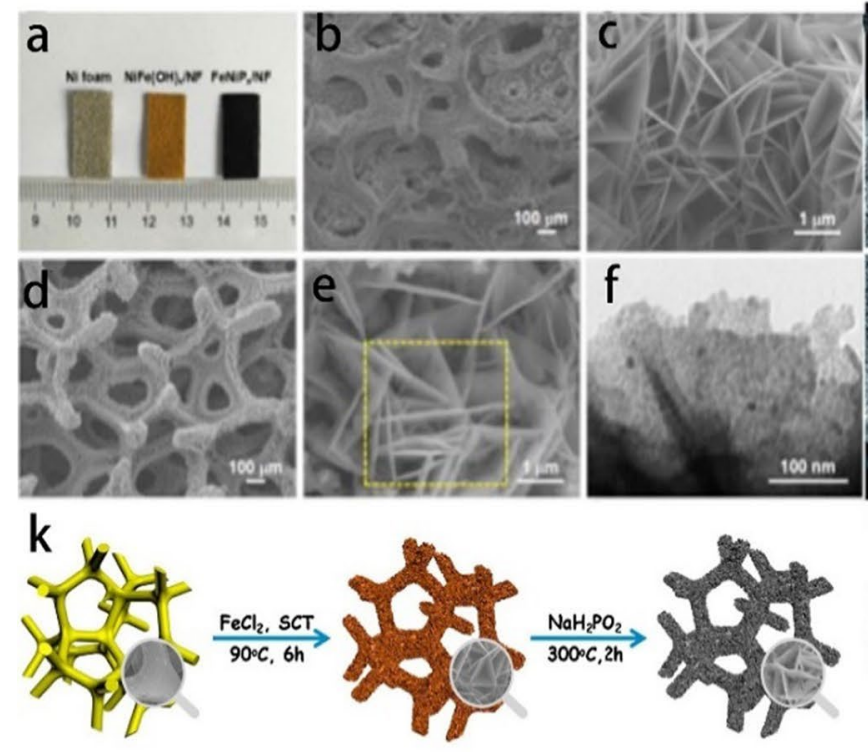

Fig. 8 a-f SEM images of FeNiP. g-i Low and high-magnification top-view SEM images of the as-fabricated self-supported porous $\mathrm{Ni}-\mathrm{P}$ foam. $\mathbf{j}$ EDX spectrum taken from the rectangular region. $\mathbf{k}$
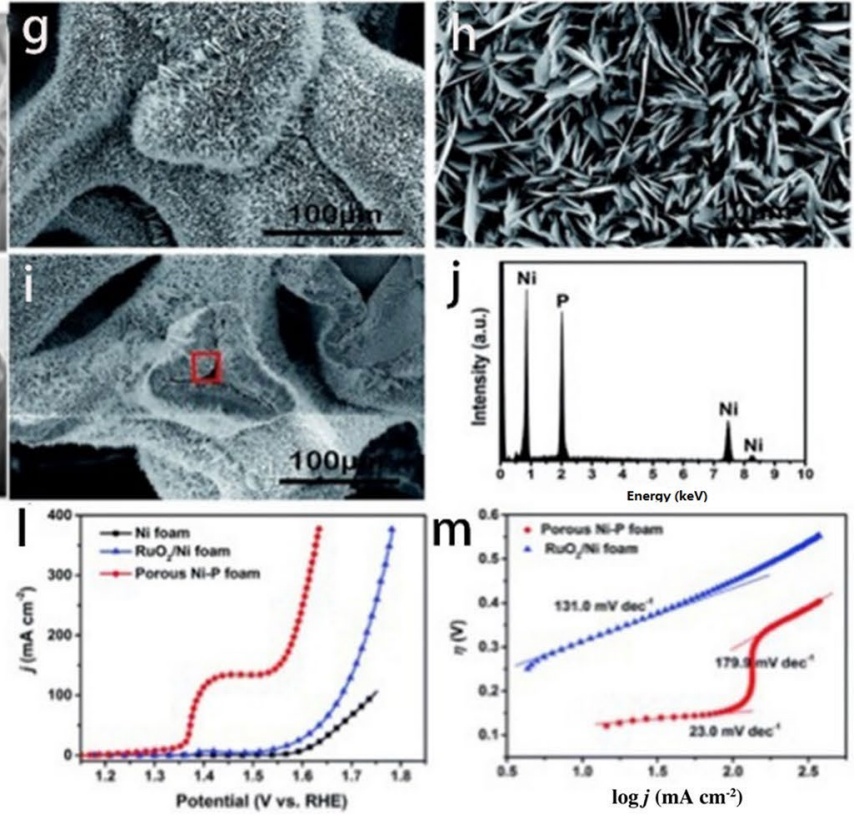

Schematic illustration of the formation of $\mathrm{FeNiP}_{x} / \mathrm{NF}$. $\mathbf{l}-\mathbf{m}$ Polarization curve and Tafel plot of Ni-P [98, 103] 
a novel magnetic field-assisted method for the synthesis of boron-doped NiFe alloys. In this study, the researchers found that the addition of $\mathrm{NaBH}_{4}$ as a boron doping source decreased the magnetic moment of the intermediate product, resulting in a high specific surface area for the obtained nanochains. SEM images of the nanochains before and after boron doping are shown in Fig. 9a-d. Various other alloys including NiCo, NiMo and Ni-B have also been explored as OER catalysts with promising results $[112,115,116]$.

Ternary metal alloys have also been applied as OER catalysts. For example, Rosalbino et al. [112] tested the electrocatalytic performance of $\mathrm{NiCoM}$ alloys (in which $\mathrm{M}=\mathrm{Cr}, \mathrm{Mn}$ or $\mathrm{Cu}$ ) in $1 \mathrm{M} \mathrm{NaOH}$ solution and found that catalytic activities increased because of the combination of $d$-orbital of $\mathrm{Ni}$ with the $d$-orbital of $\mathrm{Cr}, \mathrm{Mn}$ and $\mathrm{Cu}$. This also increases the electrical conductivity. One issue associated with these alloys is the low electrical conductivity, however, but this can be addressed by the introduction of hybrid materials. Research has shown that Ni alloys within hybrid compounds can possess significantly better performances than that of single metal hybrid materials. Such enhancements in catalytic activity are thought to be caused by synergetic effects in these hybrid alloys [119]. For example, Yu et al. [120] reported the synthesis of a NiCo alloy encapsulated in nitrogen-doped carbon nanotubes (NCNTs) using a one-pot pyrolysis method. The resulting hybrid alloy was revealed to possess a nanotube structure as confirmed by SEM and TEM analysis in which the presence of stripes at the CNT compartments attributed to the entrapment of graphene sheets within the CNTs. In addition, the catalyst synthesized at a pyrolysis temperature of $800{ }^{\circ} \mathrm{C}$ possessed the lowest onset potential and therefore the highest activity as confirmed by electrochemical tests, achieving a low overpotential of $41 \mathrm{mV}$ at a current density of $10 \mathrm{~mA} \mathrm{~cm}$.

Aside from Ni-based oxides, LDHs, phosphides and alloys, Ni-based sulphides and selenides are also capable of catalysing OER reactions in alkaline media [121-126].

\subsubsection{Cobalt Oxides}

OER catalysts for alkaline electrolysis can also include transition metal oxides, such as $\mathrm{RuO}_{2}, \mathrm{IrO}_{2}, \mathrm{PtO}_{2}, \mathrm{MnO}_{2}$ and $\mathrm{Co}_{3} \mathrm{O}_{4}$. Noble metal oxides, despite being more active, are not suitable for commercial applications because of high costs. Therefore, the development of non-noble metal oxides as OER catalysts for alkaline electrolysis has become the focus of many researchers $[127,128]$.

Of these non-noble metal oxides, Co-based oxides have been found to be very promising as an OER catalyst because the microstructure of $\mathrm{Co}_{3} \mathrm{O}_{4}$ can have profound influences on the performance of these catalysts [127-131]. A comparative study was conducted by Koza et al. [128] for the electrodeposition of crystalline $\mathrm{Co}_{3} \mathrm{O}_{4}$ onto stainless steel-type electrodes and they found from the obtained XRD patterns that by increasing reflux temperatures, the crystallite size

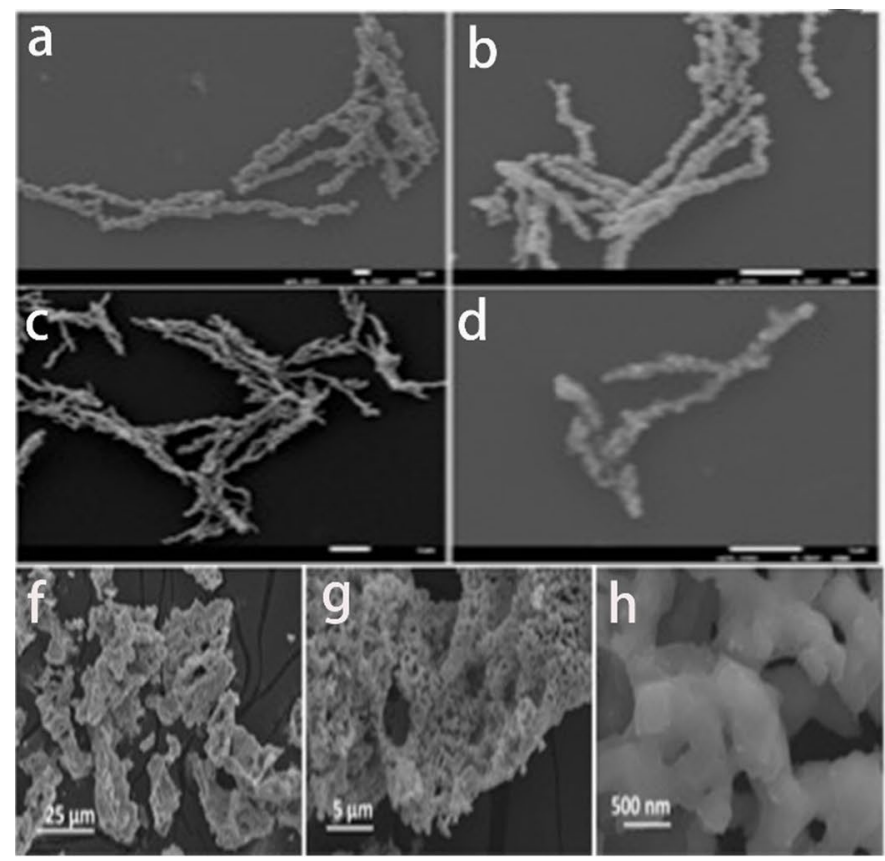

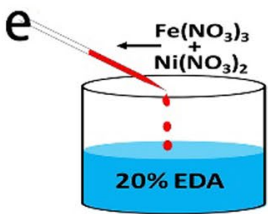

(a) $\mathrm{Ni}_{3} \mathrm{Fe}-\mathrm{PC}$

(b) $\mathrm{Ni}_{3} \mathrm{Fe} / \mathrm{NiFe}_{2} \mathrm{O}_{4} / \mathrm{C}$

(c) $\mathrm{Ni}_{3} \mathrm{Fe}-\mathrm{BC}$

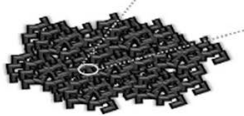

(3)

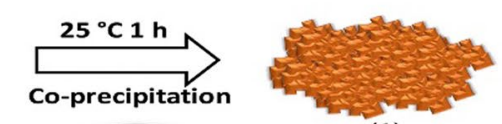

(1)
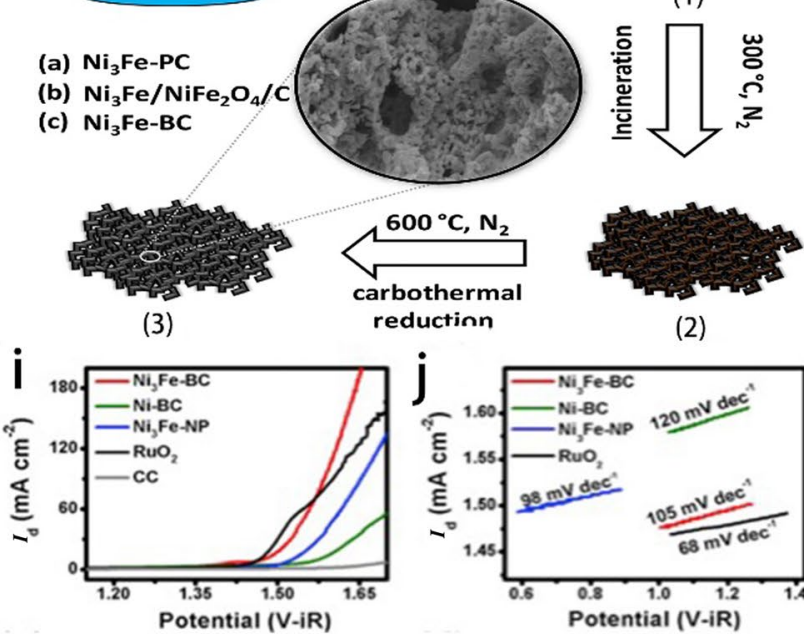

(2)

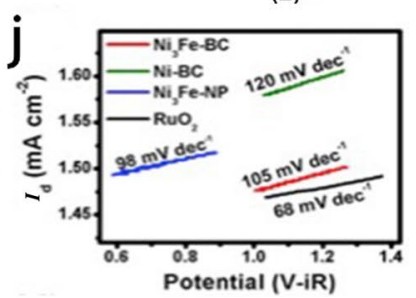

Fig. 9 a-d SEM images and magnetic behaviours of Fe/Ni nanochains before and after boron doping. e Schematic representation of an experimental method used for the synthesis of $\mathrm{Ni}_{3} \mathrm{Fe}-\mathrm{BC}$. $\mathbf{f}-\mathbf{h}$ SEM images of $\mathrm{Ni}_{3} \mathrm{Fe}-\mathrm{BC}$. $\mathbf{i}-\mathbf{j}$ Polarization curve and Tafel plot [105, 107] 
of the catalysts can increase from $2 \mathrm{~nm}\left(\right.$ at $50{ }^{\circ} \mathrm{C}$ ) to $26 \mathrm{~nm}$ (at $103{ }^{\circ} \mathrm{C}$ ). In addition, the crystalline $\mathrm{Co}_{3} \mathrm{O}_{4}$ obtained at $103{ }^{\circ} \mathrm{C}$ produced a Tafel slope of $49 \mathrm{mV} \mathrm{dec}^{-1}$, whereas the amorphous film deposited at $50{ }^{\circ} \mathrm{C}$ only produced a Tafel slope of $36 \mathrm{mV} \mathrm{dec}^{-1}$ [128]. In another example, Sun et al. [129] synthesized a catalyst composed of atomically thin layered $\mathrm{Co}_{3} \mathrm{O}_{4}$ porous sheets with a thickness of $0.45 \mathrm{~nm}$ and a pore occupancy of roughly $30 \%$ and found that the resulting catalyst sheets exhibited an electrocatalytic current density of $341.7 \mathrm{~mA} \mathrm{~cm}^{-2}$, which was about 50 times higher than that of the bulk.

Ranaweera et al. [129] also developed a facile binderfree method for the synthesis of flower-shaped $\mathrm{Co}_{3} \mathrm{O}_{4}$ nanostructures in which the resulting catalyst provided a high OER activity with an overpotential value of $356 \mathrm{mV}$ to reach a current density of $10 \mathrm{~mA} \mathrm{~cm}^{-2}$ (Fig. $10 \mathrm{~g}$, h). Here, SEM micrographs of the resulting $\mathrm{Co}_{3} \mathrm{O}_{4}$ catalyst at different magnifications confirmed a flower-shaped morphology (Fig. 10e, f) in which the researchers attributed the observed high electrocatalytic activity to the nanoporous structure and the direct contact between the $\mathrm{Co}_{3} \mathrm{O}_{4}$ and the $\mathrm{Ni}$ foam. This binder-free and cost-effective approach towards the synthesis of nanoporous materials has great potential for large-scale industrial applications [130].

The incorporation of other transition metals with Cobased oxides into composites can also increase OER performances because of enhanced electrical conductivities [39, 132-139]. In one example, Zhu et al. [134] composited $\mathrm{Fe}, \mathrm{Ni}$ and $\mathrm{Fe} / \mathrm{Ni}$ into mesoporous $\mathrm{Co}_{3} \mathrm{O}_{4}$ [135] and observed an unusual synergetic effect in which the pore size distribution of Fe increased from $3 \sim 15$ to $3 \sim 18 \mathrm{~nm}$ for the resulting $\mathrm{Fe} / \mathrm{Co}_{3} \mathrm{O}_{4}$. Because of this increase, this obtained composite catalyst achieved a current density of $10 \mathrm{~mA} \mathrm{~cm}^{-2}$ with a lower overpotential value of $380 \mathrm{mV}$ as compared with $420 \mathrm{mV}$ for mesoporous $\mathrm{Co}_{3} \mathrm{O}_{4}$. Similar synergetic effects were also observed for spinal metal oxides such as $\mathrm{MnCo}_{2} \mathrm{O}_{4}$ and $\mathrm{ZnCo}_{2} \mathrm{O}_{4}[132,139]$. The special morphology of $\mathrm{ZnCo}_{2} \mathrm{O}_{4}$ is shown in Fig. 10a-d, $\mathrm{i}-\mathrm{n}$ along with its electrochemical performance.
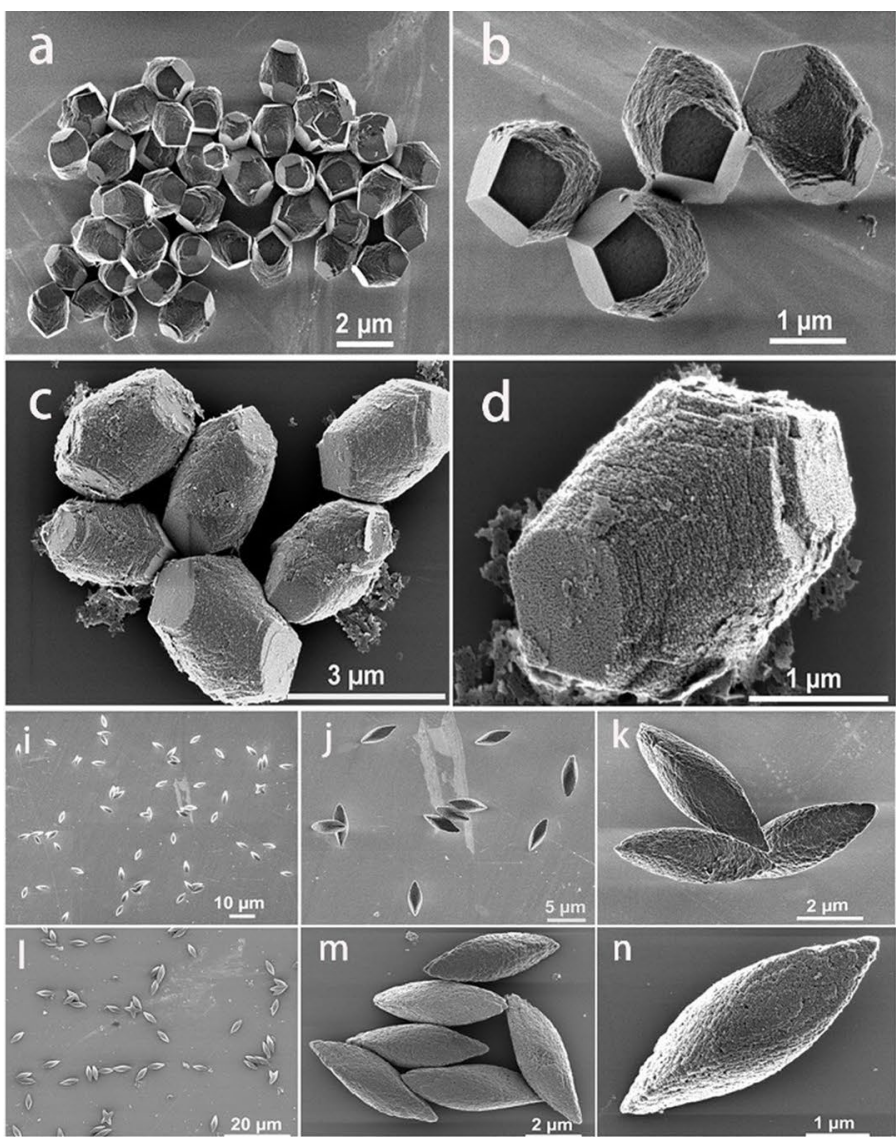
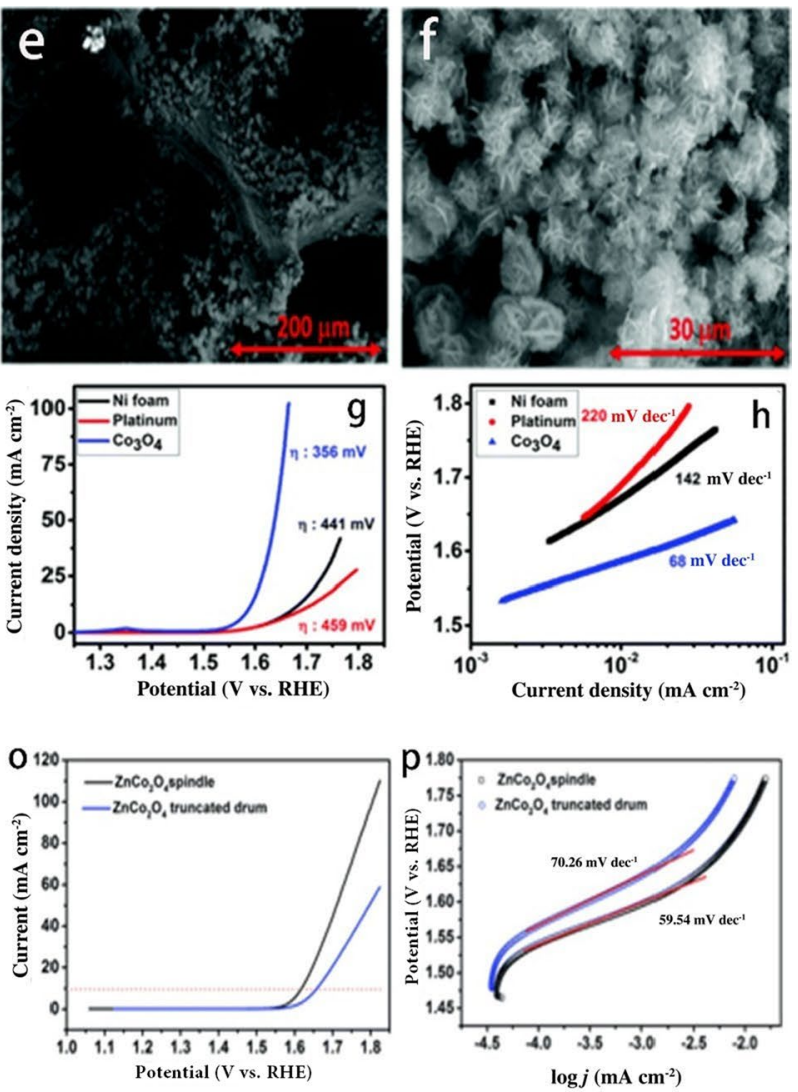

Fig. 10 a-d SEM images of truncated drum-shaped $\mathrm{ZnCo}_{2} \mathrm{O}_{4}$ precursors and porous $\mathrm{ZnCo}_{2} \mathrm{O}_{4}$ truncated drums obtained by annealing at $400{ }^{\circ} \mathrm{C}$ for $2 \mathrm{~h}$. $\mathbf{i}-\mathbf{n}$ SEM images of spindle-like $\mathrm{ZnCo}_{2} \mathrm{O}_{4}$ precursors and porous $\mathrm{ZnCo}_{2} \mathrm{O}_{4}$ microspindles obtained by annealing. o-p LSV curves obtained at a sweep rate of $5 \mathrm{mV} \mathrm{s}^{-1}$ and Tafel plots of the OER currents [139]. e-f SEM images of synthesized $\mathrm{Co}_{3} \mathrm{O}_{4}$ at various magnifications. $\mathbf{g}-\mathbf{h}$ OER polarization curves and Tafel slopes [130] 
Despite promising results, further OER performance improvements of $\mathrm{Co}_{3} \mathrm{O}_{4}$ catalysts are needed to overcome issues of low intrinsic conductivity and thermal stability. In this regard, hybrid materials using graphite and graphene as supports are of prime interest [140-147]. This is because they possess a high surface area, high mechanical strength and high chemical stability, making it a suitable candidate as the substrate for the fabrication of composite oxides. For example, Suryanto et al. [139] fabricated a composite of graphene $/ \mathrm{Co}_{3} \mathrm{O}_{4}$ using a controlled layer-bylayer method [140] and found that this strategy enhanced OER activities because of the synergetic effects between the conductive graphene and $\mathrm{Co}_{3} \mathrm{O}_{4}$, resulting in more exposed active sites. Therefore, hybrid compounds possess immense potential for OER catalyst applications in alkaline media.

\subsubsection{Cobalt Phosphides}

Transition metal phosphides are another important class of compounds for OER catalysis in alkaline media. And although Co phosphides, possessing different morphologies with Co oxides and Co hydroxides which are mainly used as OER catalysts, are mainly used as HER catalysts, their high HER performances have led researchers to explore their viability as OER catalysts as well [148-150]. For example, Liu et al. [148] reported the development of a regular hollow polyhedron CoP electrocatalyst for OER using Co-centred metal organic frameworks (MOFs) as a template and cobalt as the raw material, with the resulting catalyst being found to be capable of catalysing both HER and OER reactions. In this study, SEM micrographs confirmed the retention of the hollow polyhedron shape of $\mathrm{CoP}$, in which the as-synthesized CoP hollow polyhedron provided both a large specific surface area and a high porosity that can offer more active sites. In electrochemical testing, it was found that the resulting catalyst only required an overpotential of $400 \mathrm{mV}$ to achieve a current density of $10 \mathrm{~mA} \mathrm{~cm}^{-2}$ (Fig. 11a-d). This low-cost and simple synthesis method based on MOFs as a template can be extended to other OER catalysts with different morphologies and structures as well. In another example, Dutta et al. [148] fabricated a needle-like 1D structured $\mathrm{Co}_{2} \mathrm{P}$ to enhance catalytic performances in which they found that the activity of the catalyst is a surface phenomenon, in which changing the shape has immense effects on performance [149]. CoP with different morphologies (including bimetallic phosphides) can also be obtained such as nanowires, nanocubes [151-153].
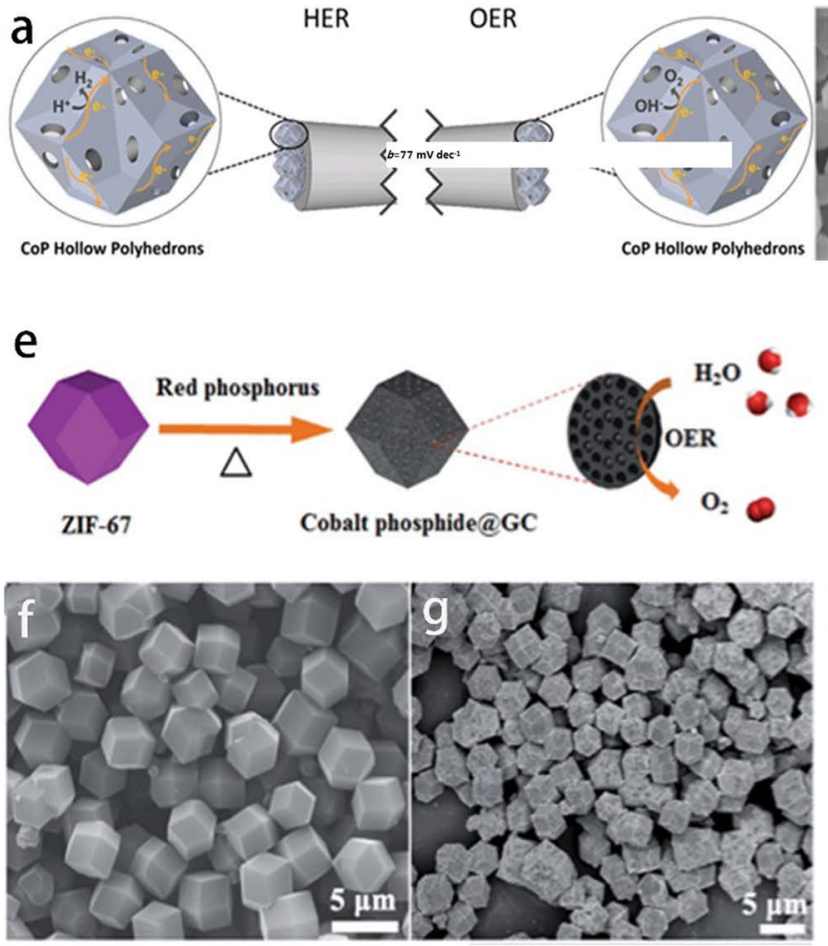

Fig. 11 a Schematic diagram to illustrate the HER and OER catalytic principles of CoP hollow polyhedrons. b-d Low- and (inset) highmagnification SEM images of $\mathrm{ZIF}-67, \mathrm{Co}_{3} \mathrm{O}_{4}$ polyhedron and $\mathrm{CoP}$ hollow polyhedron. h-i Polarization curve and Tafel slope [148]. e

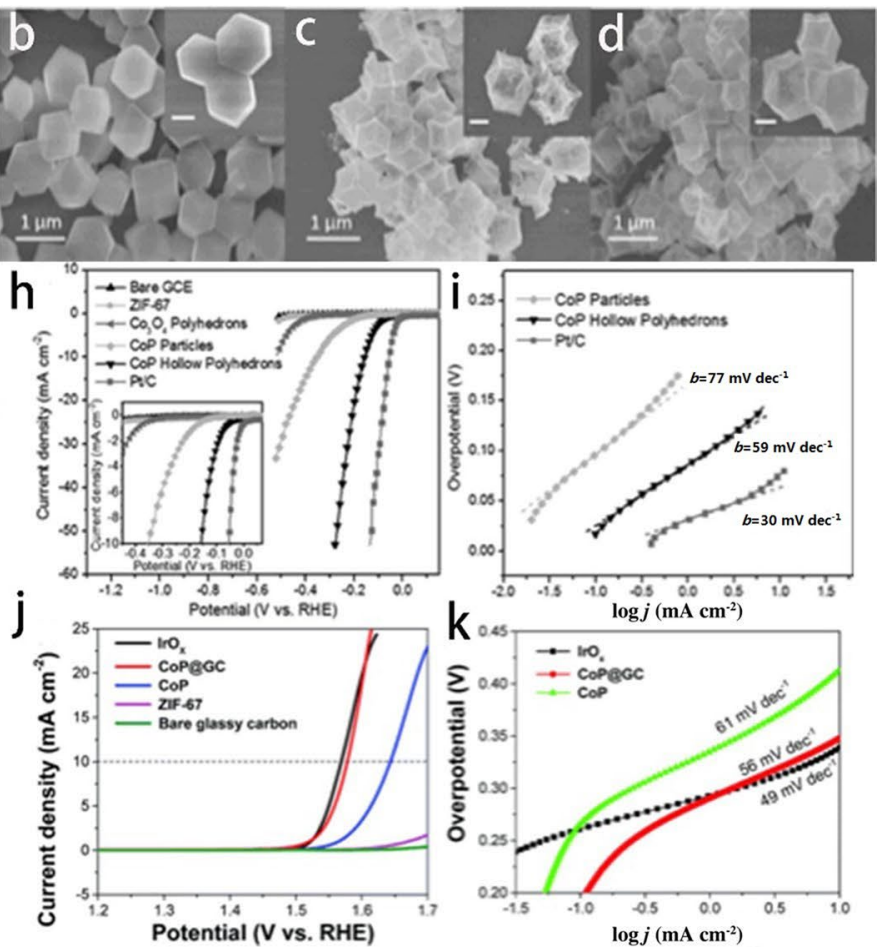

Schematic illustration of the preparation process of the hybrid composite. f-g FESEM images of the preformed ZIF-67 precursor and hybrid composite. j-k Polarization curve and Tafel slope [162] 
The introduction of other metals to obtain bimetallic phosphides (CoNiP, CoFeP, CoFePO, CoMnP) is another helpful method to improve catalytic performances in which the combination of structural and compositional effects can provide more opportunities for tailored electrocatalytic properties [102, 154-157]. For example, Fu et al. [154] synthesized a Co-Ni phosphide (CoNiP) catalyst using a hard template method and found that the obtained catalyst possessed a highly ordered mesoporous structure with large mesopores. In $1 \mathrm{M} \mathrm{KOH}$ solution, the synthesized catalyst demonstrated improvements in catalytic performance because of the synergetic effects between $\mathrm{Co}$ and $\mathrm{Ni}$. Following this approach, more bimetallic phosphides have also been developed such as $\mathrm{CoFe}$ and CoMnP [154] with promising results.

Cobalt phosphide hybrid materials have also been widely employed as OER catalysts because of the synergetic effects between the components. Hybrid composites include $\mathrm{CoP}_{2} / \mathrm{RGO}, \mathrm{CoP} / \mathrm{C}, \mathrm{MnO}_{2}-\mathrm{CoP}_{3} / \mathrm{Ti}, \mathrm{CoP} @$ CoPNG, FeCo and CoP/GC [158-162]. In one example, Wang et al. [158] synthesized a novel OER catalyst based on the $\mathrm{CoP}_{2} / \mathrm{RGO}$ using a phosphidation method and achieved a current density of $10 \mathrm{~mA} \mathrm{~cm}^{-2}$ with a low Tafel slope value of $96 \mathrm{mV} \mathrm{dec}{ }^{-1}$. Here, the increase in catalytic activity was attributed to the synergetic effects between RGOs and $\mathrm{CoP}_{2}$, which combined the high intrinsic conductivity of the RGO with $\mathrm{CoP}_{2}$ [158]. In another example, a novel cobalt phosphide/graphitic carbon polyhedral hybrid composite was formed by Wu et al. [161] using pyrolysis and phosphidation of Co-based zeolitic imidazolate frameworks (ZIF-67). Here, SEM images confirmed the presence of the polyhedral structure of the template even after high-temperature phosphidation at $700{ }^{\circ} \mathrm{C}$ (Fig. 11f, g). The schematic illustration of the synthesis process and electrocatalytic performances is shown in Fig. 11e.

Other Co-based compounds that can be used as OER catalysts include sulphides [163-165], nitrides [166-168] and selenides $[169,170]$. These compounds, such as $\mathrm{CoS}$, $\mathrm{Co}_{3} \mathrm{O}_{4} / \mathrm{CoS}_{2}, \mathrm{Co}_{9} \mathrm{~S}_{8} / \mathrm{N}-\mathrm{S} \mathrm{CNS}, \mathrm{Co}_{4} \mathrm{~N}, \mathrm{CoFeN} @ \mathrm{MWC}-$ NTs, CoSe, Fe-doped CoS [171], Fe-doped CoSe, CoFeS, Mn-doped CoN, and $\mathrm{CoS}_{2} / \mathrm{CNTs}$ [172], have also been explored with promising results. In summary, Co-based compounds, including oxide, phosphide, nitride, selenide, sulphide and hybrid forms, possess enormous potential for OER catalysis in alkaline media.

\subsubsection{Mn Oxides}

Aside from Ni- and Co-based compounds, manganese oxides have recently also gained attention as viable candidates to replace noble metals catalysts and are being widely studied for their OER activities. For manganese oxides, the electrochemical and physicochemical properties are highly dependent on morphology and crystallographic nature [173-180]. Therefore, to study the effects of structure on OER activity, Meng et al. [177] synthesized four different crystal lattices of $\mathrm{MnO}_{2}$, including $\alpha, \beta, \sigma-\mathrm{MnO}_{2}$ and amorphous $\mathrm{MnO}_{2}$ (AMO), and analysed them. Here, XRD patterns confirmed the amorphous nature of the AMO with three weak peaks and SEM images revealed aggregated particles of less than $50 \mathrm{~nm}$. In the obtained results, as shown in Fig. $12 \mathrm{~b}, \mathrm{~g}-\mathrm{j}, \sigma-\mathrm{MnO}_{2}$ exhibited a nanostructured flowerlike morphology composed of nanoplates $(500 \mathrm{~nm} \times 20 \mathrm{~nm})$, whereas $\beta-\mathrm{MnO}_{2}$ and $\alpha-\mathrm{MnO}_{2}$ possessed morphologies of nanorods and nanofibres, respectively. Electrochemical measurements were subsequently conducted and revealed that $\sigma-\mathrm{MnO}_{2}$ produced the lowest overpotential $(490 \mathrm{mV})$ as compared with the other crystallographic structures at a current density of $10 \mathrm{~mA} \mathrm{~cm}{ }^{-2}$. In another study to further investigate the effects of structure on OER activities, Maruthapandian et al. [179] synthesized manganese oxides with different morphologies on the surface of Ti foil. In this study, the reactions were carried out at 40,70 and $90^{\circ} \mathrm{C}$, and the corresponding morphologies of the samples obtained at these temperatures were in the structures of cotton wool, nanosheets and nanoarrays, respectively. The OER performance testing was conducted and the researchers found that the superior performance was obtained with the nanowire structure as compared with the other two morphologies (cotton wool and nanosheet arrays). From these two examples, it is clear that the morphology of Mn-based oxides is key to OER activities. In addition, like $\mathrm{Ni}$ and $\mathrm{Co}$, bimetallic oxides of $\mathrm{Mn}$ are also more electrochemically active than the corresponding single metal oxides and these bimetallic oxides include $\mathrm{MnCrO}, \mathrm{MnFeO}$ and $\mathrm{Ni}$-doped $\mathrm{Mn}_{3} \mathrm{O}_{4}$ [178-184].

The intrinsically low electrical conductivity of manganese oxides can also be improved by using carbon as a support and through incorporating other metals to form binary metallic oxides for the fabrication of nanostructured oxides. For example, Bhandary et al. [178] combined both of these concepts and electrosynthesized MnFe oxide layers onto the surface of porous carbon paper [179]. In this study, SEM micrographs revealed a nanostructured flower-like morphology (Fig. 12c-f) and the obtained catalyst demonstrated high electrochemical activities for both ORRs and OERs. XRD analysis was conducted to confirm the phase structure of the resulting $\mathrm{Mn}_{2} \mathrm{O}_{3}$ and the observed diffraction peaks were in good agreement with standard $\mathrm{Mn}_{2} \mathrm{O}_{3} / \mathrm{C}$ cubic.

The effects of doping on the OER performance of manganese oxides have also been reported by Maruthapandian et al. [179] in which in their study, a catalyst composed of $10 \mathrm{wt} \% \mathrm{Ni}$ in $\mathrm{Mn}_{2} \mathrm{O}_{3}$ (an optimum value) demonstrated an improved OER performance with an overpotential value of only $283 \mathrm{mV}$ and a Tafel slope value of $165 \mathrm{mV} \mathrm{dec}{ }^{-1}$ 


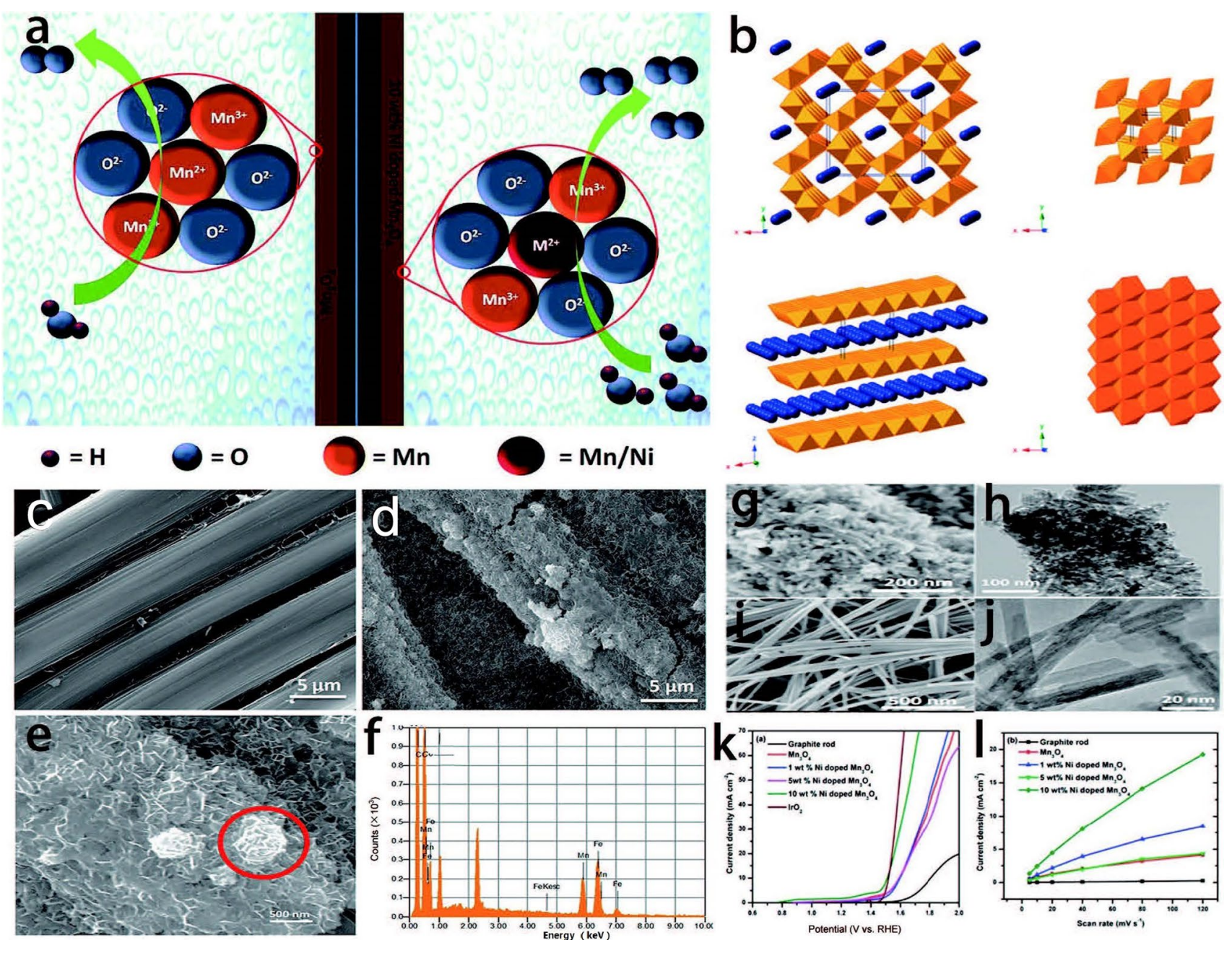

Fig. 12 a Schematic illustration of the catalytic activity of $\mathrm{Mn}_{3} \mathrm{O}_{4}$ and $10 \mathrm{wt} \%$ Ni-doped $\mathrm{Mn}_{3} \mathrm{O}_{4}$. $\mathbf{k}-\mathbf{l} \mathrm{LSV}$ and capacitive current density profiles [180]. b Structures of manganese oxide. $\mathbf{g}-\mathbf{j}$ SEM images of $\mathrm{MnO}_{2}$ [178]. c-f SEM images and EDX results of MnFe oxide [179]

to reach a current density of $10 \mathrm{~mA} \mathrm{~cm}{ }^{-2}$. This increased catalytic activity might be because of the improved absorption/desorption of hydroxide and oxyhydroxide atoms associated with the intermediates, as well as the improved electron transport between the electrolyte/active materials of the $\mathrm{Mn}_{3} \mathrm{O}_{4}$ /electrode surface, along with the increased surface area and active sites. The schematic illustration of the catalytic activity is shown in Fig. 12a. This finding into the doping of non-precious metals into $\mathrm{Mn}_{3} \mathrm{O}_{4}$ can be helpful in lowering the costs of OER catalysts.

In addition to $\mathrm{Ni}$-, $\mathrm{Co}$ - and $\mathrm{Mn}$-based compounds, $\mathrm{Fe}$ and $\mathrm{Cu}$ compounds have also been reported to be favourable choices for OER [185-189]. As a result, transition metals have enormous potential to replace noble metals for OERs in alkaline electrolysis, reducing costs and providing promising applications in water electrolysis.

\subsection{Catalysts for OER in Proton Exchange Membrane Electrolysis (PEM Electrolysis)}

\subsubsection{Noble Metal Catalysts}

PEM electrolysis is another emerging field for energy storage and conversion. Although this technology has been commercially available for about 10 years, expensive materials are normally required to achieve higher efficiencies and longer lifetimes than alkaline technologies. Despite this, PEM electrolysis possesses several advantages such as high current density, high degree of gas purity and high operating safety because of a solid polymer electrolyte separator. Therefore, areas of interest for researchers in PEM electrolysis include material and component development [190]. 
As for the OER catalyst of PEM electrolysis, commonly used catalysts include oxides of Ir and $\mathrm{Ru}$, with ruthenium oxides showing more promise than iridium oxides in terms of performance. For example, Song et al. [191] conducted a comparative analysis of $\mathrm{Ir}, \mathrm{Ru}$ and their corresponding oxides as OER catalysts in PEM electrolysis and found that although $\mathrm{RuO}_{2}$ possessed better electrocatalytic performances than Ir and Ir oxide, it was unstable in acidic media. And despite $\mathrm{IrO}_{2}$ possessing lower electrocatalytic performances than $\mathrm{RuO}_{2}$, it was highly stable up to 10000 cycles. The researchers also found that the performance of $\mathrm{IrO}_{2}$ can be further enhanced through modifying the synthesis method by using colloidal iridium hydroxide hydrate as a precursor, which permits a lower heat treatment temperature. Other noble metal and composite-based catalysts used as OER catalysts in PEM electrolysis are $\mathrm{Ir}, \mathrm{Pt}, \mathrm{Ag}, \mathrm{IrO}_{2} / \mathrm{Pt}$ and $\mathrm{NPG} / \mathrm{IrO}_{2}$ (nanoporous gold//rO $\mathrm{I}_{2}$ ).

One of the main challenges for OER catalysis in PEM electrolysis is the cost, and various efforts have been taken and new strategies have been developed to reduce the cost of the catalysts. These include the reduction in catalyst loading, the increase in catalytic activity through increasing surface areas, the synthesis of nanosized Ir oxides [191, 192]. Different support materials for enhancing the catalytic performance of these noble metal catalysts have also been explored including carbon-based materials (graphene) and Ebonex materials for nanosized noble catalysts.

In general, preparation methods and experimental conditions greatly influence both catalyst material activity and stability [192] with several research groups publishing results on the synthesis of different Ebonex-supported electrocatalysts (Pt, Co, PtCo, Ir, PtIr, etc.) as well as their characterization and application in low-temperature hydrogen energy systems. The different preparation methods that have been reported in these studies include boron hydride wet chemical reduction, impregnation sol-gel deposition, thermal decomposition of metal salts and electroplating [193].

\subsubsection{Non-noble Metal Catalysts}

Commonly used noble metal catalysts for OERs in PEM electrolysis such as Ir and Ru possess the lowest overpotentials, with Ir-based catalysts possessing better stability than Ru-based catalysts, resulting in their high demand. However, to reduce the cost of catalysts, different strategies have been employed, including the exploration of non-precious metal catalysts with high activity and durability. However, it is unlikely that a completely non-noble metal-based catalyst will ever be identified for PEM systems. Therefore, the most feasible method is to decrease noble metal loading.

One strategy to decrease noble metal loading is to dope noble catalysts with non-precious elements that can in turn improve stability because of the resulting changes in electronic structure. In this way, the OER performance of the multi-metallic catalyst is not only dominated by the intrinsic properties of the components, but also by their synergistic effects, crystallite phases, surface properties, sizes, shapes and pore structures, all of which can be determined by preparation methods. In the literature, many important doping elements including fluorine, tin, tantalum, molybdenum and manganese have been explored and have shown promise [194-200]. For example, a novel dopant/alloying element (fluorine) for noble metal oxide electrocatalysts was developed by Kadakia et al. [195] to determine the effects of fluorine doping. In their study, the fluorine content on a pre-treated Ti foil was varied from 5\% to 30\% through the thermal decomposition of a homogeneous mixture of $\mathrm{IrCl}_{4}$ and $\mathrm{NH}_{4} \mathrm{~F}$ in ethanol-DI water solution. XRD patterns of the resulting thin-film $\mathrm{IrO}_{2}$ with different fluorine contents revealed a rutile-type structure that was like that of $\mathrm{RuO}_{2}$. In the subsequent electrochemical testing, an increase in electrochemical performances was observed with increasing fluorine content up to $10 \mathrm{wt} \%$, beyond which a decrease in specific surface area and electrocatalytic activity was observed. According to the researchers, this decrease in specific surface area might be related to the exothermic reaction of $\mathrm{NH}_{4} \mathrm{~F}$ burning, which occurs during the formation of the catalyst powder. The heat released during this process could also cause the agglomeration of $\mathrm{IrO}_{2} \mathrm{~F}$ composites, also resulting in decreased specific surface areas [195].

Studies have also revealed that the stability of $\mathrm{IrO}_{2}$ and $\mathrm{RuO}_{2}$ can be improved through doping with other oxides such as $\mathrm{SnO}_{2}, \mathrm{Co}_{3} \mathrm{O}_{4}, \mathrm{MnO}_{2}$ and $\mathrm{Ta}_{2} \mathrm{O}_{5}$ [201-203]. However, increases in concentration of these inexpensive oxides can lead to decreases in active surface area and electrical conductivity. Recently, Kadakia et al. [196] reported that the doping of solid solutions of $\mathrm{IrO}_{2}$ and corrosion-resistant oxides $\left(\mathrm{SnO}_{2}, \mathrm{Nb}_{2} \mathrm{O}_{5}\right)$ with fluorine can result in improved electrochemical activities and durability as well as the reduction of $\mathrm{IrO}_{2}$ loading. The researchers here suggested that this increased activity might be due to the increase in electrical conductivity with the shifting of the $d$-band centre towards pure $\mathrm{IrO}_{2}$. A similar strategy was adopted for F-doped $(\mathrm{SnRu}) \mathrm{O}_{2}$ in the same study and the observed Tafel slope value for $10 \mathrm{wt} \% \mathrm{~F}$ was found to be $65 \mathrm{mV} \mathrm{dec}^{-1}$ at a current density of $10 \mathrm{~mA} \mathrm{~cm}^{-2}$ (Fig. 13f-h).

Another method to develop low-cost Ir-based catalysts for OERs is the use of a high specific surface area support for the electrocatalyst. By using a support, the agglomeration of the electrocatalyst can be minimized, which increases active surface areas. In this method, the support material should be electrically conductive, chemically stable, inexpensive and readily available. In addition, the particle size difference of the supported and unsupported nanoparticles should not allow for the penetration of large particles into the catalyst layer. Synergetic effects arising from the addition of support 

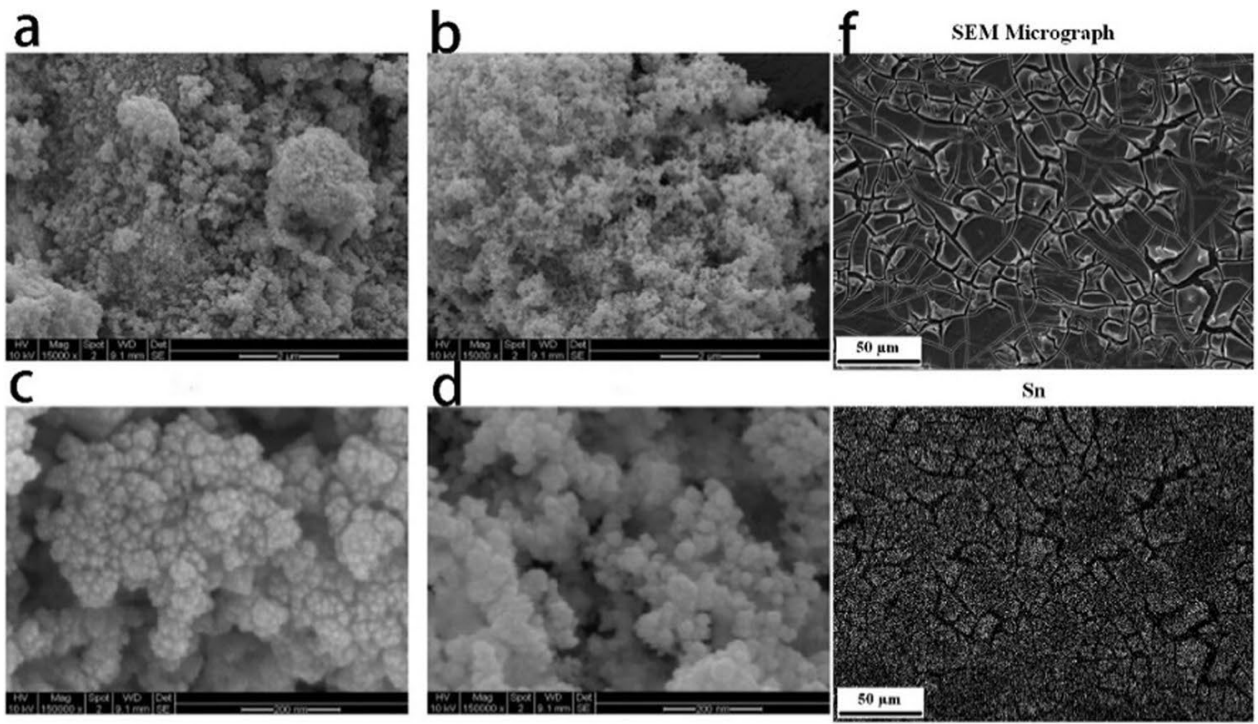

e

g
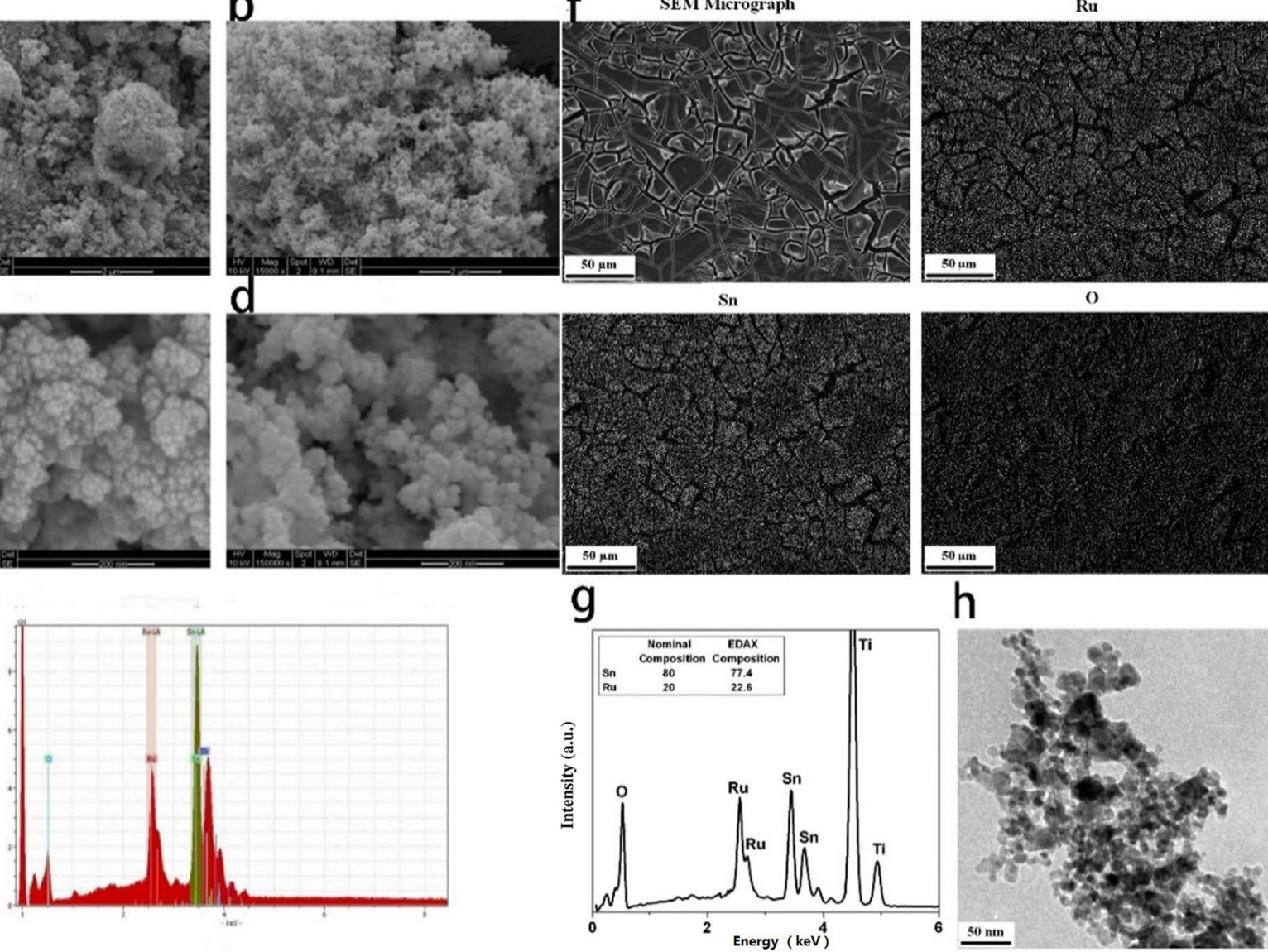

h

Fig. 13 a-d SEM images of $\mathrm{RuO}_{2} / \mathrm{ATO} \times 15000, \mathrm{ATO} \times 15000$, $\mathrm{RuO}_{2} / \mathrm{ATO} \times 150000$ and ATO $\times 150000$. e EDX spectrum of $\mathrm{RuO}_{2} /$ ATO [197]. f SEM micrograph along with X-ray mapping of Ru,

materials can also influence electrochemical performances of the catalyst [200, 204-207]. Based on this concept of using supports, $\mathrm{Wu}$ et al. [203] used $\mathrm{Sb}$-doped $\mathrm{SnO}_{2}$ as a support for $\mathrm{RuO}_{2}$ catalysts and found that with the Ru deposition, the particle size of the antimony-doped tin oxide (ATO) increased from 30 40nm to $40 \sim 50 \mathrm{~nm}$ (Fig. 13a-e). The researchers also found that because of the support material, the agglomeration of $\mathrm{RuO}_{2}$ was prevented. In this study, $\mathrm{RuO}_{2}$, despite having insufficient stabilities for OER, was picked because it exhibits less overpotential than $\mathrm{IrO}_{2}$ and is several times cheaper. The electrochemical properties of $\mathrm{RuO}_{2}$ can also be improved by using $\mathrm{SnO}_{2}$ as a support because of its semiconductor nature. The reason Sb-doped $\mathrm{SnO}_{2}$ was used instead of $\mathrm{SnO}_{2}$ in this study is because $\mathrm{Sb}$ doped $\mathrm{SnO}_{2}$ possesses higher electrical conductivity than $\mathrm{SnO}_{2}$ because of the pentavalent nature of $\mathrm{Sb}$. A similar approach has also been adopted for $\mathrm{IrO}_{2}$ [200].

Alternatively, if metal oxides with low electrical conductivities were used as support materials, it can cause an increase in noble metal loading. To overcome this issue,

Sn and O. g EDAX of $\left(\mathrm{Sn}_{0.8} \mathrm{Ru}_{0.2}\right) \mathrm{O}_{2} / 10 \mathrm{~F}$ film. $\mathbf{h}$ TEM bright field image of $\left(\mathrm{Sn}_{0.8} \mathrm{Ru}_{0 \cdot 2}\right) \mathrm{O}_{2}: 10 \mathrm{~F}$ film showing the presence of fine nanoparticles [204]

transition metal carbides have attracted much attention as support materials and as electrocatalysts [208-211] and many different metal carbides such as $\mathrm{TiC}, \mathrm{SiC}-\mathrm{Si}$ and $\mathrm{TaC}$ have been studied as support materials for $\mathrm{IrO}_{2}$. For example, Karimi et al. [208] conducted a comparative analysis of six different metal carbides as support materials, including $\mathrm{TaC}, \mathrm{NbC}, \mathrm{TiC}, \mathrm{WC}, \mathrm{NbO}$ and $\mathrm{Sb}_{2} \mathrm{O}_{5}-\mathrm{SnO}_{2}$, and numerous factors were evaluated for OER catalyst applications such as surface area, $\mathrm{IrO}_{2}$ loading and conductivity. Here, the results revealed that to choose a good support for Ir electrocatalysts, both OER activity and support surface areas are important and must be taken into consideration.

The above discussions into non-noble metals for PEM electrolysis clearly indicate that pure non-noble metals are not suitable for OERs; while non-noble metals should be used as dopants or support materials for noble metals. In addition, non-precious transition metal oxides such as niobium oxide $\left(\mathrm{Nb}_{2} \mathrm{O}_{2}\right)$, tin oxide $\left(\mathrm{SnO}_{2}\right)$, tantalum oxide $\left(\mathrm{Ta}_{2} \mathrm{O}_{5}\right)$ and titanium oxide $\left(\mathrm{TiO}_{2}\right)$ can be used as catalyst compositing materials to decrease overall operational costs. 
However, these non-precious transition metal oxides do not show any activity for OER in PEM electrolysis. And because of this, the goal of achieving non-noble metal catalysts for the OER in PEM electrolysis is still not practical.

\subsection{Catalysts for OER in Solid Oxide Electrolysis}

\subsubsection{Noble Metal Catalysts}

A solid oxide electrolysis cell (SOEC) is the reverse mode of a solid oxide fuel cell (SOFC). In SOECs, the oxygen evolution reaction occurs at the anode which is the cathode in SOFCs and the limiting component of SOECs is the anode. In general, the performance of the anode OER process needs to be improved and one method of improving OERs is the addition of noble metals such as Pd, Pt or Ag to the anode. However, the catalytic effects of the addition of small amounts of noble metals have not been explored much and very few literature sources are available [212-214].

And in one of the few sources addressing the addition of a small amount of noble metal to form catalysts, Erning et al. [212] reported that the addition of small amounts of palladium $(\mathrm{Pd})$ can activate the catalytic process in which the addition of small amounts of $\mathrm{Pd}\left(0.1 \mathrm{mg} \mathrm{cm}^{-2}\right)$ to $\mathrm{La}_{0.84} \mathrm{Sr}_{0.6} \mathrm{MnO}_{3}$ (LSM) was found to decrease the activation energy from 200 to $100 \mathrm{~kJ} \mathrm{~mol}^{-1}$. However, this study was conducted on an SOFC rather than on an SOEC. In another study conducted by Sahibzada et al. [214], $\mathrm{La}_{0.6} \mathrm{Sr}_{0.4} \mathrm{Co}_{0.2} \mathrm{Fe}_{0.8} \mathrm{O}_{3}$ cathode (LSCF) performances were improved through adding small amounts of $\mathrm{Pd}$ as a promotor in which the addition of Pd was found to decrease the overall cell resistance by $15 \%$.

However, despite these promising findings, these noble metal-doped compounds are not suitable choices for SOECs and alternative low-cost and efficient materials need to be developed for high-temperature operating SOECs.

\subsubsection{Non-noble Metal Catalysts}

Barium-strontium-cobalt-ferro (BSCF) perovskite-type catalysts have been shown to possess high catalytic activities for SOFC cathodes; in addition, these perovskites also possess potential for applications as the anode in SOECs [214]. For example, Bo et al. [215] reported a novel combustion method for the development of a BSCF oxygen electrode for use as an anode and the resulting anodic material demonstrated lower area specific resistance $(A S R)$ values of $0.66 \Omega \mathrm{cm}^{2}$ at $750{ }^{\circ} \mathrm{C}, 0.27 \Omega \mathrm{cm}^{2}$ at $800{ }^{\circ} \mathrm{C}$ and $0.077 \Omega \mathrm{cm}^{2}$ at $850{ }^{\circ} \mathrm{C}$, which were lower than commonly used LSM, LSC and LSCF. In their study, XRD analysis confirmed the presence of single-phase perovskites at a calcination temperature of $900{ }^{\circ} \mathrm{C}$ and the HRTEM identified the presence of monodispersed particles with an average size less than $20 \mathrm{~nm}$. In addition, the presence of barium, strontium, cobalt, iron and oxygen was also analysed through EDX elemental techniques. Here, the exceptionally high catalytic activity of BSCF was thought to be responsible for the low $A S R$ values.

The LSCF is another important class of perovskites used as electrode materials for both SOFCs and SOECs [216-219]. For example, Fan et al. [219] reported an infiltration method for the development of $\mathrm{La}_{0.6} \mathrm{Sr}_{0.4} \mathrm{Co}_{0.2} \mathrm{Fe}_{0.8} \mathrm{O}_{3-\sigma}$ (LSCF)-YSZ (yttria-stabilized zirconia) as an oxygen electrode. In this study, SEM micrographs showed that the unmodified $\mathrm{Y}_{2} \mathrm{O}_{3}$-stabilized zirconia (YSZ) backbone possessed a clean surface and clearly visible grain boundaries (Fig. 14h-1) and that after infiltration, nanosized LSCF particles were uniformly distributed on the surface of the porous YSZ.

A novel bifunctional $\mathrm{SrCo}_{0.8} \mathrm{Fe}_{0.1} \mathrm{Ga}_{0.1}$ (SCFG) electrode material was also developed by Meng et al. [220] that could work simultaneously in both SOFCs and SOECs. In their study, the researchers used a sol-gel method to synthesize a perovskite doped with $\mathrm{Ga}^{3+}$ to form SCFG. And because of the modification of this material, the electrical conductivity of the resulting SCFG achieved a maximum value of $319 \mathrm{~S} \mathrm{~cm}^{-1}$ at $600{ }^{\circ} \mathrm{C}$. In addition, the maximum power density reached 1044,836 and $586 \mathrm{~mW} \mathrm{~cm}^{-2}$ at 750,700 and $650{ }^{\circ} \mathrm{C}$, respectively, and a hydrogen production rate of $22.9 \mathrm{~mL} \mathrm{~m}^{-1} \mathrm{~cm}^{-2}$ was achieved at a cell voltage of $2 \mathrm{~V}$ for an SOEC.

In another study, Boulfrad et al. [221] added small amounts of $\mathrm{Ce}_{0.9} \mathrm{Gd}_{0.1} \mathrm{O}_{2-\sigma}$ ( $\mathrm{CGO}$ ) to $\left(\mathrm{La}_{0.15} \mathrm{Sr}_{0.25}\right)_{0.97} \mathrm{Cr}_{0.5} \mathrm{Mn}_{0.5} \mathrm{O}_{3}$ (LSCM) to overcome the poor ionic conductivity of LSCM in applications as an anode material. In this study, the catalyst was pre-coated with $5 \mathrm{wt} \% \mathrm{Ni}$ from nitrates and an increase in catalytic performance was observed with polarization resistances decreasing from about $0.60 \Omega \mathrm{cm}^{2}$ to $0.38 \Omega \mathrm{cm}^{2}$ at $900{ }^{\circ} \mathrm{C}$. This increase in catalytic activity was attributed to the presence of Ni nanoparticles as shown in Fig. 14k-m.

Studies have also reported that metallic ratios and temperature have profound influences on the microstructure, composition and electrochemical property of perovskites [222, 223]. Based on this, the effects of Ni/Co ratios were evaluated in a recent study by Chrzan et al. [220] for a yttria-stabilized zirconia backbone with a $\mathrm{Ce}_{0.8} \mathrm{Gd}_{0.2} \mathrm{O}_{1.95}$ barrier layer and a $\mathrm{LaNi}_{1-x} \mathrm{Co}_{x} \mathrm{O}_{3-\sigma}(x=0.4-0.7)$ catalyst for application in SOECs in which the electrochemical results in the study demonstrated that the lowest polarization resistance $\left(67 \Omega \mathrm{cm}^{2}\right.$ at $\left.600{ }^{\circ} \mathrm{C}\right)$ can be obtained at a $\mathrm{Ni}$ :Co ratio of $1: 1\left(\mathrm{LaNi}_{0.5} \mathrm{Co}_{0.5} \mathrm{O}_{3-\sigma}\right)$.

To address the low melting temperature and high activity of bismuth-based oxides, Ai et al. [224] 

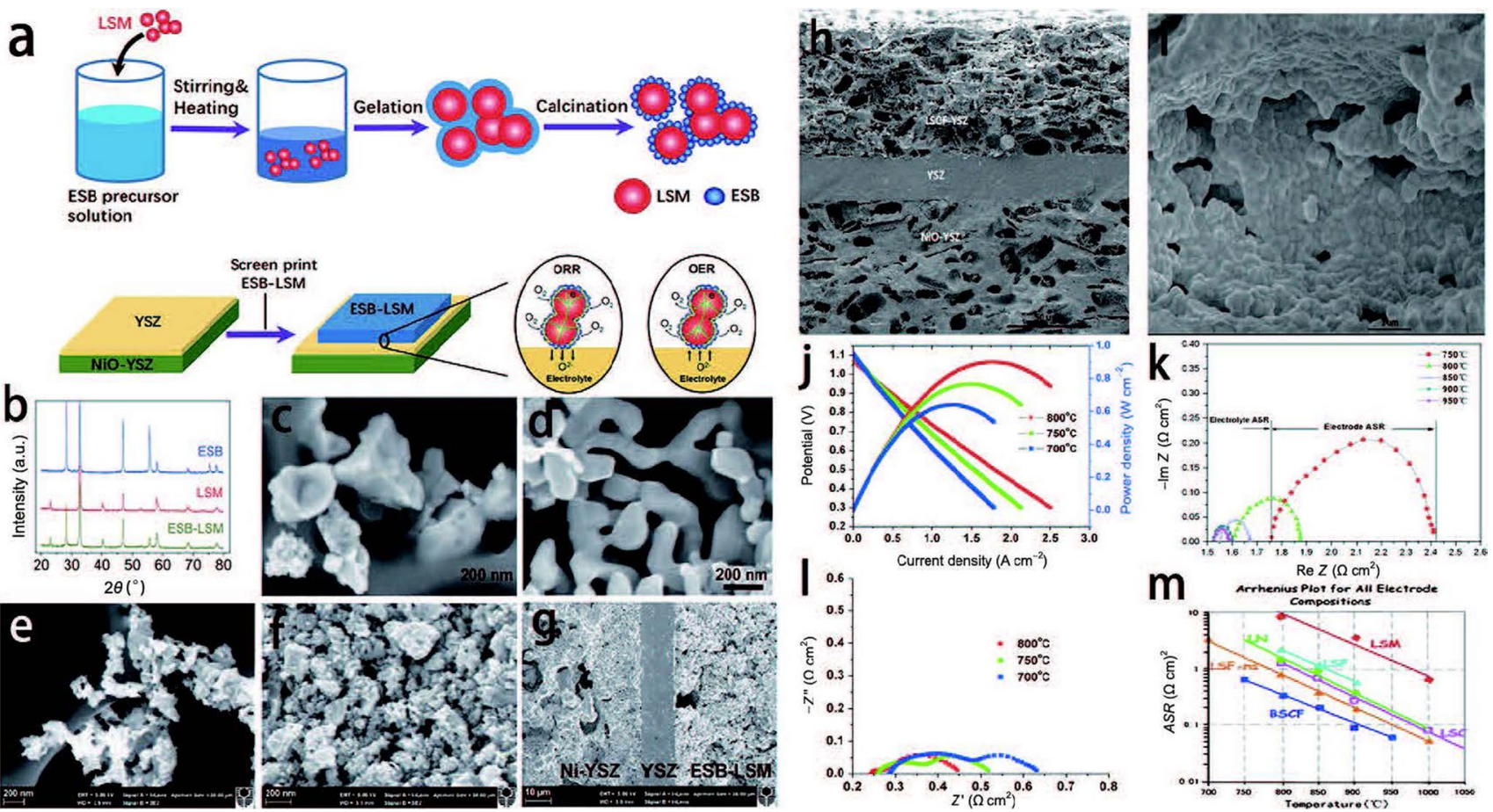

Fig. 14 a Schematic of the synthesis of nanostructured ESB decorated LSM (ESB-LSM) powder by using the gelation process and direct assembly of the ESB-LSM electrode on a Ni-YSZ anode-supported YSZ electrolyte cell. $\mathbf{b}$ XRD patterns of ESB, LSM and ESBLSM powders. $\mathbf{c}-\mathbf{e}$ SEM micrographs of the as-prepared ESB, LSM and ESB-LSM powders. $\mathbf{f}$ Surface of a directly assembled ESB-LSM electrode. $\mathbf{g}$ Cross section of a Ni-YSZ anode [224]. $\mathbf{h}-\mathbf{i}$ SEM micro-

successfully synthesized a $40 \mathrm{wt} \% \mathrm{Er}_{0.4} \mathrm{Bi}_{1.6} \mathrm{O}_{3}$ decorated with $\mathrm{La}_{0.76} \mathrm{Sr}_{0.19} \mathrm{MnO}_{3+\sigma}$ (ESB-LSM) using a new gelation method. In this method, the pre-sintering step at conventional elevated temperatures was prevented and subsequently, these modifications led to improved current densities with peak power densities of 1.62, 0.32, 0.17, 0.40 and $0.20 \mathrm{~W} \mathrm{~cm}^{-2}$ being achieved at 750, 700, 650, 600 and $550{ }^{\circ} \mathrm{C}$, respectively.

Overall, the performance of anodic catalysts for SOECs is highly dependent on the composition of the different metals, the pre-treatment method, the combustion temperature and the synthesis method. And based on the discussions above for SOEC oxygen electrodes, electrode materials can be classified into three main categories: (1) noble metals such as $\mathrm{Pt}$ or Ag that can be used as oxygen electrode in SOECs but are very expensive and difficult to apply commercially; (2) ceramic electrodes such as SFM, LSV, LSCM and LSM that possess good ionic and electrical conductivities but are catalytically slow and unstable; and (3) composite electrodes such as Ni-YSZ, NI-SDC, LSC-YSZ and LSM-YSZ that possess enhanced catalytic activities and thermal expansions matching with electrolytes [221-230]. graphs of the fractured cross section of LSCF-infiltrated NiO-YSZ/ YSZ/LSCF-YSZ RSOFC and porous YSZ backbone. $\mathbf{j}$ Plots of voltage and power density versus current density curves. I Nyquist electrochemical impedance spectra (EIS) plots at open circuit [219]. $\mathbf{k}-\mathbf{m}$ EIS analyses of BSCF and ASR comparisons with other oxygen electrodes [215]

\section{Electrocatalysts for HER}

\subsection{Catalysts for HER in Alkaline Electrolysis}

\subsubsection{Noble Metal Catalysts}

The hydrogen evolution reaction (HER) is the other necessary reaction at the cathode in water electrolysis in which platinum (Pt)- and palladium (Pd)-based catalysts are commonly used. However, the commercial application of these noble metal-based catalysts is hindered by high costs and scarcity [231, 232]. To overcome this challenge, researchers have attempted to disperse Pt-based catalysts onto the surface of various supports in the form of single atoms or sub-nanometric clusters. For example, the support that is commonly used for the dispersion of Pt is carbon black. There are two issues associated with the support strategy, however, one of which is the unfavourable changes to the electronic and geometric properties of $\mathrm{Pt}$, and the other is the possible detachment of particles from the support, with both issues causing dramatic decreases to Pt catalyst activities [233-237]. In this regard, carbon nanotubes (CNTs) have 
been explored and have shown promise as a support for Ptbased nanoparticles (NPs) with additional treatment, such as nitrogen doping, which can activate the pie electrons in the conjugated carbon, as shown in Fig. 15a, c-h. In one example, Ma et al. [235] synthesized a catalyst composed of Pt-based nanoparticles supported on bamboo-like CNTs which demonstrated a high catalytic property (with an overpotential of $40 \mathrm{mV}$ and a Tafel slope of $33 \mathrm{mV} \mathrm{dec}^{-1}$ ) that was near the activity of commercially available $20 \mathrm{wt} \% \mathrm{Pt} / \mathrm{C}$.

Other than the use of carbon black and CNTs as supports to stabilize noble metal catalysts, reducible metal oxides, due to their strong interactions with metal, can also be used as supports to effectively stabilize noble metals in their oxidized state. This effect of strong metal-support interactions (SMSI) can also be seen in electrocatalysis [238-241]. For example, Wang et al. [239] synthesized ultrafine and stable $\mathrm{Pt}$ nanoclusters with a trigonal prismatic coordination cage with sulphur atoms on the edges and their electrochemical tests indicated that the synthesized Pt NCs possessed high electrocatalytic performances towards HERs with low overpotentials and high current densities. This observed high catalytic activity was attributed to the highly active surface of the ultrafine Pt NCs and the synergistic effects between Pt NCs and the cage matrix [241]. The schematic illustration of the process used by Wang et al. is shown in Fig. 15b. In addition, Cheng et al. [231] reported the synthesis of sub-nanometric Pt clusters which were uniformly distributed on the surface of a $\mathrm{TiO}_{2}$ support that demonstrated high stability and enhanced mass activity. Here, the high stability of the prepared $\mathrm{PtO}_{x} / \mathrm{TiO}_{2}$ was attributed to the strong interactions between $\mathrm{PtO}_{x}$ and the $\mathrm{TiO}_{2}$ support, and in comparison with commercially available $\mathrm{Pt} / \mathrm{C}$, the supported $\mathrm{PtO}_{x}$ provided a 8.4 times enhanced mass activity and improved stability for the HER [231].

Up to now, Pt-based catalysts are the most efficient catalysts for HER; however, low earth abundance and high cost have prohibited their large-scale commercial application. Because of this, researchers are now devoting efforts to find alternative materials to be used as HER catalysts in water electrolysis.

\subsubsection{Non-noble Metal Catalysts}

Transition metal compounds including Ni compounds (alloys, phosphides, sulphides), Co compounds (phosphides and sulphides) and Mo compounds (sulphides and nitrides) are of prime importance as HER catalysts, and their electrocatalytic performances are provided in Table 5.

3.1.2.1 Ni-Based Alloys According to the Sabatier principle of electrocatalysis, the efficiency of a catalyst is dependent on the heat of absorption of the reaction intermediate on the
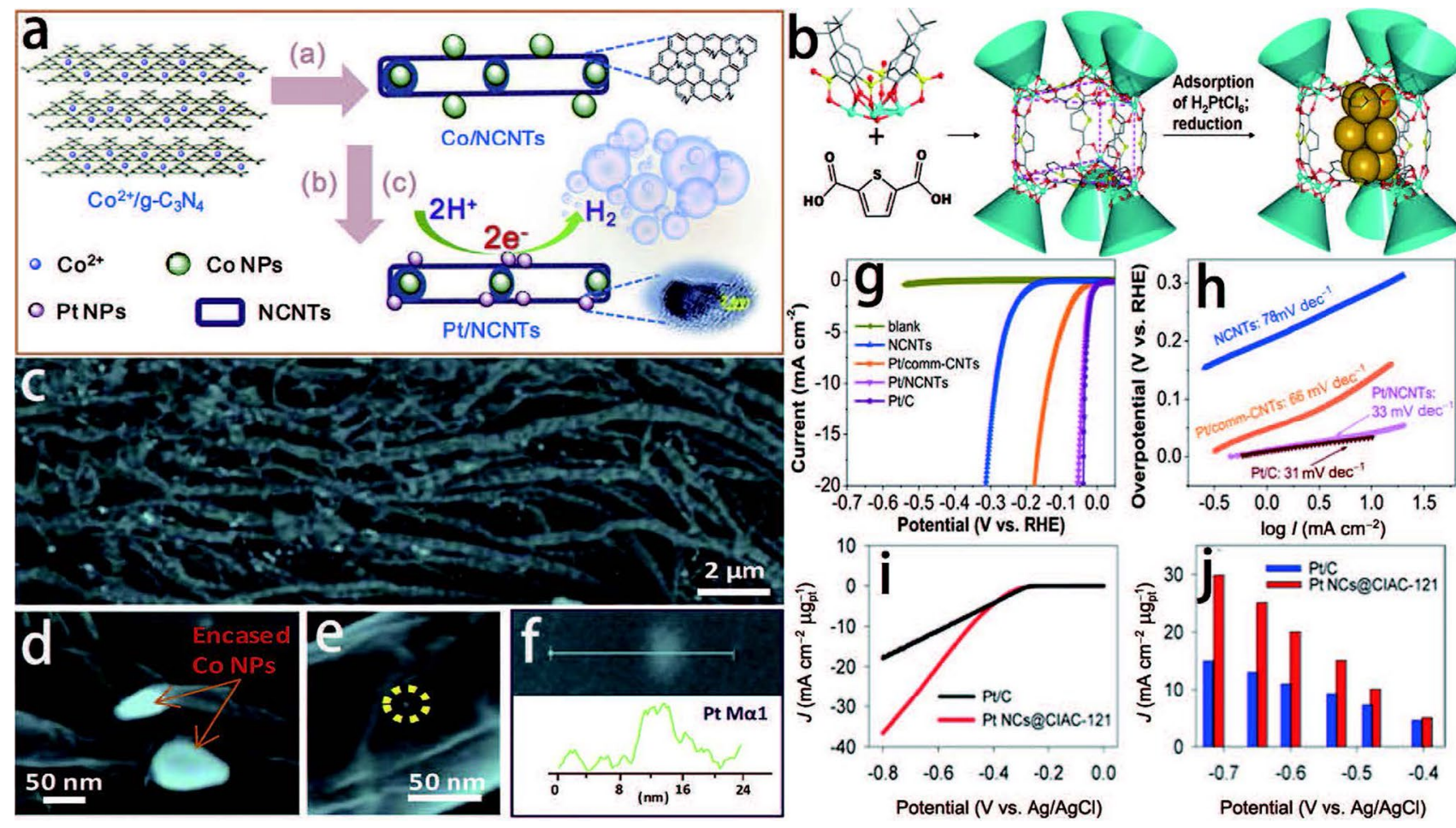

Fig. 15 a Schematic illustration for the preparation of Pt NPs bonding to NCNTs (Pt/NCNTs). c-f High- and low-magnification SEM images of Co NP@CNTs. g-h Polarization curve and Tafel slope
[237]. b Illustration of the assembly of trigonal prismatic $\left\{\mathrm{Ni}_{24}\right\}$ coordination cages (CIAC-121) and the fabrication of ultrafine $\mathrm{Pt}$ NCs [241] 
electrode surface [242]. In the case of HER catalytic activity, the activity is observed to follow a volcano-type relation in which the hydrogen binding free energy should be closest to that of state-of-the-art Pt catalysts $\left(\Delta G_{\mathrm{H}}\right.$ approximately zero). Therefore, the incorporation of other metals to $\mathrm{Ni}$ (smaller values of $\Delta G_{\mathrm{H}}$ as compared with other earth abundant metals) to form alloys such as $\mathrm{NiCo}, \mathrm{NiMo}, \mathrm{NiCu}$ and ternary metal alloys such as NiMoZn is a promising method to produce electrocatalysts with enhanced HER performances. In addition, synergetic effects can be observed if two transition metals are combined, increasing conductivity [242-254], making Ni-Co alloys efficient electrocatalysts due to improved intrinsic catalytic activities and corrosion resistance behaviours in alkaline media. For example, Sun et al. [243] reported the synthesis of mesoporous $\mathrm{NiCo}$ alloys through the electroless deposition method by using different compositions of lyotropic liquid crystals (LLC) as the mesoporous template. Here, SEM and TEM images confirmed a highly ordered mesoporous structure for the $\mathrm{Ni}_{58} \mathrm{Co}_{42}$ (Fig. 16b-e, j) alloy which provided the highest electrocatalytic activity with an overpotential value of $52 \mathrm{mV}$ and a Tafel slope of $60 \mathrm{mV} \mathrm{dec}{ }^{-1}$. This improved electrocatalytic activity in the study was attributed by the researchers to the synergetic effects between $\mathrm{Ni}$ and $\mathrm{Co}$ as well as to the enlarged exposure of catalytically active sites. Similarly in another study, ternary metal alloys (NiCoP) were synthesized by Yang et al. [248] using Ni foam as a substrate and the resulting alloy only required an overpotential value of $107 \mathrm{mV}$ and a Tafel slope of $62 \mathrm{mV} \mathrm{dec}^{-1}$ to achieve a current density of $10 \mathrm{~mA} \mathrm{~cm}{ }^{-2}$. The catalysis model of the synthesized NiCoP is shown in Fig. 16a.

Yin et al. [250] also reported that the composition and morphology of alloy catalysts for HER are tuneable by using the galvanostatic method and is highly dependent on applied currents. In their obtained SEM images, as shown in Fig. 16f-i, it can be seen that through increasing current
Table 5 HER catalysts in alkaline media

\begin{tabular}{|c|c|c|c|c|c|}
\hline Material & Electrolyte & $\begin{array}{l}\text { Overpotential } \\
(\mathrm{mV})\end{array}$ & $\begin{array}{l}\text { Tafel slope } \\
\left(\mathrm{mV} \mathrm{dec}{ }^{-1}\right)\end{array}$ & $\begin{array}{l}\text { Current density } \\
\left(\mathrm{mA} \mathrm{cm}^{-2}\right)\end{array}$ & References \\
\hline $\mathrm{Ni} / \mathrm{Co}$ & $1 \mathrm{M} \mathrm{NaOH}$ & - & 60 & 10 & [243] \\
\hline $\mathrm{Ni} / \mathrm{Co}-\mathrm{NC}$ & $1 \mathrm{M} \mathrm{KOH}$ & 68 & 180 & 10 & [244] \\
\hline $\mathrm{Ni} / \mathrm{Mo}$ & $1 \mathrm{M} \mathrm{NaOH}$ & - & - & - & [245] \\
\hline $\mathrm{Ni} / \mathrm{Mn}$ & $1 \mathrm{M} \mathrm{KOH}$ & - & 58.97 & 10 & [247] \\
\hline $\mathrm{NiCoP}$ & $1 \mathrm{M} \mathrm{KOH}$ & 107 & 62 & 10 & [248] \\
\hline $\mathrm{Ni}-\mathrm{S}-\mathrm{Fe}$ & $1 \mathrm{M} \mathrm{KOH}$ & 222 & 84.6 & 10 & [257] \\
\hline $\mathrm{Ni}_{2} \mathrm{P}$ pea pod & $1 \mathrm{M} \mathrm{KOH}$ & 60 & 54 & 10 & [258] \\
\hline $\mathrm{NiP}_{2}$ nanosheets & $1 \mathrm{M} \mathrm{KOH}$ & 75 & - & 10 & [259] \\
\hline $\mathrm{Ni}_{2} \mathrm{P}$ NPs & $1 \mathrm{M} \mathrm{KOH}$ & 138 & - & 10 & [261] \\
\hline $\mathrm{Mn}-\mathrm{NiP}_{2}$ & $1 \mathrm{M} \mathrm{KOH}$ & 69 & - & 10 & [263] \\
\hline $\mathrm{Ni}-\mathrm{Fe}-\mathrm{P}$ & $1 \mathrm{M} \mathrm{KOH}$ & - & 64.6 & 10 & [264] \\
\hline $\mathrm{W}-\mathrm{Ni}_{2} \mathrm{P}$ & $1 \mathrm{M} \mathrm{KOH}$ & 110 & 39 & 10 & [267] \\
\hline $\mathrm{NiS}_{2} / \mathrm{CC}$ & $1 \mathrm{M} \mathrm{KOH}$ & 243 & 104 & 10 & [271] \\
\hline $\mathrm{Ni}_{3} \mathrm{~S}_{2} \mathrm{NWs}$ & $1 \mathrm{M} \mathrm{KOH}$ & 200 & - & 10 & [273] \\
\hline NiS/MoS/C & $1 \mathrm{M} \mathrm{KOH}$ & 117 & 58 & 10 & [274] \\
\hline V-NiS & $1 \mathrm{M} \mathrm{KOH}$ & 125 & - & 10 & [276] \\
\hline CoP nanotubes & $1 \mathrm{M} \mathrm{KOH}$ & & 60 & 10 & [284] \\
\hline 3D CoP NWs & $1 \mathrm{M} \mathrm{KOH}$ & - & 65 & 10 & [278] \\
\hline $\mathrm{Co}_{2} \mathrm{P}$ NRs & $1 \mathrm{M} \mathrm{KOH}$ & 45 & 67 & 10 & [285] \\
\hline CoP NPs WS $\mathrm{W}_{2}$ & $1 \mathrm{M} \mathrm{KOH}$ & 50 & 64.3 & 10 & [286] \\
\hline $\mathrm{Co}_{9} \mathrm{~S}_{8}-\mathrm{NSG}$ & $1 \mathrm{M} \mathrm{KOH}$ & 65 & 84 & 10 & [298] \\
\hline $\mathrm{Co}_{9} \mathrm{~S}_{8}-\mathrm{NiS}$ & $1 \mathrm{M} \mathrm{KOH}$ & 163 & 83 & 10 & [301] \\
\hline $\mathrm{MoS}_{2}$ nanoplates & $1 \mathrm{M} \mathrm{KOH}$ & 90 & 53 & 10 & [306] \\
\hline $\mathrm{MoS}_{2} / \mathrm{Ti}$ & $1 \mathrm{M} \mathrm{KOH}$ & 108 & 52 & 10 & [309] \\
\hline $\mathrm{MoS}_{2} / \mathrm{C}_{3} \mathrm{~N}_{4}$ & $1 \mathrm{M} \mathrm{KOH}$ & 153 & 43 & 10 & [310] \\
\hline $\mathrm{MoS}_{2} / \mathrm{CB}$ & $1 \mathrm{M} \mathrm{KOH}$ & - & 39 & 10 & [312] \\
\hline MoP/CC & $1 \mathrm{M} \mathrm{KOH}$ & 87 & 61 & 10 & [325] \\
\hline MoP NA/CC & $1 \mathrm{M} \mathrm{KOH}$ & 124 & 58 & 10 & [328] \\
\hline $\mathrm{MoO}_{2} / \mathrm{MoC} / \mathrm{C}$ & $1 \mathrm{M} \mathrm{KOH}$ & 233 & - & 10 & [329] \\
\hline $\mathrm{N}-\mathrm{Mo}_{2} \mathrm{C}$ & $1 \mathrm{M} \mathrm{KOH}$ & 52 & 49.7 & 10 & [335] \\
\hline
\end{tabular}




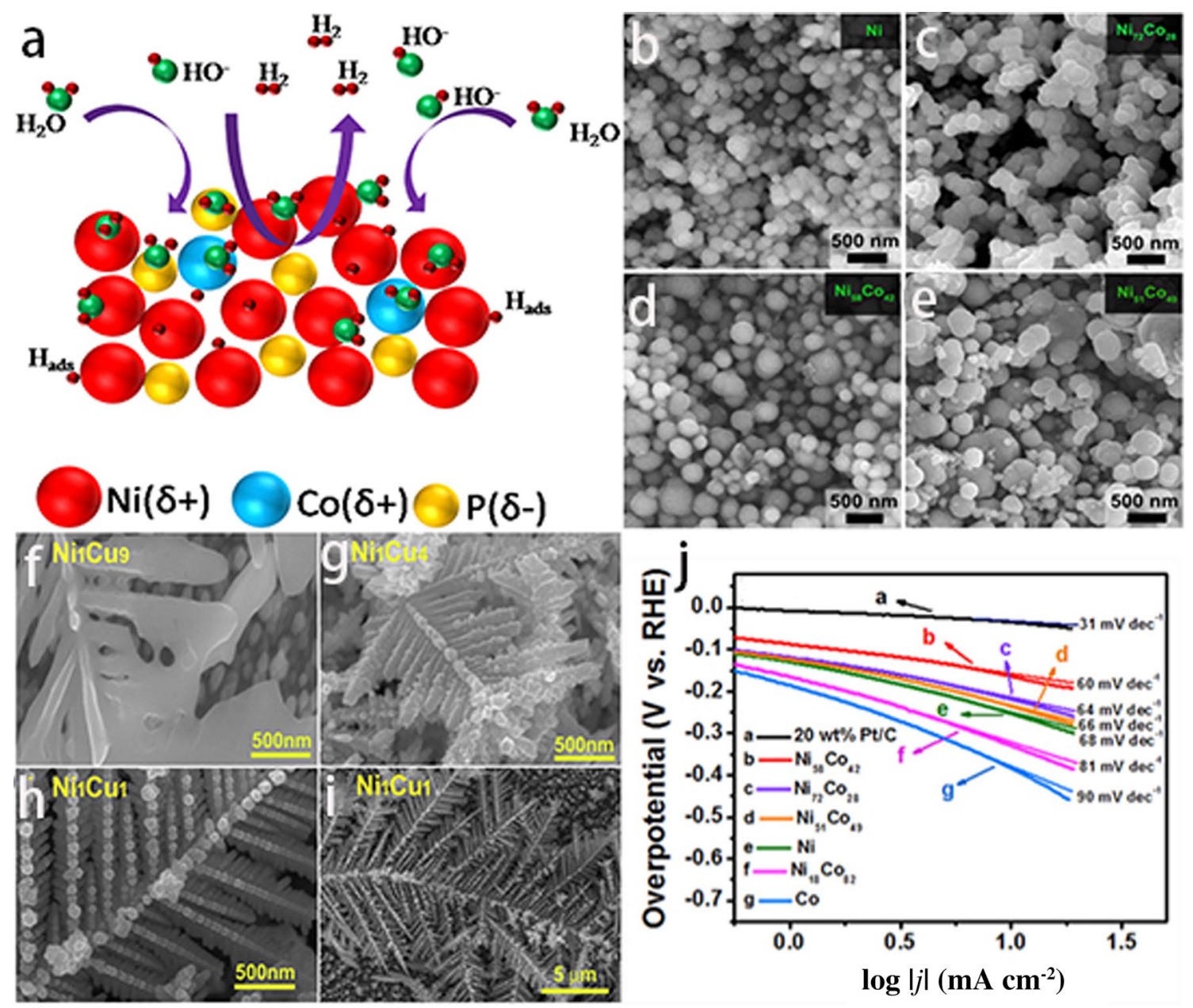

Fig. 16 a Schematic illustration of electrocatalytic HER on the surface of catalysts in alkaline media [248]. b-e SEM images of mesostructured $\mathrm{Ni}_{100-x} \mathrm{Co}_{x}$ alloys prepared from different LLC compo-

densities, the branches of the trunk become thicker, denser and more symmetrical and that the $\mathrm{NiCu}$ alloy with a 1:1 composition possessed the highest catalytic activity. In another study conducted by Wu et al. [253], electrodeposition was used to synthesize ternary alloys of $\mathrm{Ni}-\mathrm{S}-\mathrm{Fe}$ by using $\mathrm{Cu}$ foil as a substrate. Here, the synergetic effects of $\mathrm{Ni}$ and $\mathrm{Fe}$, combined with the increased surface areas of $\mathrm{Ni}-\mathrm{S}-\mathrm{Fe}$ along with the effects of Fe doping, resulted in high HER performances compared with $\mathrm{Ni}-\mathrm{S}$ alloys with a small overpotential value of $222 \mathrm{mV}$ and a Tafel slope of $84.5 \mathrm{mV} \mathrm{dec}^{-1}$.

Although the intrinsic and extrinsic activities of Ni catalysts in HER applications can be improved through alloying with other earth abundant non-noble metals or through synthesizing nanostructured materials, cathodes based on these $\mathrm{Ni}$ catalysts still face several issues, such as cathodic fouling by the electrodeposition of trace metals present in the electrolyte, unsatisfactory structures and poor long-term stability [255-257]. Therefore, further enhancements in alloy-based $\mathrm{Ni}$ catalysts are needed to overcome these challenges. sitions. $\mathbf{j}$ Tafel plot of NiCo [243]. $\mathbf{f}-\mathbf{i}$ FESEM micrographs of the $\mathrm{Ni}_{x} \mathrm{Cu}_{y}$ alloys prepared under deposition conditions [251]

3.1.2.2 Ni-Based Phosphides Transition metal phosphides (TMPs) are another important class of compounds that can be used as electrocatalysts for HERs in alkaline electrolysis. These phosphides possess high electrocatalytic activity, long-term stability and bifunctional properties as both HER and OER catalysts. For HERs, transition metal phosphides are more suitable for application because of their higher electrical conductivities as compared with corresponding transition metal oxides (TMOs). And because of this desirable property, Ni-based phosphides are gaining immense importance as HER catalysts [258-263]. In one example, a novel cost-effective method was developed for the synthesis of nickel phosphide nanoparticles by Bai et al. [256] in which glucose was used as a carbon source and $\mathrm{NiNH}_{4} \mathrm{PO}_{4} \mathrm{H}_{2} \mathrm{O}$ nanorods as a precursor. The resulting nanoparticles in this study were found to be encapsulated in carbon fibres and enhanced catalytic activities were observed because of the increase in surface areas and active sites, providing a low overpotential value of $60 \mathrm{mV}$ and a Tafel slope 
of $54 \mathrm{mV} \mathrm{dec}{ }^{-1}$ with a current density of $10 \mathrm{~mA} \mathrm{~cm}^{-2}$. The schematic illustration of the synthesis method is shown in Fig. 17a.

The interfacing of Ni-based phosphides with carbon materials is useful in increasing performances because carbon materials possess high electrical conductivities and large surface areas. As an example, Jeoung et al. [258] synthesized $\mathrm{Ni}_{2} \mathrm{P}$ nanoparticles (NPs) entrapped in 3D graphene through the thermal conversion of a coordinated compound followed by phosphidation. The schematic illustration of the synthesis process is shown in Fig. 17b. In this study, TEM images confirmed a uniform distribution of Ni NPs throughout the graphene matrix with an average diameter of $5 \mathrm{~nm}$ (Fig. 17c-f) and XRD confirmed a single-phase cubic structure for the $\mathrm{NiO}$. In the resulting catalyst, the graphitic layer can stabilize the large surface areas of the $\mathrm{Ni}_{2} \mathrm{P}$ NPs and facilitate electron transfer because of the contact between them. In addition, the graphene can act as both a protective layer and an enhancing matrix for the catalytically active $\mathrm{Ni}_{2} \mathrm{P}$ NPs. As a result, the catalyst provided a high electrocatalytic activity with a Tafel slope value of $56 \mathrm{mV} \mathrm{dec}{ }^{-1}$. Further improvements in electrocatalytic activity can also be achieved through doping $\mathrm{NiP}_{2}$ with $\mathrm{Mn}$ and compared with pure $\mathrm{NiP}_{2}$, doped nickel phosphides

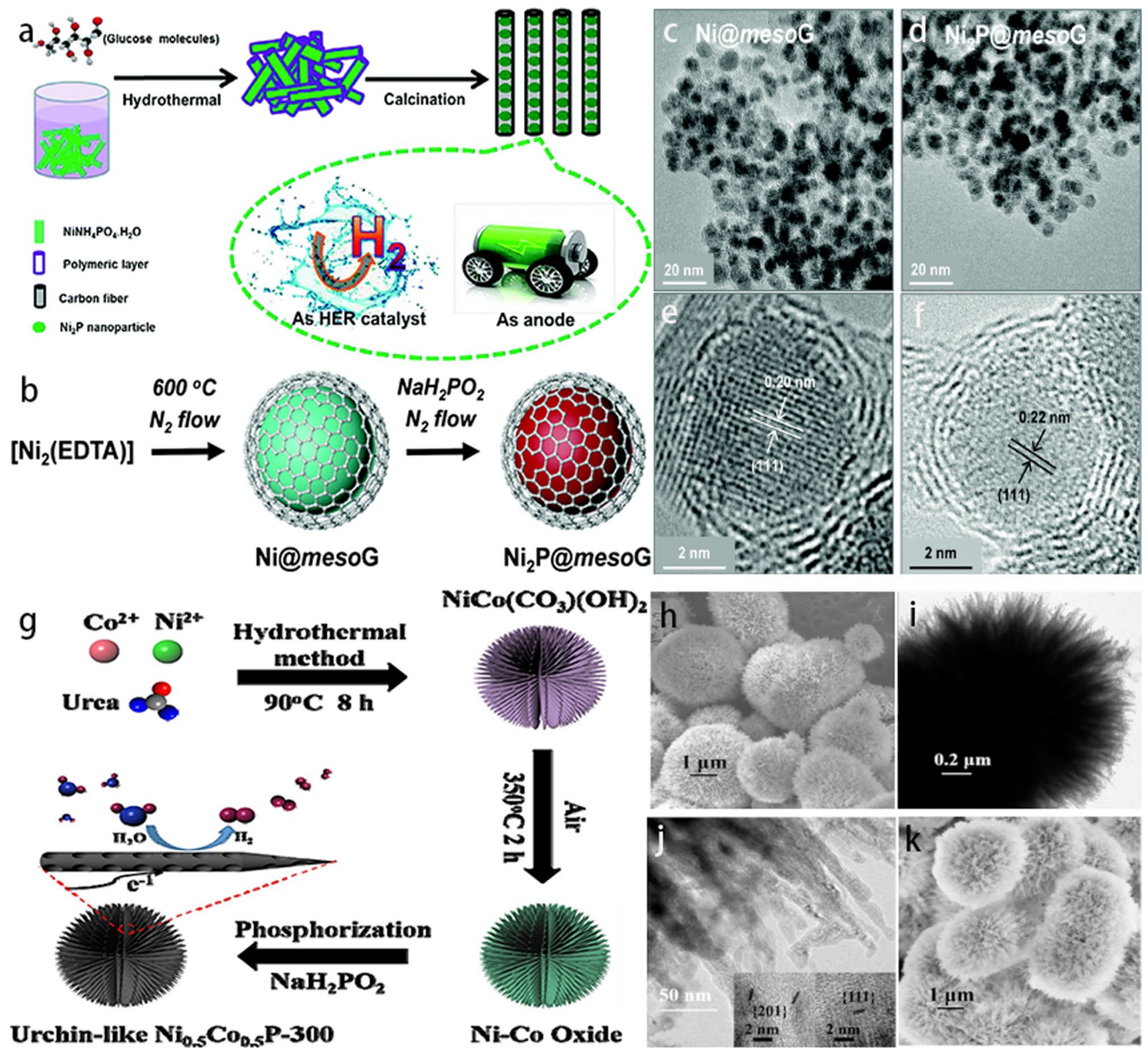

Fig. 17 a Schematic illustration of the synthesis process for the peapod-like $\mathrm{Ni}_{2} \mathrm{P} / \mathrm{C}$ nanocomposite [258]. b Schematic illustration of the $\mathrm{Ni}_{2} \mathrm{P}$ NPs entrapped in 3D mesoporous graphene $\left(\mathrm{Ni}_{2} \mathrm{P} @\right.$ mesoG). c-f TEM and HRTEM images of the $\mathrm{Ni} @$ mesoG and the $\mathrm{Ni}_{2} \mathrm{P} @$
mesoG [260]. g Schematic illustration of the synthesis process for urchin-like porous $\mathrm{Ni}_{0.5} \mathrm{Co}_{0.5} \mathrm{P}-300$. h-k SEM and TEM images of $\mathrm{Ni}_{0.5} \mathrm{Co}_{0.5} \mathrm{P}-300$ [268] 
possess higher performances because of lower neutral hydrogen absorption free energies [263].

One disadvantage of using carbon materials in alkaline conditions, however, is the degradation of the carbon material which leads to low electrocatalytic performances as a result of the loss in reaction kinetics and oxygen mass transport. Here, the corrosion of carbon black is one of the main degradation processes in cathodic environments, leading to lowered performances due to decreased active surface areas.

Bimetallic phosphides such as NiFeP, $\mathrm{NiPS}_{3}, \mathrm{~W}-\mathrm{NiP}$, $\mathrm{NiCoP}$ and NiCoP/NF and NiCoP@CNT/NF have also been employed as HER catalysts because they are generally more effective than their single metal phosphides [264-270]. For example, Li et al. [268] reported the synthesis of highly dispersed NiCoP nanoparticles on the surface of Ni foam modified with carbon nanotubes that possessed more active sites. In the SEM micrographs, the electrodeposition of NiCoP on the surface of the CNT/NF was confirmed and resulted in a novel urchin-like morphology (Fig. 17h-k) that provided more exposed active sites, leading to improved catalytic activities. A schematic illustration of the synthesis process is shown in Fig. 17g.

3.1.2.3 Ni-Based Chalcogenides Ni-based chalcogenides (Ni sulphides and selenides) have also shown high catalytic activities towards HERs. These chalcogenides include $\mathrm{NiS}_{2}$,
3D $\mathrm{Ni}_{3} \mathrm{~S}_{2}, \mathrm{NiS}-\mathrm{MoS}_{2}$, Ni-Co-MoS, V-doped NiS, NiSe, NiSe@CoP, Ni-W-S and Ni-S-CeO 2 [271-278]. Among these chalcogenides, $\mathrm{Ni}$ sulphides are important because they are highly abundant and possess high intrinsic activities and good electrical transport abilities. In one example, Yang et al. [272] fabricated a $3 \mathrm{D} \mathrm{Ni}_{3} \mathrm{~S}_{2}$ nanofilm on a nanoporous copper substrate $\left(\mathrm{Ni}_{3} \mathrm{~S}_{2} @ \mathrm{NPC}\right)$ and the resulting catalyst demonstrated high catalytic activities in both acidic and alkaline media, with an overpotential value of 91.6 and $60.8 \mathrm{mV}$, respectively. The researchers conducted DFT studies to illustrate the electronic structure and relative density states of the rhombohedral crystal planes, and here, XRD patterns of the template were used as a reference and highlighted the characteristic peaks of the rhombohedral crystal plane. Density functional theory calculations were also performed to demonstrate the electronic band structure and relevant density of the rhombohedral $\mathrm{Ni}_{3} \mathrm{~S}_{2}$ states. As shown in Fig. 18a, b-e, the nickel sulphides in the catalyst exist in a cubic-type structure in which nickel atoms are tetrahedrally bonded to the body-centred cubic sulphur atoms.

Another potential method to improve Ni sulphide performances towards HERs is to dope them with other elements. Based on this, Shang et al. [274] obtained vanadium (V)doped NiS nanowires supported on Ni foam through in situ cathodic activation (ISCA) in which the formation of nanowires enlarged active surface areas, exposed more sites and allowed for faster electrolyte diffusions to the active surfaces

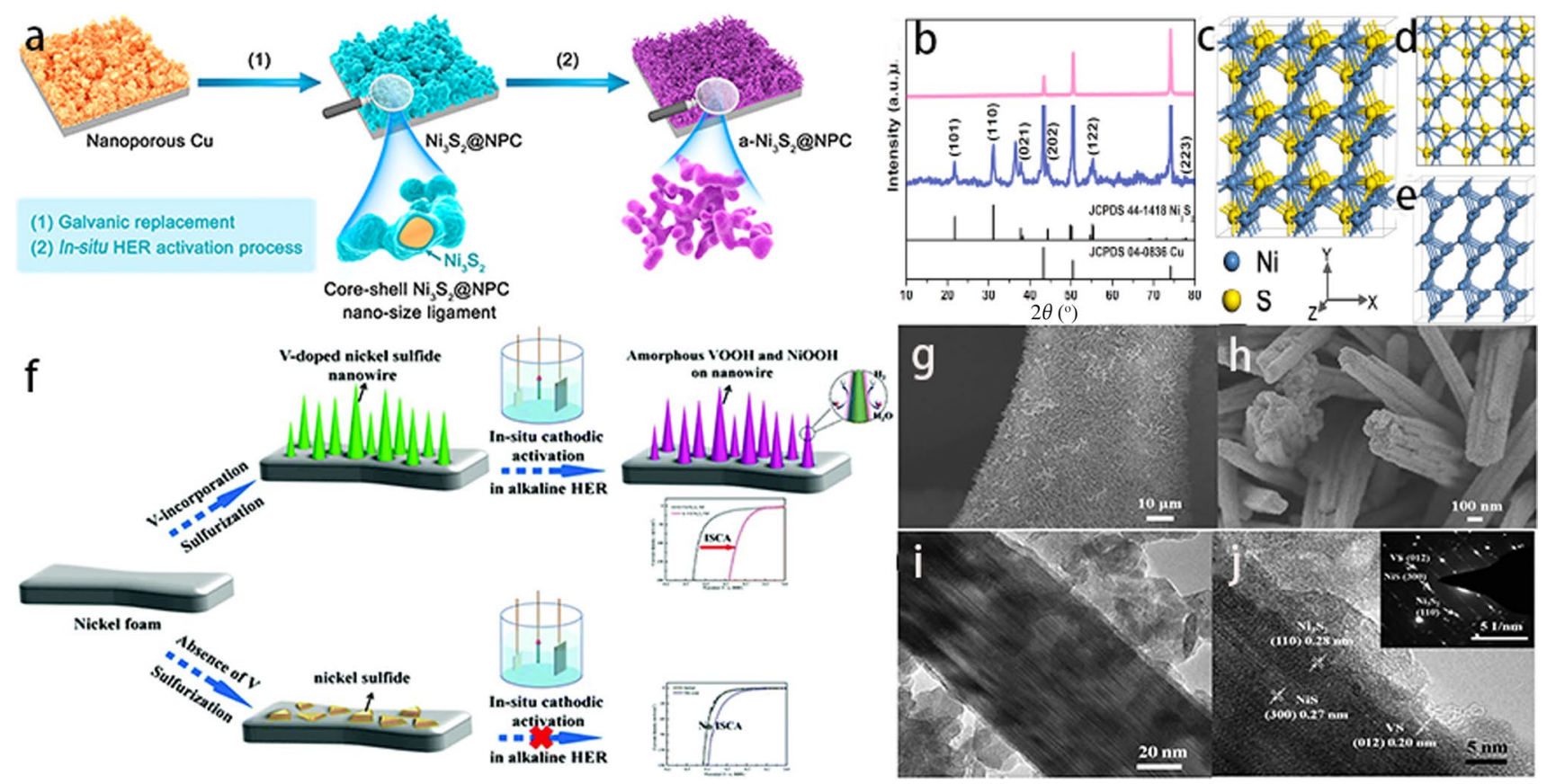

Fig. 18 a Schematic illustration showing the fabrication process of the nanoporous $\mathrm{Ni}_{3} \mathrm{~S}_{2} @ \mathrm{NPC}$ electrode and its in situ activation process during HER electrolysis. b XRD patterns of bare NPC (pink line) and the $\mathrm{Ni}_{3} \mathrm{~S}_{2} @ \mathrm{NPC}$ (navy line). c-d Front and top views of the
$\mathrm{Ni}_{3} \mathrm{~S}_{2}$ supercell $(3 \times 3 \times 3)$ showing the crystal structure. e Network of $\mathrm{Ni}-\mathrm{Ni}$ bond paths in heazlewoodite $\mathrm{Ni}_{3} \mathrm{~S}_{2}$ crystallites [272]. f Schematic representation of the in situ cathodic activation (ISCA) of the $\mathrm{VS} / \mathrm{Ni}_{x} \mathrm{~S}_{y} / \mathrm{NF}$. $\mathbf{g}-\mathbf{j}$ SEM and TEM images of the VS/Ni $\mathrm{S}_{x} / \mathrm{NF}$ [276] 
of the electrode. Here, the effect of the incorporation of $\mathrm{V}$ can be observed through the obtained SEM and TEM images in which the triangle-like nanosheets transformed to nanowires (Fig. 18g-j). And because of this change in morphology, the electrocatalytic performance of NiS greatly improved. The ISCA process is illustrated in Fig. 18f.

As for molybdenum-nickel disulphides, synergetic effects can be observed between Mo and $\mathrm{Ni}$ in which nickel sites can act as an excellent water dissociation centre, and Mo can provide decent adsorption capability towards hydrogen [279-281]. These synergetic effects on the interface of $\mathrm{Ni}-\mathrm{Mo}-\mathrm{S}$ are helpful in promoting catalytic kinetics, resulting in improved catalytic activities. Key issues with Ni-based chalcogenide catalysts are activity loss and morphology collapse during the catalytic process, and it is still challenging to synthesize stable and catalytically active $\mathrm{Ni}$ based chalcogenide catalysts [282, 283].

3.1.2.4 Co-Based Phosphides Like Ni-based phosphides, Co-based phosphides also have the potential to be used as HER catalysts [277, 278, 284-290]. For example, Li et al. [289] conducted the synthesis of CoP nanocrystals embedded in carbon matrixes without the use of any harsh conditions or harmful organic reagents. Here, the use of a conductive carbon as the support assisted in improving the conductivity of the hybrid as well as provided more active sites as a result of the dispersion of active phases. Both SEM and TEM images and the schematic diagram of the resulting carbon are shown in Fig. 19b-j, and from these, it can be seen that the mesoporous structure of the carbon support is also helpful in hindering the aggregation of CoP nanoparticles. Because of all these factors, the resulting catalyst demonstrated a low Tafel slope value of $56.67 \mathrm{mV} \mathrm{dec}-1$ and an overpotential of $112.18 \mathrm{mV}$ at a current density of $10 \mathrm{~mA} \mathrm{~cm}{ }^{-2}$. The entire process for the synthesis is shown in Fig. 19a.

Cobalt phosphides are inferior to Pt catalysts for HER in alkaline media in terms of catalytic activity. However, metal (hydroxide) oxide interfaces have emerged recently as an effective method to enhance catalytic performances. As an example, Zhang et al. [290] conducted the selective phosphidation of $\mathrm{CoP}-\mathrm{CeO}_{2}$ hybrids on Ti mesh $\left(\mathrm{CoP}-\mathrm{CeO}_{2} / \mathrm{Ti}\right)$, and their resulting catalyst produced high catalytic activities. Here, the researchers assumed that the water dissociation process can be enhanced by $\mathrm{CeO}_{2}$, therefore improving formation rates of $\mathrm{H}^{*}$ adsorption intermediates. SEM micrographs confirm the formation of nanosheets as shown in Fig. 19j-1. In electrochemical testing in a $1 \mathrm{M} \mathrm{KOH}$ solution, the catalyst demonstrated high stability and a low overpotential value of $43 \mathrm{mV}$ to deliver $10 \mathrm{~mA} \mathrm{~cm}^{-2}$. A schematic illustration of the synthesis process is shown in Fig. $19 \mathrm{~m}$.

Hybrid compounds composed of carbon materials and metal compounds can have immense influences on HER performance in which the synergetic effects between the high intrinsic conductivity of carbon materials and the large exposed surface area of metal compounds collectively increase catalytic activities [293-295]. For example, Lin et al. [283] synthesized an efficient hybrid compound composed of N, P co-doped carbon nanoflakes (NPCFs) and CoP nanorods (NRs) through the direct pyrolysis of a mixture of biomass macromolecule sodium alginate and ammonium hypophosphite. [285] The obtained catalyst, because of the synergistic effects, produced a high electrocatalytic activity with a low Tafel slope value of $67 \mathrm{mV} \mathrm{dec}{ }^{-1}$ and an overpotential of only $45 \mathrm{mV}$ (Fig. 19o-r).

In recent years, Co-based phosphides with different morphologies such as nanowires, nanosheets, nanoparticles [287, 288], urchin-like CoP nanowires [289, 290], CoP nanowires arrays [277] and CoP nanotubes [153] have been successfully synthesized and show promising HER performances in alkaline media. They can also be used as supports or in combination with other materials to enhance electrocatalytic activities [296, 297].

3.1.2.5 Co-Based Chalcogenides Cobalt-based chalcogenides (sulphides and selenides) can catalyse HER processes in alkaline electrolysis [298-302], and Co sulphides have been proven to be efficient electrocatalysts. However, two issues are present in these cobalt-based chalcogenides, including low active surface areas and agglomeration of catalysts during HER operations [298]. An effective solution to these issues is to tune catalyst morphologies to enhance performance, and based on this, Kim et al. [298] prepared a 1D array of $\mathrm{CoS}_{2}$ on the surface of carbon fibre paper (CFP) as an efficient electrocatalyst [300] which demonstrated high catalytic activities. As shown in Fig. 20a-j, SEM images revealed a pine tree-like nanocolumn structure for the $\mathrm{CoS}_{2} / \mathrm{CFP}$ (Fig. 20a-j) in which the observed high catalytic activity can be attributed to. This special morphology is thought to be helpful in exposing more active sites for HER. In another study, Wang et al. [300] fabricated $\mathrm{CoSe}_{2} /$ CFP nanowires with a necklace-like morphology (Fig. 20kn) and the resulting catalyst showed a high electrocatalytic activity, providing a low Tafel slope value of $34 \mathrm{mV} \mathrm{dec}-1$ and a stability of up to 5000 cycles. The possible reason for this increased performance was attributed to the special nanostructure, which can ensure high contact areas with the electrolyte and increase the release of hydrogen gas bubbles from the surface.

Further improvements in the catalytic performance of cobalt-based chalcogenides can be made through synthesizing hybrid materials, such as $\mathrm{Co}_{9} \mathrm{~S}_{8}-\mathrm{MoS}_{x}, \mathrm{Co}_{9} \mathrm{~S}_{8} / \mathrm{GO}$ and $\mathrm{Co}_{9} \mathrm{~S}_{8}-\mathrm{Ni}_{\mathrm{S}} / \mathrm{Ni}$ foams. For example, Zhou et al. [297] prepared a hybrid catalyst containing cubic $\mathrm{Co}_{9} \mathrm{~S}_{8}$ and nanocrystalline $\mathrm{MoS}_{x}$ that displayed a high catalytic activity with an overpotential value of just $98 \mathrm{mV}$ at a current 

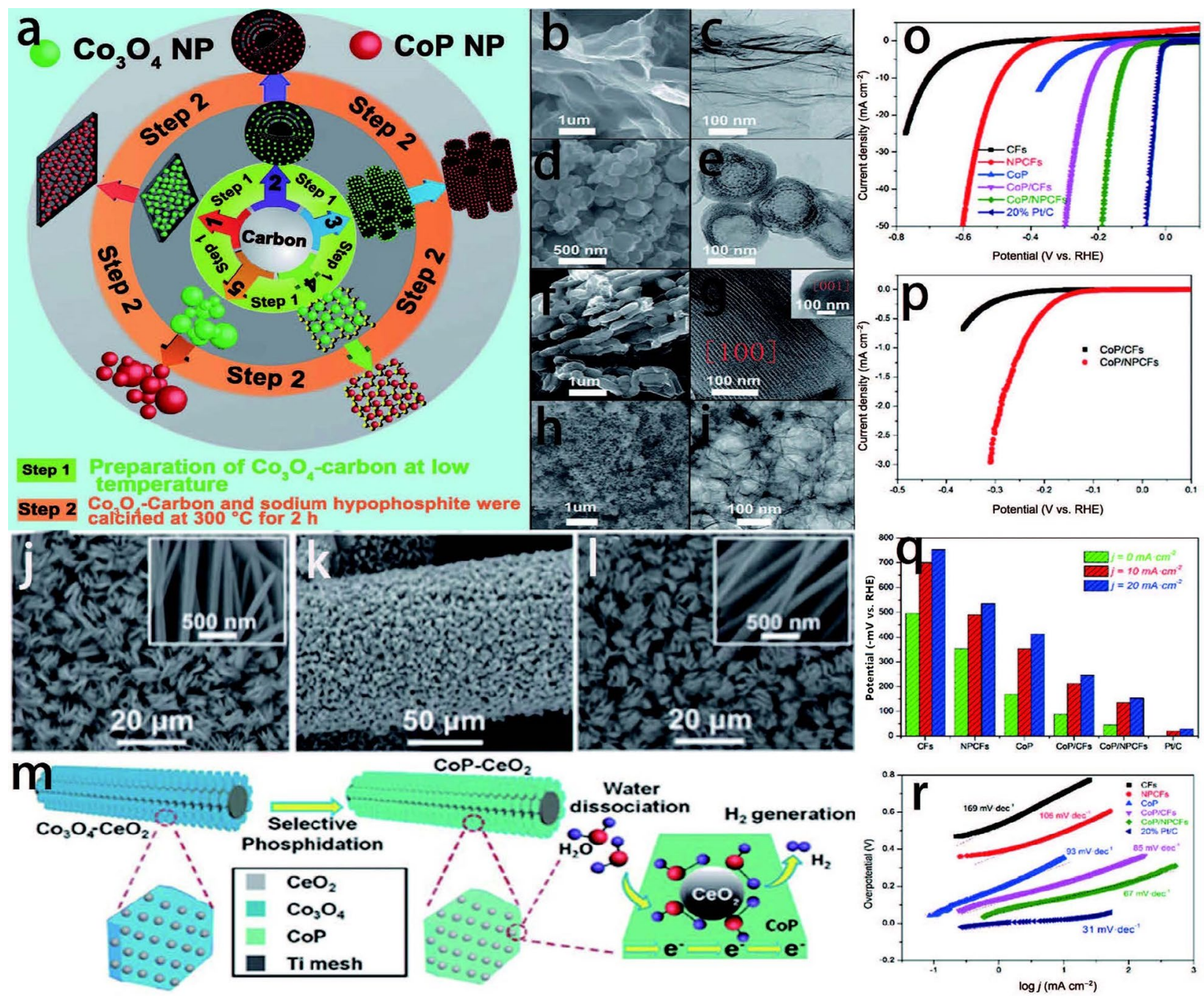

Fig. 19 a Illustration of the preparation procedures for free CoP NPs, Co. $\mathbf{b}-\mathbf{j}$ SEM and TEM images of the RGO, mesoporous carbon vesicles, ordered mesoporous carbon, and macroporous carbon [291]. j-l SEM images of the $\mathrm{Co}_{3} \mathrm{O}_{4}-\mathrm{CeO}_{2} / \mathrm{Ti}$ and the $\mathrm{CoP}-\mathrm{CeO}_{2} / \mathrm{Ti}$. m Sche-

density of $10 \mathrm{~mA} \mathrm{~cm}{ }^{-2}$ in a $1 \mathrm{M}$ alkaline solution. In addition, the introduction of heteroatom dopants $(\mathrm{N}, \mathrm{B}, \mathrm{S}, \mathrm{P}, \mathrm{F}$, etc.) to these composites can greatly enhance catalytic performances as well. For example, Gong et al. [301] found in their study that elemental $\mathrm{N}$ was the most effective dopant to be introduced into these hybrid materials in the improvement of catalytic activity. The researchers here suggest that this is because of the similar atomic sizes of nitrogen atoms and carbon atoms in the graphene and graphitic carbon, resulting in the efficient donation of electron pairs from the $\mathrm{N}$ atom to the $s p^{2}$-hybridized carbon atom [303, 304]. In another example, Li et al. [298] reported the synthesis of $\mathrm{Co}_{9} \mathrm{~S}_{8}$ nanoparticles embedded in a N, S Co-doped graphene-unzipped carbon nanotube composite as a high-performance electrocatalyst for HERs. In this study, the as-synthesized catalyst matic illustration of selective phosphidation in the catalyst synthesis and catalytic process [292]. o-r LSV, histogram, BET surface area normalized LSV and Tafel slope of the CoP/NPCFs hybrid catalyst [285]

outperformed many binary and ternary carbon-based composites in the literature and the excellent HER performances were attributed to the combined effects of abundant HER active sites created by $\mathrm{Co}_{9} \mathrm{~S}_{8}$ NPs, structural defects in the carbon support induced by $\mathrm{N}$ and $\mathrm{S}$ doping, and increased conductivity because of the 3D structure.

Recently, many important developments have been made in Co-based sulphides and selenides as HER electrocatalysts, but there is still room for further development. This is because the HER, being a surface process, requires more exposed active sites and the prevention of the agglomeration of electrocatalysts during the HER.

3.1.2.6 Mo Sulphides Molybdenum disulphides (such as $\mathrm{MoS}_{2}$ ) have been extensively used as HER catalysts because 

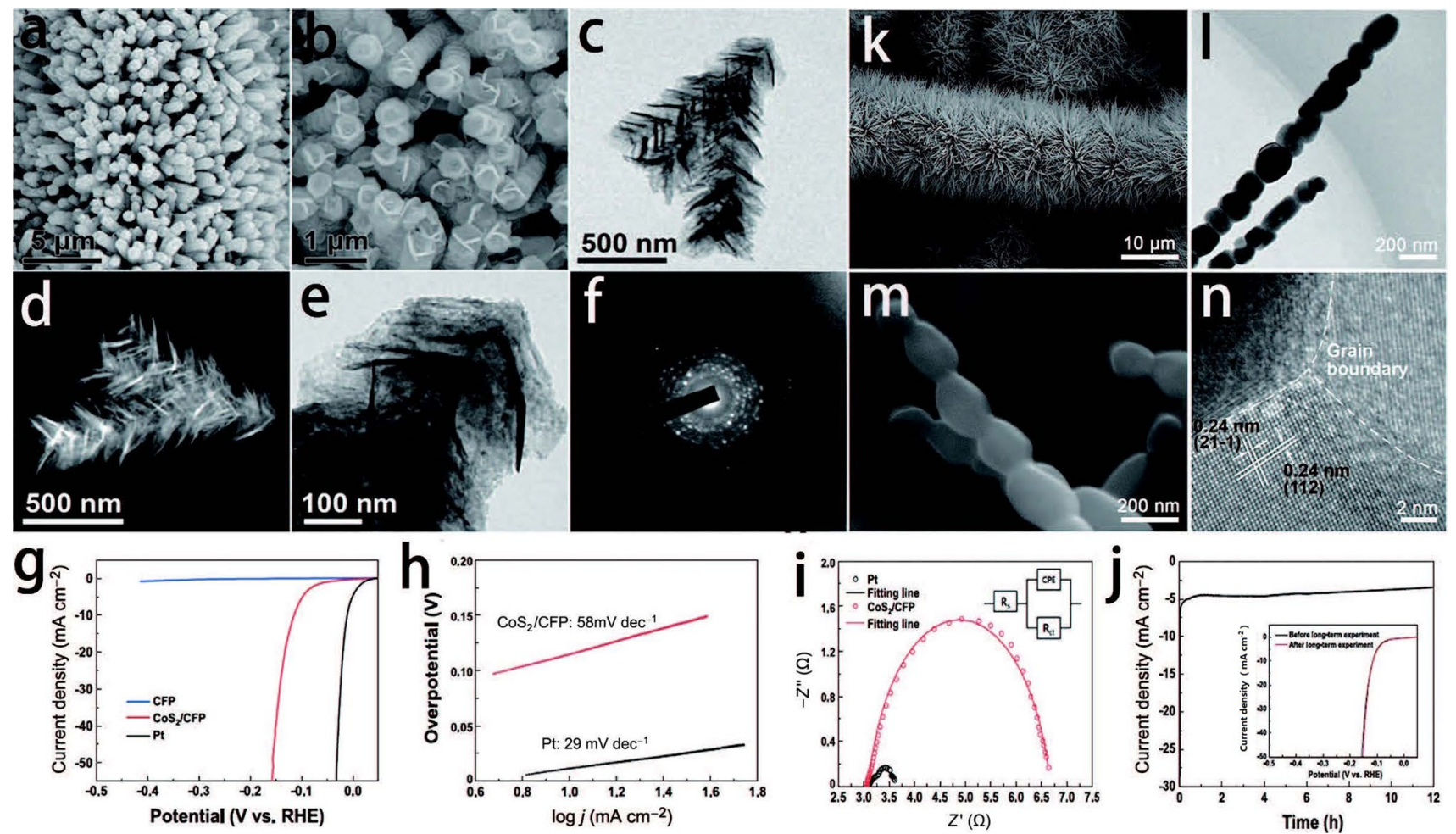

Fig. 20 a-f SEM, TEM and SAED patterns of $\mathrm{CoS}_{2}$ nanopine tree array. $\mathbf{g}-\mathbf{j}$ Polarization curve, Tafel slope, EIS spectra and long-term stability test of $\mathrm{CoS}_{2}$ [300]. k-n SEM images and TEM images of the necklace-like CoSe ${ }_{2}$ NWs on CFP (selenized at $450{ }^{\circ} \mathrm{C}$ ) [302]

of their special structural and electronic properties in which the electrocatalytic properties of $\mathrm{MoS}_{2}$ are highly dependent on the exposed edges [305-311]. For example, Yan et al. [306] reported the synthesis of ultrathin $\mathrm{MoS}_{2}$ nanoplates with rich active sites through a facile solvent dependent control route. The formation of the ultrathin nanoplates was confirmed by the SEM and the TEM (Fig. 21a-d), and the researchers found that this highly novel synthesis route offered three advantages: (1) the resulting ultrathin $\mathrm{MoS}_{2}$ nanoplates were rich with basal edges, leading to increased active sites; (2) the introduction of active $\mathrm{S}$ ligands into the ultrathin plate-like $\mathrm{MoS}_{2}$ structure led to a more efficient $\mathrm{MoS}_{2}$ catalyst for HERs than simple $\mathrm{MoS}_{2}$; and (3) the direct growth of ultrathin $\mathrm{MoS}_{2}$ nanoplates through the solvent dependent method with only source precursors is facile and controllable. In this study, the resulting catalyst achieved a high catalytic activity with an overpotential value of $90 \mathrm{mV}$ and a Tafel slope value of $53 \mathrm{mV} \mathrm{dec}{ }^{-1}$ (Fig. $21 \mathrm{~m}-$ p). In another study, Shi et al. [307] grew $\mathrm{MoS}_{2}$ nanosheets on the surface of commercially available Ti plates and found that the as-synthesized catalyst worked under all $\mathrm{pH}$ values.

The morphology of $\mathrm{MoS}_{2}$ is crucial for HER catalysis [312, 313], and in a recent study, Cao et al. [310] reported an amorphous $\mathrm{MoS}_{2}$ composite with highly active carbon black (CB) that was synthesized through a one-pot hydrothermal method. Here, the obtained porous $\mathrm{MoS}_{2}$ displayed more active sites and a higher intrinsic activity than crystalline $\mathrm{MoS}_{2}$. An ultrathin $\mathrm{MoS}_{2} / \mathrm{C}_{3} \mathrm{~N}_{4}$ nanosheet composite was also fabricated by $\mathrm{Li}$ et al. [311] using graphitic carbon nitride (Fig. 21i-1), and the researchers found that $\mathrm{C}_{3} \mathrm{~N}_{4}$ can provide more metal coordination sites and offer more active sites that resulted in higher catalytic activities. Other $\mathrm{MoS}_{2}$ composites possessing carbon or graphene also presented similar effects because of the intrinsically high electrical conductivity of carbon materials [312].

Overall, molybdenum sulphides, including crystalline $\mathrm{MoS}_{2}$ and amorphous $\mathrm{MoS}_{2}$, are gaining enormous attention from researchers because of their low costs, high earth abundance, increased electrical conductivity and better stability. These nanostructured materials are generally synthesized through mechanical exfoliation [314], chemical exfoliation [315, 316], chemical vapour deposition (CVD) [317-319], solvothermal [320, 321] and electrodeposition methods [322] in preparation for employment as HER catalysts. However, despite these developments, there is still a need for strategies to prevent the agglomeration of amorphous $\mathrm{MoS}_{2}$ to expose more active sites.

3.1.2.7 Mo Phosphides Mo phosphides are also potential candidates for HERs in alkaline electrolysis because the high electrical conductivity of these phosphides gives them an edge over other Mo compounds, and many different meth- 

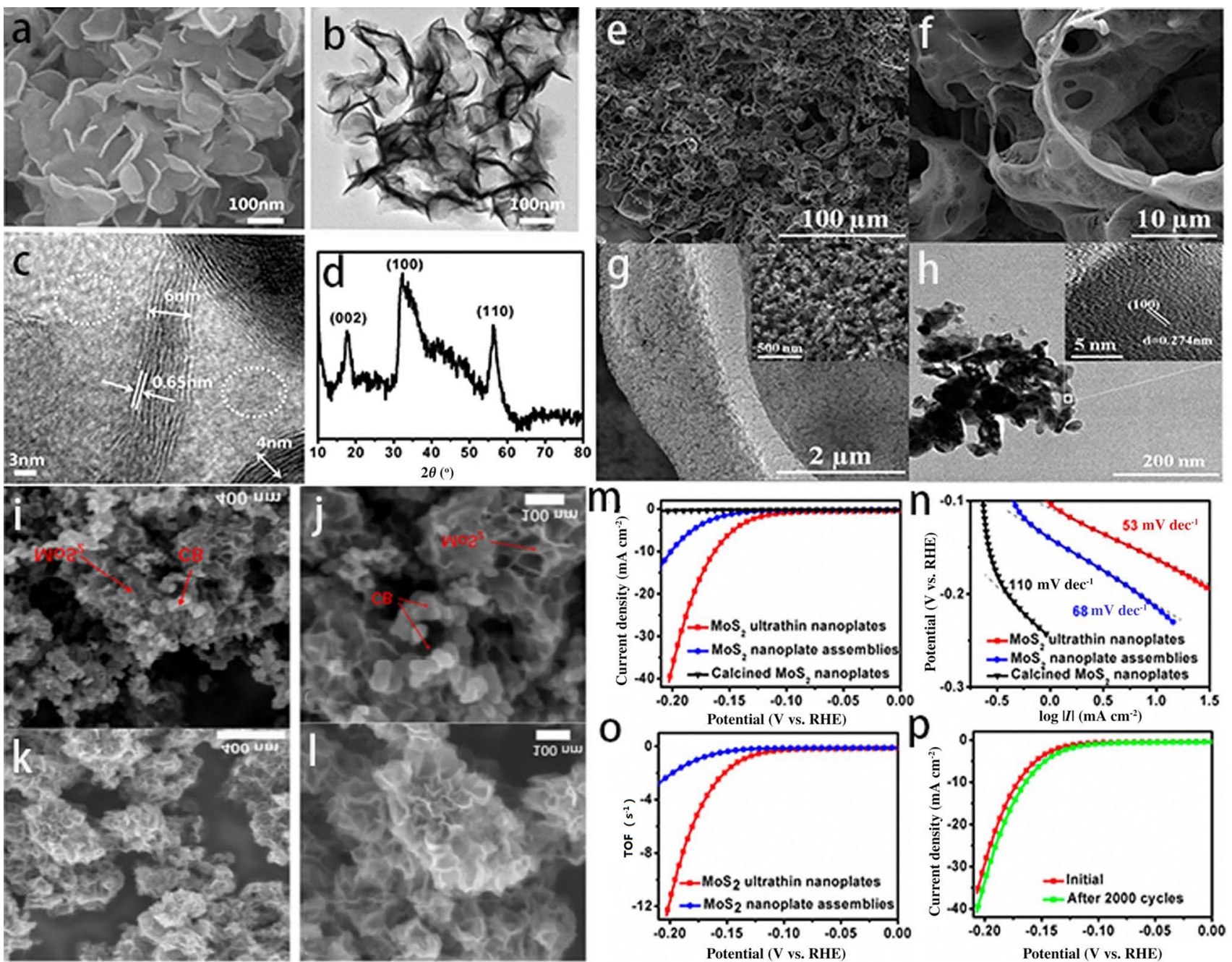

Fig. 21 a-d FESEM, TEM, high-resolution (HR) TEM and XRD patterns of ultrathin $\mathrm{MoS}_{2}$ nanoplates. m-p Polarization curves, corresponding Tafel plots, calculated turnover frequencies of various samples and stability test for the ultrathin $\mathrm{MoS}_{2}$ nanoplates [306].

ods have been adopted to enhance the electrocatalytic performance of these phosphides, including the binder-free approach and templated synthesis towards flexible phosphides [323-326]. In one example, Deng et al. [327] reported the synthesis of a high-performing 3D MoP sponge as a nonprecious metal electrocatalyst for HERs in alkaline media in which the 3D sponge-like morphology was obtained by using a template-assisted route. Usually, template synthesis methods increase catalyst costs, however, in this study, an inexpensive sponge polyurethane (PU) was used as the template, which made this process cost-effective. The resulting catalyst subsequently was found to possess a large surface area and a porous channel-rich structure, in which the side walls of the pores were composed of nanoparticles (Fig. 21e-h). These desirable characteristics allowed the catalyst to achieve a current density of $10 \mathrm{~mA} \mathrm{~cm}{ }^{-2}$ with an overpotential value of only $105 \mathrm{mV}$ and a Tafel slope of $126 \mathrm{mV} \mathrm{dec}^{-1}$.

i-l SEM images of different samples of $\mathrm{MoS}_{2}$ [312]. e-f SEM images of 3D MoP-650 at different magnifications. $\mathbf{g}-\mathbf{h}$ TEM images of 3D MoP-650, the insets show HRTEM images [327]

As discussed in earlier sections, hybrid materials with the RGO, the $\mathrm{CB}$ and the GC possess high electrocatalytic activities; therefore, hybrid materials of Mo phosphides are also promising candidates for HERs [328]. For example, Ojha et al. [321] reported a composite of reduced graphene oxide (RGO) and MoP that displayed highly efficient HER catalytic activities in both acidic and basic media in which the reported catalyst proved a good electrocatalytic performance in terms of overpotential and stability with an overpotential of $80 \mathrm{mV}$ and a Tafel slope of $51 \mathrm{mV} \mathrm{dec}^{-1}$ in the alkaline medium.

3.1.2.8 Mo Carbides Molybdenum carbides $\left(\mathrm{Mo}_{2} \mathrm{C}\right)$ are interstitial alloys which are generally produced by the incorporation of carbon atoms into the lattices of the transition metal Mo [329-332]. And despite recent advancements in $\mathrm{Mo}_{2} \mathrm{C}$, it 
is still challenging to develop facile, controllable methods for the synthesis of $\mathrm{Mo}_{2} \mathrm{C}$. To address this challenge, Liu et al. [333] reported the synthesis of $\mathrm{Mo}_{2} \mathrm{C}$ with $3 \mathrm{D}$ ultrafine $\mathrm{Mo}_{2} \mathrm{C}$ nanocrystals well distributed in carbon nanofibres through a facile electrospinning and pyrolysis route. Here, SEM and TEM images revealed a 1D interconnected structure for the as-prepared hybrid of $\mathrm{C}-\mathrm{Mo}_{2} \mathrm{C} / \mathrm{C}$ and the resulting catalyst achieved an overpotential value of $92 \mathrm{mV}$ and a Tafel slope value of $63 \mathrm{mV} \mathrm{dec}^{-1}$ in $1 \mathrm{M} \mathrm{KOH}$ solution.

To further improve the performance of $\mathrm{Mo}_{2} \mathrm{C}$, nitrogen doping has been shown to enhance HER performance in several studies [333-337]. In a recent study, Jiang et al. [334] synthesized $\mathrm{N}$-doped $\mathrm{Mo}_{2} \mathrm{C}$ nanoparticle catalysts through a one-step solid-state electrocatalytic reduction of well-mixed $\mathrm{MoS}_{2}$ and polypyrrole nanofibres in molten $\mathrm{CaCl}_{2}$ at $850{ }^{\circ} \mathrm{C}$ (Fig. 22a). Here, the $\mathrm{N}$-doping was found to increase the exposure of active sites and modify the electronic structure of $\mathrm{Mo}_{2} \mathrm{C}$, resulting in a catalyst that can operate under all $\mathrm{pH}$ values (0 14) and achieve a current density of $10 \mathrm{~mA} \mathrm{~cm}^{-2}$ with an overpotential value of $73 \mathrm{mV}$ and a Tafel slope value of $59.6 \mathrm{mV} \mathrm{dec}^{-1}$. From these promising results, it can be seen that molybdenum carbides and doped molybdenum carbides have the potential as HER catalysts in alkaline media.

Recent developments in molybdenum-based compounds (including sulphides, phosphides and carbides) have significant impacts on HER electrocatalytic performances because of their unique conductivity, chemical and thermal stability as well as their comparable catalytic property to stateof-the-art Pt group metals. However, despite the numerous enhancements in Mo-based compounds as HER catalysts, the development of facile and reliable techniques for controlled synthesis of nanostructured materials is still required.

\subsection{Catalysts for HER in PEM Electrolysis}

\subsubsection{Noble Metals}

Hydrogen evolution reactions (HERs) in PEM electrolysis are a crucial process, and in general, noble metals ( $\mathrm{Pt}$ and Pd) are used as cathode catalysts. However, because of the scarcity and high cost of these noble metals, they are unsuitable for commercial applications. Therefore, to decrease the
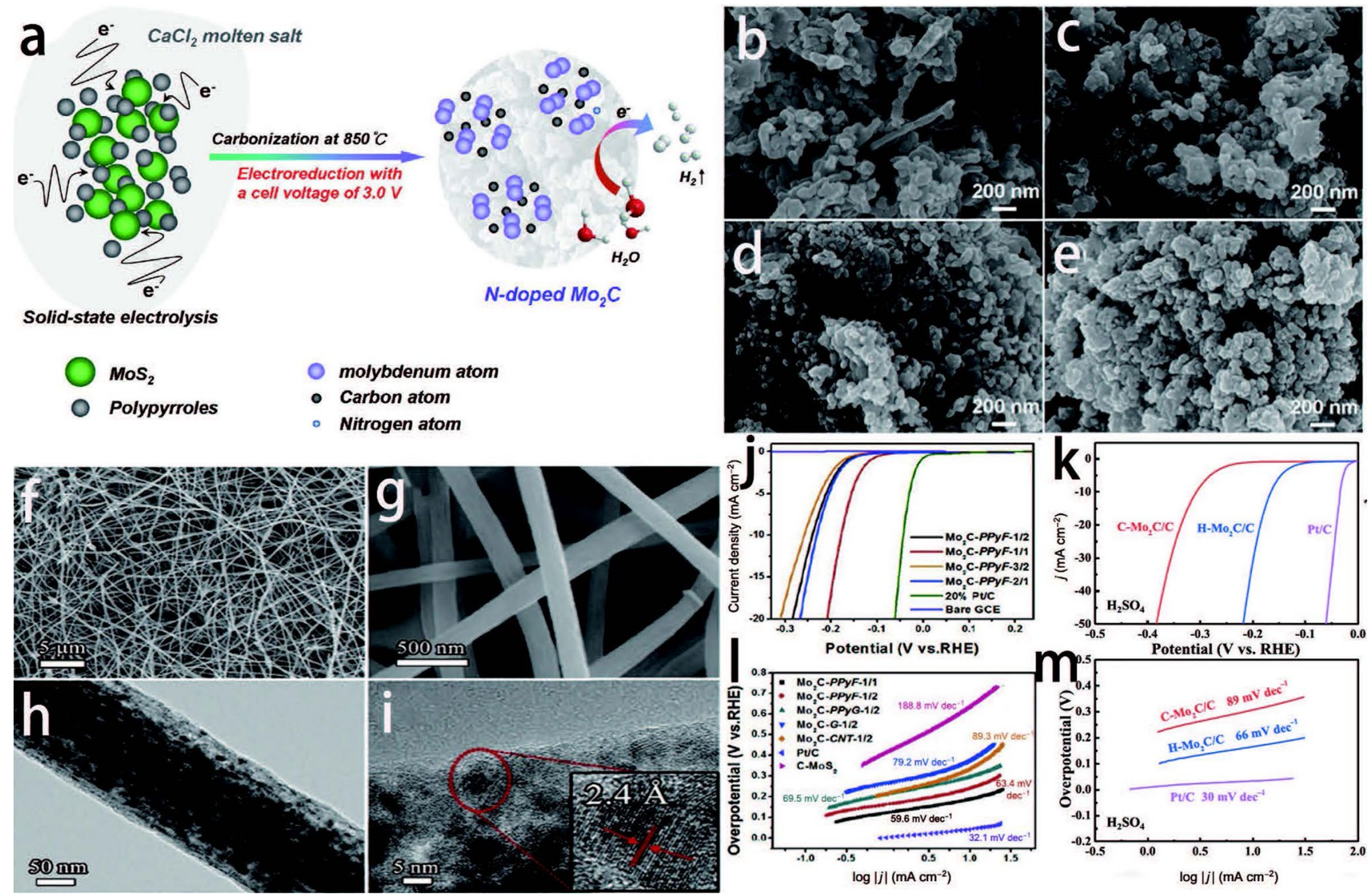

Fig. 22 a Synthetic process of $\mathrm{N}$-doped $\mathrm{Mo}_{2} \mathrm{C}$ catalysts. b-e SEM images of different $\mathrm{Mo}_{2} \mathrm{C}$. $\mathbf{j}-\mathbf{m}$ Polarization curve, Tafel slope and Nyquist plot of different $\mathrm{Mo}_{2} \mathrm{C}$ samples [336]. f-i SEM and TEM images of $\mathrm{C}-\mathrm{Mo}_{2} \mathrm{C} / \mathrm{C}$ [333] 
operational cost of PEM electrolysis, three different strategies have been adopted: (1) reducing noble metal loading; (2) using less expensive noble metals; and (3) developing alternative low-cost non-noble metal electrocatalysts.

In an example of noble metal catalysts for PEM electrolysis, Grigoriev et al. [338] synthesized Pt and Pd nanoparticles on the surface of graphitic nanofibres (GNFs) using chemical vaporization techniques (CVD). Here, TEM images confirmed the homogeneous deposition of Pt nanoparticles on the surface of the graphitic carbon and in comparison, with Vulcan X72 as a support for Pt nanoparticles, the nanoparticles synthesized on GNFs were relatively thinner and possessed a facetted structure which provided long-term stability in PEM electrolysis. Furthermore, strong interactions between the nanoparticles and the support material were also observed in the reported catalyst and the catalyst demonstrated better performances with the same Pt loading (40 wt \%) than that of the Pt/XC-72 [338, 339].

Various forms of carbon, such as carbon nanotubes (CNTs), fullerenes, carbon back (CB) and graphenes can also be used as supports for noble metals in PEM electrolysis [340, 341]. This is because these carbon materials possess high electrical conductivities, large surface areas, high stabilities and are inexpensive. In addition, further improvements to the carbon materials can be achieved through doping them with nitrogen to form nitrogen-doped carbon nanotubes (NCNTs). This strategy has been proven to be successful due to the excellent electrical conductivity of the resulting product [342]. In a recent study, Ramakrishna et al. [341] supported Pd electrocatalysts onto the surface of nitrogen-doped CNTs and their resulting catalyst demonstrated enhanced catalytic activity towards HERs. In this study, SEM micrographs revealed that the NCNTs were $100 \mu \mathrm{m}$ in length with diameters of 50 60 nm (Fig. 23a, b, e) and that the Pd catalysts were uniformly distributed on the surface of NCNTs with diameter sizes ranging from 40 to $60 \mathrm{~nm}$. The researchers in this study attributed the enhanced catalytic activities of the resulting catalyst to the higher activity of the substrate.

\subsubsection{Non-noble Metal}

To allow PEM electrolysis to be more cost-effective, transition metal carbides (TMCs) are being explored to replace noble metal catalysts. This is because various transition metal carbides are known to possess similar electronic properties as Pt catalysts. In addition, the transition metals used in commonly explored TMC catalysts (Ti, V, Mo, Ta, W) are significantly more abundant and less expensive. TMCs cannot be used as electrocatalysts on their own because they showed a higher over potential of 200 300 mV compared to pore Pt. However, instead, they are used as support materials
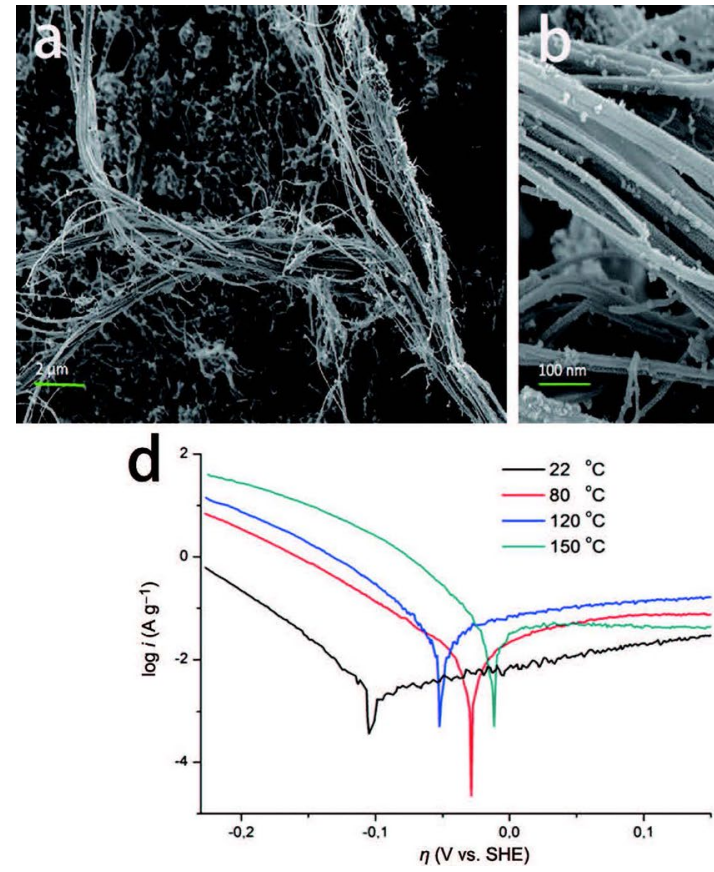

Fig. 23 a, b FESEM images of NCNTs. e Current voltage polarizations of $30 \mathrm{wt} \% \mathrm{Pd} / \mathrm{NCNTs}$ MEA in a $1 \mathrm{~cm}^{2}$ area single-cell assembly at various temperatures [343]. c SEM image of WC powder, produced
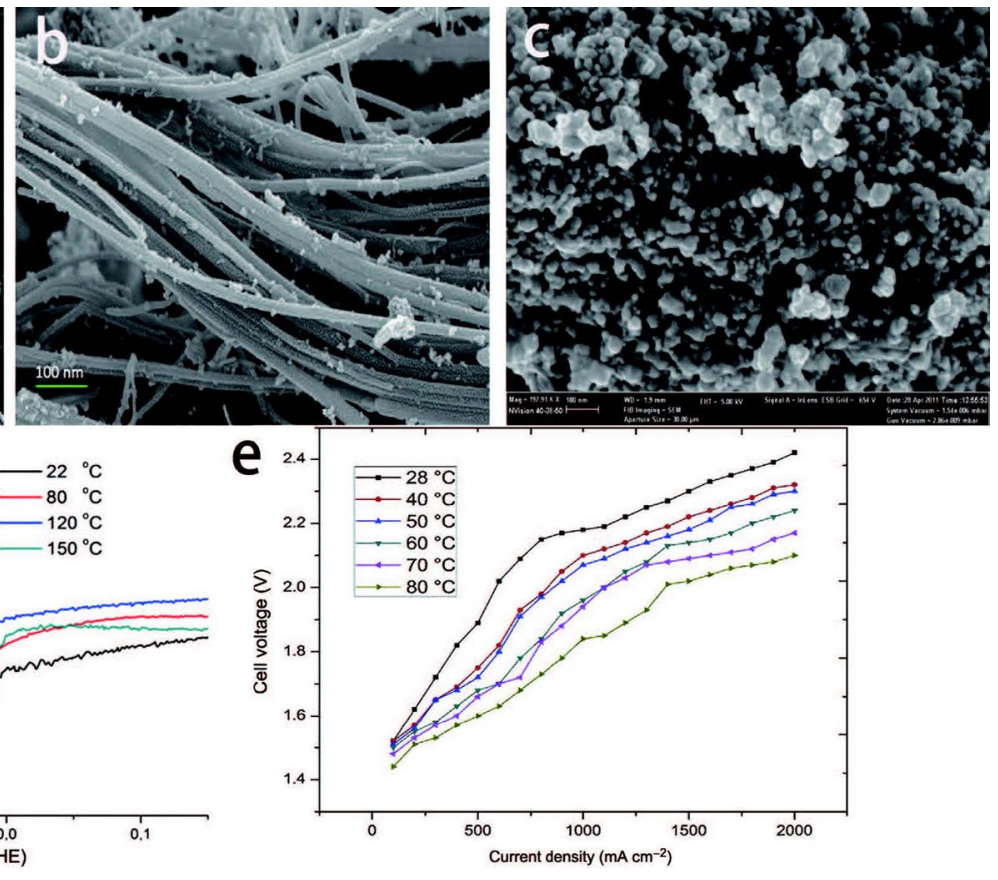

in a plasma reactor after carburization. d Tafel curves obtained for platinum electrodes at different temperatures in $85 \%$ phosphoric acid at a scan speed of $1 \mathrm{mV} \mathrm{s}^{-1}$ [344] 
for noble metals, which reduce Pt loading and subsequently decrease PEM electrolysis operational costs [343, 345-349].

In a study conducted by Kelly et al. [345], Pd supported on tungsten carbide (WC) and molybdenum carbide $\left(\mathrm{Mo}_{2} \mathrm{C}\right)$ was evaluated for the HER activity. As identified, Pd is less expensive than $\mathrm{Pt}$ and they share similar electronic and catalytic properties. And by using $\mathrm{Mo}_{2} \mathrm{C}$ and $\mathrm{WC}$ as support materials, a monolayer Pd catalyst layer was formed which decreased metal loading and therefore costs. In another study conducted by Meyers et al. [346], a comparative study was carried for Pt, Pd and gold ( $\mathrm{Au}$ ) supported on metal carbides which showed promising results.

In another study, Nikiforov et al. [343] attempted to replace Pt catalysts with tungsten carbide (WC) through synthesis using the plasma synthesis method followed by carbonization. Here, SEM and TEM images confirmed the formation of nanopowders with a maximum particle size of $20 \mathrm{~nm}$ and the effects of temperature on the electrocatalytic property of the catalysts (both Pt and WC) were investigated. In the obtained results, the researchers found that temperature had a profound effect on the performance of WC, in which maximum HER activities were observed at $150{ }^{\circ} \mathrm{C}$ (Fig. 23c, d).

\subsection{HER Catalysts in SOECs}

\subsubsection{Noble Metals}

For HERs in SOECs, the most commonly used noble metal catalysts are $\mathrm{Pt}$ and $\mathrm{Pt} / \mathrm{C}$ because they are regarded as the most electrocatalytically active. However, aside from the high cost of $\mathrm{Pt}$, extreme sensitivity to $\mathrm{Pt}$ poisoning is a major drawback of Pt catalysts in SOECs [350-352]. Therefore, as an alternative, Pd catalysts have been investigated by researchers [353] and in recent years, attention has also been given to $\mathrm{IrO}_{2}$ and $\mathrm{RuO}_{2}$ catalysts. Further improvements in noble metal catalysts can also be made by using carbon as a support material. This is because the use of carbon supported metals presents several advantages, including increased triple phase boundaries for electrochemical reactions, easier release of hydrogen gas because of the porous nature of metal catalyst and increased intrinsic conductivity of metals. In 2010, Cheng et al. [354] synthesized carbon supported $\mathrm{IrO}_{2}$ and $\mathrm{RuO}_{2}$ and studied its use for the HER in SOECs and performed the TEM to investigate the physical properties of the catalyst. However, aside from this, there has not been much exploration in this field for SOECs, and very little work has been done in this direction.

\subsubsection{Non-noble Metals}

The SOEC is the reverse of the SOFC; therefore, the anode/ cathode of SOFCs can be used as the cathode/anode for
SOECs. For example, Ni-YSZ is commonly used as an anode in SOFCs and is also a common hydrogen electrode of SOECs. Despite this, this catalyst possesses poor redox stabilities and requires a high concentration of $\mathrm{H}_{2}$ to protect the Ni from oxidation. The cause for this is the agglomeration of $\mathrm{Ni}$ particles during long-term high-temperature operations [355-357]. This issue can be minimized, however, by using redox stable perovskite oxides as the hydrogen electrode. For example, Cao et al. [358] reported the use of $\mathrm{La}_{0.3} \mathrm{Sr}_{0.7} \mathrm{Ti}_{0.3} \mathrm{Fe}_{0.7} \mathrm{O}_{3-\sigma}$ (LSTF) as a novel symmetrical electrode coated on an SDC $\left(\mathrm{Sm}_{0.2} \mathrm{Ce}_{0.8} \mathrm{O}_{1.9}\right)$-YSZ (yttria-stabilized zirconia)-SDC electrolyte. In their results, the LSTF demonstrated a good redox stability and excellent electrocatalytic activities in both anodic and cathodic conditions with maximum power densities of 215, 293 and $374 \mathrm{~mW} \mathrm{~cm}^{-2}$ being achieved at 800,850 and $900{ }^{\circ} \mathrm{C}$, respectively. The LSTF also demonstrated good short-term stability and reliable redox stability. Based on this, it is expected that LSTF can be a promising electrode material for SOECs.

$\mathrm{SrFeO}_{3-\sigma}$-based $\mathrm{ABO}_{3}$-type perovskites, despite their low redox stabilities, are also being explored as hydrogen electrodes for both SOFCs and SOECs in which the electrocatalytic performance of $\mathrm{ABO}_{3}$ type perovskites can be enhanced by A site or B site doping, which can affect crystal lattice and physical properties. In a study conducted by Liu et al. [359], the effects of the substitution of Ti for Fe on the phase structure, electrical conductivity, chemical compatibility with electrolytes and electrochemical performance of $\mathrm{SrFe}_{1-x} \mathrm{Ti}_{x} \mathrm{O}_{3-\sigma}$ were investigated. Here, it was found that the presence of $\mathrm{Ti}^{3+} / \mathrm{Ti}^{4+}$ ions in the $\mathrm{B}$ site stabilized the neighbouring oxygen octahedral $\left(\mathrm{BO}_{6}\right)$, leading to structural stability. An increase in thermal expansion and decrease in conductivity and electrochemical performance were also observed with increasing Ti content.

Therefore, perovskites, double perovskites and substituted $\mathrm{ABO}_{3}$ type perovskites are potential candidates for application as cathodes in SOECs operating at high or intermediate temperatures with important cathode materials studied in recent years being composed of $\mathrm{Sr}_{2} \mathrm{Fe}_{1.5} \mathrm{Mo}_{0.5} \mathrm{O}_{6-\delta}$ [360], $\mathrm{La}_{0.4} \mathrm{Sr}_{0.6} \mathrm{Co}_{0.2} \mathrm{Fe}_{0.7} \mathrm{Nb}_{0.1} \mathrm{O}_{3-\delta}$ [361], $\mathrm{La}_{0.7} \mathrm{Sr}_{0.3} \mathrm{Fe}_{0.7} \mathrm{Ga}_{0.3} \mathrm{O}_{3-\delta}$ [362], $\mathrm{La}_{0.6} \mathrm{Sr}_{0.4} \mathrm{Co}_{0.8} \mathrm{Fe}_{0.2} \mathrm{O}_{3}$ [363], $\mathrm{CeO}_{2}-\mathrm{LaFeO}_{3}$ [364], $\mathrm{SrFe}_{0.75} \mathrm{M}_{0.25} \mathrm{O}_{3-\delta}(\mathrm{M}=\mathrm{Ti}, \mathrm{Zr}, \mathrm{V}, \mathrm{Nb}, \mathrm{Cr}, \mathrm{Mo}, \mathrm{W})$ [365], $\mathrm{LaSr}_{2} \mathrm{Fe}_{2} \mathrm{CrO}_{9-\delta}$ [366] and Pr-substituted $\mathrm{SrTiO}_{3}[367,368]$.

\section{Summary, Challenges and Future Aspects}

\subsection{Summary}

Water electrolysis, seen as an efficient process to generate hydrogen and pure oxygen, is an emerging field of research for energy storage and conversion. Presently, alkaline and PEM electrolysis are considered mature technologies, 
whereas the SOEC is still at the laboratory scale. To increase water electrolysis energy efficiencies, both HER and OER processes, the two necessary reactions in water electrolysis, must be improved kinetically. Here, noble metals are considered to be the best electrocatalysts, however, associated issues such as high cost and low abundance of noble metals hinder the commercialization of water electrolysis technologies. And although improvements have been made to reduce noble metal loading through the modification of material compositions and morphologies or through the replacement of noble metals with non-noble metal-based catalysts, significant progresses have been insufficient.

In the case of alkaline electrolysis, various transition metal compounds, such as Ni-, Co-, $\mathrm{Mn}$ - and Fe-based compounds as well as their oxides $\left(\mathrm{MO}_{x}\right)$, phosphides $\left(\mathrm{MP}_{x}\right)$, sulphides $\left(\mathrm{MS}_{x}\right)$ and alloys $\left(\mathrm{MM}^{\prime}\right)$, have been extensively studied in recent years in an attempt to replace noble metal catalysts for both OERs and HERs in water electrolysis. Here, catalytic performance enhancements have been carried out by using several different approaches, including the increase of electrical conductivity through alloying, the improvement of stability and conductivity through synthesizing bimetallic compounds, and the creation of synergetic effects by using hybrid compounds through combining intrinsically conductive carbon with chemically reactive metal compounds. In addition, the effects of morphology on electrocatalytic performance were extensively reviewed in literature by using template-assisted and template-less fabrication techniques. Furthermore, the role of electrodes (substrate) in enhancing electrocatalytic performances has also been explored by using different substrates such as carbon cloth, graphitic carbon, carbon black and nickel foam (NF). Promising 3D materials can be obtained by using the nickel foam (NF) as a substrate, which possesses long-range porous structures that can facilitate charge transfer and mass transport.

In the case of PEM electrolysis, non-noble metal catalysts that are capable of providing efficient performances have not yet been discovered. This is because very few nonnoble metal catalysts are tolerant of the acid electrolytes used in PEM electrolysis. However, although pure non-noble metals are not suitable as catalysts for OER, they can be used as dopants or supports for noble metals. Non-precious transition metal oxides or carbides such as niobium oxide $\left(\mathrm{Nb}_{2} \mathrm{O}_{2}\right)$, tin oxide $\left(\mathrm{SnO}_{2}\right)$, tantalum oxide $\left(\mathrm{Ta}_{2} \mathrm{O}_{5}\right)$, titanium oxide $\left(\mathrm{TiO}_{2}\right)$, WC and $\mathrm{TiC}$ can be used as electrode materials to reduce noble metal loading and decrease overall operational costs, but these supports do not show any activity for OER in PEM electrolysis. Therefore, noble metals are still necessary for PEM electrolysis with the replacement of noble metals with non-noble metal catalysts for OERs being still unattainable. Because of this, more stable nonnoble metal-based electrocatalysts need to be designed and created, such as $\mathrm{Fe}-\mathrm{N}-\mathrm{C}$ and $\mathrm{Co}-\mathrm{N}-\mathrm{C}$.
In general, OER and HER catalysts for SOECs operating at high temperatures are unstable. In addition, the active surface area of electrodes needs to be enlarged and three key factors, including ionic conductivity, electronic conductivity and catalytic activity, need to be studied. SOFCs and SOECs are the reverse processes of one another, and therefore, the anode material of SOFCs can be used as the cathode material of SOECs and vice versa, and in general, noble metals are efficient catalysts for anodic and cathodic processes in SOECs operating at high temperatures. Therefore, to make the SOEC process more cost-effective for practical applications, the cost of the catalyst must be reduced and to achieve this, various non-precious catalysts have been studied. For OERs, non-noble metal catalysts include two different types of materials: (1) Ceramic materials that possess good ionic and electrical conductivities such as SFM, LSV, LSCM, LSM. These materials suffer from issues such as low electrocatalytic activity and stability, however. (2) Composite electrodes, such as Ni-YSZ, Ni-SDC, LSC-YSZ and LSM-YSZ possess enhanced catalytic activities and thermal expansion matching with electrolytes. As for the HER process in SOECs, perovskites, double perovskites and substituted $\mathrm{ABO}_{3}$-type perovskites have been explored as potential candidates for application as cathodes operating at high or intermediate temperatures.

There has been extensive research into noble metal-based and non-noble metal-based catalysts for HERs and OERs in the three different technologies of water electrolysis in recent years, and although these studies have provided many innovative ideas to develop efficient, inexpensive and stable catalysts for water electrolysis in different systems, many technical challenges remain and are discussed as follows.

\subsection{Challenges in Water Electrolysis Catalysts}

Because of the high cost of noble metal-based catalysts, non-noble metal catalysts for OER and HER processes have been extensively studied in the past few years in an attempt to reduce or replacement noble metal usage and recent developments have shown promise towards commercialization. However, several challenges remain in the production of low-cost non-noble electrocatalysts, including: (1) low electrical conductivity of transition metal compounds for OERs and HERs; (2) fundamental problem of corrosion for carbon-based hybrid catalysts in the electrolysis process for both alkaline and acidic media; (3) non-active nature of transition metal oxides for PEM electrolysis; (4) limited knowledge of catalytic mechanisms of non-noble metal catalysts employed in alkaline media; (5) corrosion of proton ion membranes caused by transitional metals $(\mathrm{Fe}$ and $\mathrm{Cu}) ;(6)$ insufficient stability of ceramic catalyst materials for OERs and HERs in SOECs operating at high temperatures; and (7) a potential drop due to excessive loading of non-noble 
metal at the anode. (8) Development of bifunctional catalysts for both OER and HER catalysts is still a challenge as the synthesis process is complicated. (9) Up to this point many catalysts have been synthesized with better performance than noble metals in one aspect only; the problem is to develop a catalyst which can surpass noble metals in all aspects. (10) Synthesis method has a direct relation with the catalysis performance, as it affects the structure of catalysts.

\subsection{Possible Research Directions}

Despite the numerous challenges faced by water electrolysis catalysts, there are many new research opportunities for scientists to develop new, highly efficient catalysts for OER and HER processes. Research directions that can be explored in the future include:

1. The development of new, facile and cost-effective methods for the synthesis of non-precious metal-based catalysts for OERs and HERs with high electrocatalytic performances. These new electrocatalyst synthesis methods can be either template or template-less methods, but they need to be inexpensive and be capable of producing catalysts with special structures that possess highly active surface area. Other than this, the development of novel techniques for the design/preparation/fabrication of catalysts is needed, which should be helpful in controlling catalyst morphologies.

2. The fundamental understanding of catalytic mechanisms to select and design new OERs and HERs catalysts. Here, catalytic reaction mechanisms of transition metal-based catalysts under different $\mathrm{pH}$ and temperature conditions require further exploration. Presently, not only are the mechanisms of water electrolysis electrocatalytic reactions in alkaline media unclear, the active centre cannot be identified with accuracy either. Further improvements in performance can be made with deeper understandings of the complete mechanism, which can lead to improved synthesis methods and doping strategies. Therefore, both theoretical calculations and experimental validations of catalytic mechanisms, such as DFT calculations on atomic levels, need to be carried out to gain deeper understandings of the catalytic process.

3. The further exploration of low-/non-noble metal-based catalysts for OERs and HERs in PEM electrolysis. There is a need to develop low-/non-noble metal catalysts that can operate in strong acidic conditions $(\mathrm{pH}<3)$. In addition, these catalysts should also ideally possess high electrocatalytic performances comparable to state-ofthe-art noble metal catalysts along with high stabilities.

4. The development of low-/non-noble metal-based catalyst materials for OERs and HERs in SOECs. Because electrode material degradation is a major challenge in SOECs, a thorough understanding of the degradation mechanisms of ceramic-based catalysts is necessary.
This understanding can pave pathways towards the development of new catalytic materials for SOECs.

Overall, these future research directions will hopefully address current challenges in the development of effective and widely applicable strategies for non-noble metal-based catalysts for water electrolysis.

Acknowledgements We gratefully acknowledge the financial support from the National Key Research and Development Program of China (2017YFB0102900) and Shanghai Pujiang Program (17PJD016).

\section{Compliance with Ethical Standards}

Conflict of interest The authors declare that they have no conflicts of interest.

Open Access This article is distributed under the terms of the Creative Commons Attribution 4.0 International License (http://creativeco mmons.org/licenses/by/4.0/), which permits use, duplication, adaptation, distribution and reproduction in any medium or format, as long as you give appropriate credit to the original author(s) and the source, provide a link to the Creative Commons license and indicate if changes were made.

\section{References}

1. Nikolaidis, P., Poullikkas, A.: A comparative overview of hydrogen production processes. Renew. Sustain. Energy Rev. 67, 597-611 (2017)

2. Singh, S., Jain, S., Venkateswaran, P.S., et al.: Hydrogen: a sustainable fuel for future of the transport sector. Renew. Sustain. Energy Rev. 51, 623-633 (2015)

3. Hassmann, K., Kühne, H.M.: Primary energy sources for hydrogen production. Int. J. Hydrog. Energy 18, 635-640 (1993)

4. López Ortiz, A., Meléndez Zaragoza, M.J., Collins-Martínez, V.: Hydrogen production research in Mexico: a review. Int. J. Hydrog. Energy 41, 23363-23379 (2016)

5. Sharma, S., Ghoshal, S.K.: Hydrogen the future transportation fuel: from production to applications. Renew. Sustain. Energy Rev. 43, 1151-1158 (2015)

6. Veziroğlu, T.N., Sahin, S.: 21st Century’s energy: Hydrogen energy system. Energy Convers. Manag. 49, 1820-1831 (2008)

7. Marbán, G., Valdés-Solís, T.: Towards the hydrogen economy? Int. J. Hydrog. Energy 32, 1625-1637 (2007)

8. Sobrino, F.H., Monroy, C.R., Pérez, J.L.H.: Critical analysis on hydrogen as an alternative to fossil fuels and biofuels for vehicles in Europe. Renew. Sustain. Energy Rev. 14, 772-780 (2010)

9. Mori, D., Hirose, K.: Recent challenges of hydrogen storage technologies for fuel cell vehicles. Int. J. Hydrog. Energy 34, 4569-4574 (2009)

10. Ball, M., Wietschel, M.: The future of hydrogen—opportunities and challenges. Int. J. Hydrog. Energy 34, 615-627 (2009)

11. Züttel, A.: Hydrogen storage methods. Naturwissenschaften 91, 157-172 (2004)

12. Barbir, F.: Transition to renewable energy systems with hydrogen as an energy carrier. Energy 34, 308-312 (2009)

13. Ahmed, A., Al-Amin, A.Q., Ambrose, A.F., et al.: Hydrogen fuel and transport system: a sustainable and environmental future. Int. J. Hydrog. Energy 41, 1369-1380 (2016)

14. Milazzo, M.F., Spina, F., Primerano, P., et al.: Soy biodiesel pathways: global prospects. Renew. Sustain. Energy Rev. 26, 579-624 (2013) 
15. Achten, W.M.J., Verchot, L., Franken, Y.J., et al.: Jatropha biodiesel production and use. Biomass Bioenergy 32, 1063-1084 (2008)

16. Balat, M., Balat, M.: Political, economic and environmental impacts of biomass-based hydrogen. Int. J. Hydrog. Energy 34, 3589-3603 (2009)

17. Hosseini, S.E., Wahid, M.A.: Hydrogen production from renewable and sustainable energy resources: promising green energy carrier for clean development. Renew. Sustain. Energy Rev. 57, 850-866 (2016)

18. Balat, M.: Hydrogen in fueled systems and the significance of hydrogen in vehicular transportation. Energy Source Part B 2, 49-61 (2007)

19. Muradov, N., Veziroğlu, T.N.: From hydrocarbon to hydrogen-carbon to hydrogen economy. Int. J. Hydrog. Energy 30, 225-237 (2005)

20. Caldwell, D.L.: Production of chlorine. In: Bockris, J.O., Conway, B.E., Yeager, E., et al. (eds.) Comprehensive Treatise of Electrochemistry, pp. 105-166. Springer, Boston (1981)

21. Balat, M.: Potential importance of hydrogen as a future solution to environmental and transportation problems. Int. J. Hydrog. Energy 33, 4013-4029 (2008)

22. Blasi, A., Fiorenza, G., Freda, C., et al.: 6-Steam reforming of biofuels for the production of hydrogen-rich gas. In: Gugliuzza, A., Basile, A. (eds.) Membranes for Clean and Renewable Power Applications, pp. 145-181. Woodhead Publishing, Cambridge (2014)

23. Serban, M., Lewis, M.A., Marshall, C.L., et al.: Hydrogen production by direct contact pyrolysis of natural gas. Energy \& Fuels 17, 705-713 (2003)

24. Schlapbach, L., Züttel, A.: Hydrogen-storage materials for mobile applications. Nature 414, 353-358 (2001)

25. Carmo, M., Fritz, D.L., Mergel, J., et al.: A comprehensive review on PEM water electrolysis. Int. J. Hydrog. Energy 38, 4901-4934 (2013)

26. Trasatti, S.: Water electrolysis: who first? J. Electroanal. Chem. 476, 90-91 (1999)

27. Choi, P., Bessarabov, D.G., Datta, R.: A simple model for solid polymer electrolyte (SPE) water electrolysis. Solid State Ion. 175, 535-539 (2004)

28. Ursua, A., Gandía, L.M., Sanchis, P.: Hydrogen production from water electrolysis: current status and future trends. Proc. IEEE 100, 410-426 (2012)

29. Holladay, J.D., Hu, J., King, D.L., et al.: An overview of hydrogen production technologies. Catal. Today 139, 244-260 (2009)

30. Tahir, M., Pan, L., Idrees, F., et al.: Electrocatalytic oxygen evolution reaction for energy conversion and storage: a comprehensive review. Nano Energy 37, 136-157 (2017)

31. Laguna-Bercero, M.A.: Recent advances in high temperature electrolysis using solid oxide fuel cells: a review. J. Power Sources 203, 4-16 (2012)

32. Zha, Y., Disabb-Miller, M.L., Johnson, Z.D., et al.: Metalcation-based anion exchange membranes. Chem. Soc. Rev. 134, 4493-4496 (2012)

33. Beainy, A., Karami, N., Moubayed, N.: Simulink model for a PEM electrolyzer based on an equivalent electrical circuit (2015). In: International conference on renewable energies for developing countries 2014, Beirut, Lebanon, 26-27 Nov 2014

34. Nuttall, L.J., Fickett, A.P., Titterington, W.A.: Hydrogen generation by solid polymer electrolyte water electrolysis. In: Veziroğlu, T.N. (ed.) Hydrogen Energy: Part A, pp. 441-455. Springer, Boston (1975)

35. Gong, M., Wang, D.Y., Chen, C.C., et al.: A mini review on nickel-based electrocatalysts for alkaline hydrogen evolution reaction. Nano Res. 9, 28-46 (2016)
36. Zhang, C., Wang, B., Shen, X., et al.: A nitrogen-doped ordered mesoporous carbon/graphene framework as bifunctional electrocatalyst for oxygen reduction and evolution reactions. Nano Energy 30, 503-510 (2016)

37. Oh, J., Mee Lee, J., Yoo, Y., et al.: New insight of the photocatalytic behaviors of graphitic carbon nitrides for hydrogen evolution and their associations with grain size, porosity, and photophysical properties. Appl. Catal. B 218, 349-358 (2017)

38. Busch, M., Halck, N.B., Kramm, U.I., et al.: Beyond the top of the volcano? - a unified approach to electrocatalytic oxygen reduction and oxygen evolution. Nano Energy 29, 126-135 (2016)

39. Wang, J., Liu, J., Zhang, B., et al.: Synergistic effect of two actions sites on cobalt oxides towards electrochemical wateroxidation. Nano Energy 42, 98-105 (2017)

40. Birss, V.I., Damjanovic, A., Hudson, P.G.: Oxygen evolution at platinum electrodes in alkaline solutions II. Mechanism of the reaction. J. Electrochem. Soc. 133, 1621-1625 (1986)

41. Conway, B.E., Liu, T.C.: Characterization of electrocatalysis in the oxygen evolution reaction at platinum by evaluation of behavior of surface intermediate states at the oxide film. Langmuir 6, 268-276 (1990)

42. Zheng, J.: Pt-free NiCo electrocatalysts for oxygen evolution by seawater splitting. Electrochim. Acta 247, 381-391 (2017)

43. Makarova, M.V., Jirkovský, J., Klementová, M., et al.: The electrocatalytic behavior of $\mathrm{Ru}_{0.8} \mathrm{Co}_{0.2} \mathrm{O}_{2-x}$-the effect of particle shape and surface composition. Electrochim. Acta 53, 2656-2664 (2008)

44. Lewis, N.S., Nocera, D.G.: Powering the planet: Chemical challenges in solar energy utilization. Proc. Natl. Acad. Sci. U. S. A. 103, 15729-15735 (2006)

45. Li, H., Tang, Q., He, B., et al.: Robust electrocatalysts from an alloyed $\mathrm{Pt}-\mathrm{Ru}-\mathrm{M}(\mathrm{M}=\mathrm{Cr}, \mathrm{Fe} \mathrm{Co}, \mathrm{Ni}, \mathrm{Mo})$-decorated Ti mesh for hydrogen evolution by seawater splitting. J. Mater. Chem. A 4, 6513-6520 (2016)

46. Liu, X., Wang, X., Yuan, X., et al.: Rational composition and structural design of in situ grown nickel-based electrocatalysts for efficient water electrolysis. J. Mater. Chem. A 4, 167-172 (2016)

47. Hammes-Schiffer, S.: Theory of proton-coupled electron transfer in energy conversion processes. Acc. Chem. Res. 42, 1881-1889 (2009)

48. Stojić, D.L., Marčeta, M.P., Sovilj, S.P., et al.: Hydrogen generation from water electrolysis-possibilities of energy saving. J. Power Sources 118, 315-319 (2003)

49. Luo, B., Yan, X., Xu, S., et al.: Synthesis of worm-like PtCo nanotubes for methanol oxidation. Electrochem. Commun. 30, 71-74 (2013)

50. Man, I., Su, H.Y., Calle-Vallejo, F., et al.: Universality in oxygen evolution electrocatalysis on oxide surfaces. ChemCatChem $\mathbf{3}$, 1159-1165 (2011)

51. Liu, J., Wang, J., Zhang, B., et al.: Hierarchical $\mathrm{NiCo}_{2} \mathrm{~S}_{4} @ \mathrm{NiFe}$ LDH heterostructures supported on nickel foam for enhanced overall-water-splitting activity. ACS Appl. Mater. Interfaces 9, 15364-15372 (2017)

52. Norskov, J.K., Christensen, C.H.: Toward efficient hydrogen production at surfaces. Science 312, 1322 (2006)

53. Lee, S.H., Lee, H., Cho, M., et al.: A layered hollow sphere architecture of iridium-decorated carbon electrode for oxygen evolution catalysis. Carbon 115, 50-58 (2017)

54. Cherevko, S., Geiger, S., Kasian, O.: Oxygen and hydrogen evolution reactions on $\mathrm{Ru}, \mathrm{RuO}_{2}$, Ir, and $\mathrm{IrO}_{2}$ thin film electrodes in acidic and alkaline electrolytes: a comparative study on activity and stability. Catal. Today 262, 170-180 (2016)

55. Danilovic, N., Subbaraman, R., Chang, K.C., et al.: Activity-stability trends for the oxygen evolution reaction on monometallic 
oxides in acidic environments. J. Phys. Chem. Lett. 5, 2474-2478 (2014)

56. Pi, Y., Zhang, N., Guo, S., et al.: Ultrathin laminar Ir superstructure as highly efficient oxygen evolution electrocatalyst in broad pH range. Nano Lett. 16, 4424-4430 (2016)

57. Jiao, Y., Zheng, Y., Jaroniec, M., et al.: Design of electrocatalysts for oxygen- and hydrogen-involving energy conversion reactions. Chem. Soc. Rev. 44, 2060-2086 (2015)

58. Li, G., Li, S., Ge, J., et al.: Discontinuously covered $\mathrm{IrO}_{2}-\mathrm{RuO}_{2} @$ $\mathrm{Ru}$ electrocatalysts for the oxygen evolution reaction: how high activity and long-term durability can be simultaneously realized in the synergistic and hybrid nano-structure. J. Mater. Chem. A 5, 17221-17229 (2017)

59. Liyanage, D.R., Li, D., Cheek, Q.B., et al.: Synthesis and oxygen evolution reaction (OER) catalytic performance of $\mathrm{Ni}_{2-x} \mathrm{Ru}_{x} \mathrm{P}$ nanocrystals: enhancing activity by dilution of the noble metal. J. Mater. Chem. A 5, 17609-17618 (2017)

60. Huang, H., Yu, C., Zhao, C., et al.: Iron-tuned super nickel phosphide microstructures with high activity for electrochemical overall water splitting. Nano Energy 34, 472-480 (2017)

61. Jiang, F., Zheng, T., Yang, Y.: Preparation and electrochromic properties of tungsten oxide and iridium oxide porous films. J. NonCryst. Solids 354, 1290-1293 (2008)

62. Arciga-Duran, E., Meas, Y., Pérez-Bueno, J.J., et al.: Effect of oxygen vacancies in electrodeposited $\mathrm{NiO}$ towards the oxygen evolution reaction: role of $\mathrm{Ni}$-glycine complexes. Electrochim. Acta 268, 49-58 (2018)

63. Babar, P.T., Lokhande, A.C., Gang, M.G., et al.: Thermally oxidized porous $\mathrm{NiO}$ as an efficient oxygen evolution reaction (OER) electrocatalyst for electrochemical water splitting application. J. Ind. Eng. Chem. 60, 493-497 (2018)

64. Zhang, T., Wu, M.Y., Yan, D.Y.: Engineering oxygen vacancy on $\mathrm{NiO}$ nanorod arrays for alkaline hydrogen evolution. Nano Energy 43, 103-109 (2018)

65. Wu, Z., Zou, Z., Huang, J., et al.: Fe-doped NiO mesoporous nanosheets array for highly efficient overall water splitting. J. Catal. 358, 243-252 (2018)

66. Zheng, Z., Geng, W., Wang, Y., et al.: $\mathrm{NiCo}_{2} \mathrm{O}_{4}$ nanoflakes supported on titanium suboxide as a highly efficient electrocatalyst towards oxygen evolution reaction. Int. J. Hydrog. Energy 42, 119-124 (2017)

67. Chen, R., Wang, H.Y., Miao, J., et al.: A flexible high-performance oxygen evolution electrode with three-dimensional NiCo2O4 core-shell nanowires. Nano Energy 11, 333-340 (2015)

68. Yan, K.L., Shang, X., Li, Z., et al.: Ternary mixed metal Fedoped $\mathrm{NiCo}_{2} \mathrm{O}_{4}$ nanowires as efficient electrocatalysts for oxygen evolution reaction. Appl. Surf. Sci. 416, 371-378 (2017)

69. Schoeberl, C., Manolova, M., Freudenberger, R.: Sol-geldeposited cobalt and nickel oxide as an oxygen evolution catalyst in alkaline media. Int. J. Hydrog. Energy 40, 11773-11778 (2015)

70. Xiao, Y., Feng, L., Hu, C., et al.: $\mathrm{NiCo}_{2} \mathrm{O}_{4} 3$-dimensional nanosheet as effective and robust catalyst for oxygen evolution reaction. RSC Adv. 5, 61900-61905 (2015)

71. Zeng, L., Zhao, T.S., Zhang, R.H., et al.: $\mathrm{NiCo}_{2} \mathrm{O}_{4}$ nanowires@ $\mathrm{MnO}_{x}$ nanoflakes supported on stainless steel mesh with superior electrocatalytic performance for anion exchange membrane water splitting. Electrochem. Commun. 87, 66-70 (2018)

72. Chanda, D., Hnát, J., Bystron, T., et al.: Optimization of synthesis of the nickel-cobalt oxide based anode electrocatalyst and of the related membrane-electrode assembly for alkaline water electrolysis. J. Power Sources 347, 247-258 (2017)

73. Cheng, H., Su, Y.Z., Kuang, P.Y., et al.: Hierarchical $\mathrm{NiCo}_{2} \mathrm{O}_{4}$ nanosheet-decorated carbon nanotubes towards highly efficient electrocatalyst for water oxidation. J. Mater. Chem. A 3, 19314-19321 (2015)

74. Ning, Y., Ma, D., Shen, Y., et al.: Constructing hierarchical mushroom-like bifunctional $\mathrm{NiCo} / \mathrm{NiCo}_{2} \mathrm{~S}_{4} @ \mathrm{NiCo} / \mathrm{Ni}$ foam electrocatalysts for efficient overall water splitting in alkaline media. Electrochim. Acta 265, 19-31 (2018)

75. Yang, Y., Zhou, M., Guo, W., et al.: $\mathrm{NiCoO}_{2}$ nanowires grown on carbon fiber paper for highly efficient water oxidation. Electrochim. Acta 174, 246-253 (2015)

76. Shao, Y., Zheng, M., Cai, M., et al.: improved electrocatalytic performance of core-shell $\mathrm{NiCo} / \mathrm{NiCoO}_{x}$ with amorphous $\mathrm{FeOOH}$ for oxygen-evolution reaction. Electrochim. Acta 257, 1-8 (2017)

77. Yan, K.L., Shang, X., Gao, W.K., et al.: Ternary $\mathrm{MnO}_{2} /$ $\mathrm{NiCo}_{2} \mathrm{O}_{4} / \mathrm{NF}$ with hierarchical structure and synergistic interaction as efficient electrocatalysts for oxygen evolution reaction. J. Alloys Compd. 719, 314-321 (2017)

78. Zhang, Y., Zhang, H., Fang, L., et al.: Facile synthesis of nickel manganese composite oxide nanomesh for efficient oxygen evolution reaction and supercapacitors. Electrochim. Acta 245, 32-40 (2017)

79. Zhang, D., Meng, L., Shi, J., et al.: One-step preparation of optically transparent $\mathrm{Ni}-\mathrm{Fe}$ oxide film electrocatalyst for oxygen evolution reaction. Electrochim. Acta 169, 402-408 (2015)

80. Liu, G., Gao, X., Wang, K., et al.: Uniformly mesoporous $\mathrm{NiO} /$ $\mathrm{NiFe}_{2} \mathrm{O}_{4}$ biphasic nanorods as efficient oxygen evolving catalyst for water splitting. Int. J. Hydrog. Energy 41, 17976-17986 (2016)

81. Browne, M.P., Stafford, S., O’Brien, M., et al.: The goldilocks electrolyte: examining the performance of iron/nickel oxide thin films as catalysts for electrochemical water splitting in various aqueous $\mathrm{NaOH}$ solutions. J. Mater. Chem. A 4, 1139711407 (2016)

82. Hwang, G.J., Gil, B.M., Ryu, C.H.: Preparation of the electrode using $\mathrm{NiFe}_{2} \mathrm{O}_{4}$ powder for the alkaline water electrolysis. J. Ind. Eng. Chem. 48, 242-248 (2017)

83. Xie, Y., Wang, X., Tang, K., et al.: Blending $\mathrm{Fe}_{3} \mathrm{O}_{4}$ into a Ni/ $\mathrm{NiO}$ composite for efficient and stable bifunctional electrocatalyst. Electrochim. Acta 264, 225-232 (2018)

84. Görlin, M., Gliech, M., de Araújo, J.F.: Dynamical changes of a Ni-Fe oxide water splitting catalyst investigated at different pH. Catal. Today 262, 65-73 (2016)

85. Jiang, J., Zhang, C., Ai, L.: Hierarchical iron nickel oxide architectures derived from metal-organic frameworks as efficient electrocatalysts for oxygen evolution reaction. Electrochim. Acta 208, 17-24 (2016)

86. Banerjee, S., Debata, S., Madhuri, R., et al.: Electrocatalytic behavior of transition metal (Ni, Fe, $\mathrm{Cr}$ ) doped metal oxide nanocomposites for oxygen evolution reaction. Appl. Surf. Sci. 449, 660-668 (2018)

87. Liu, H., Wang, Y., Lu, X., et al.: The effects of Al substitution and partial dissolution on ultrathin $\mathrm{NiFeAl}$ trinary layered double hydroxide nanosheets for oxygen evolution reaction in alkaline solution. Nano Energy 35, 350-357 (2017)

88. Yan, K., Lafleur, T., Chai, J., et al.: Facile synthesis of thin $\mathrm{NiFe}-$ layered double hydroxides nanosheets efficient for oxygen evolution. Electrochem. Commun. 62, 24-28 (2016)

89. Li, X., Zai, J., Liu, Y., et al.: Atomically thin layered $\mathrm{NiFe}$ double hydroxides assembled 3D microspheres with promoted electrochemical performances. J. Power Sources 325, 675-681 (2016)

90. Zhang, K., Wang, W., Kuai, L., et al.: A facile and efficient strategy to gram-scale preparation of composition-controllable $\mathrm{Ni}-\mathrm{Fe}$ LDHs nanosheets for superior OER catalysis. Electrochim. Acta 225, 303-309 (2017) 
91. Youn, D.H., Park, Y.B., Kim, J.Y., et al.: One-pot synthesis of $\mathrm{NiFe}$ layered double hydroxide/reduced graphene oxide composite as an efficient electrocatalyst for electrochemical and photoelectrochemical water oxidation. J. Power Sources 294, 437-443 (2015)

92. Zhan, T., Liu, X., Lu, S., et al.: Nitrogen doped NiFe layered double hydroxide/reduced graphene oxide mesoporous nanosphere as an effective bifunctional electrocatalyst for oxygen reduction and evolution reactions. Appl. Catal. B Environ. 205, 551-558 (2017)

93. Lee, E., Park, A.H., Park, H.U., et al.: Facile sonochemical synthesis of amorphous $\mathrm{NiFe}$-(oxy)hydroxide nanoparticles as superior electrocatalysts for oxygen evolution reaction. Ultrason. Sonochem. 40, 552-557 (2018)

94. Xia, D.C., Zhou, L., Qiao, S., et al.: Graphene/Ni-Fe layered double-hydroxide composite as highly active electrocatalyst for water oxidation. Mater. Res. Bull. 74, 441-446 (2016)

95. Stern, L.A., Feng, L., Song, F., et al.: $\mathrm{Ni}_{2} \mathrm{P}$ as a Janus catalyst for water splitting: the oxygen evolution activity of Ni2P nanoparticles. Energy Environ. Sci. 8, 2347-2351 (2015)

96. Liu, G., He, D., Yao, R., et al.: Enhancing the water oxidation activity of $\mathrm{Ni}_{2} \mathrm{P}$ nanocatalysts by iron-doping and electrochemical activation. Electrochim. Acta 253, 498-505 (2017)

97. Pu, Z., Xue, Y., Li, W., et al.: Efficient water splitting catalyzed by flexible $\mathrm{NiP}_{2}$ nanosheet array electrodes under both neutral and alkaline solutions. New J. Chem. 41, 2156-2159 (2017)

98. Wang, X., Li, W., Xiong, D., et al.: Fast fabrication of selfsupported porous nickel phosphide foam for efficient, durable oxygen evolution and overall water splitting. J. Mater. Chem. A 4, 5639-5646 (2016)

99. Ren, J., Hu, Z., Chen, C., et al.: Integrated $\mathrm{Ni}_{2} \mathrm{P}$ nanosheet arrays on three-dimensional $\mathrm{Ni}$ foam for highly efficient water reduction and oxidation. J. Energy Chem. 26, 1196-1202 (2017)

100. Zhang, B., Lui, Y.H., Ni, H., et al.: Bimetallic $\left(\mathrm{Fe}_{x} \mathrm{Ni}_{1-x}\right)_{2} \mathrm{P}$ nanoarrays as exceptionally efficient electrocatalysts for oxygen evolution in alkaline and neutral media. Nano Energy 38, 553-560 (2017)

101. Jin, L., Xia, H., Huang, Z., et al.: Phase separation synthesis of trinickel monophosphide porous hollow nanospheres for efficient hydrogen evolution. J. Mater. Chem. A 4, 10925-10932 (2016)

102. Barwe, S., Andronescu, C., Vasile, E., et al.: Influence of Ni to Co ratio in mixed $\mathrm{Co}$ and Ni phosphides on their electrocatalytic oxygen evolution activity. Electrochem. Commun. 79, 41-45 (2017)

103. Xiao, C., Zhang, B., Li, D.: Partial-sacrificial-template synthesis of $\mathrm{Fe} / \mathrm{Ni}$ phosphides on ni foam: a strongly stabilized and efficient catalyst for electrochemical water splitting. Electrochim. Acta 242, 260-267 (2017)

104. Zhang, C., Xie, Y., Deng, H., et al.: Ternary nickel iron phosphide supported on nickel foam as a high-efficiency electrocatalyst for overall water splitting. Int. J. Hydrog. Energy 43, 7299-7306 (2018)

105. Bandal, H.A., Jadhav, A.R., Kim, H.: Facile synthesis of bicontinuous $\mathrm{Ni}_{3} \mathrm{Fe}$ alloy for efficient electrocatalytic oxygen evolution reaction. J. Alloys Compd. 726, 875-884 (2017)

106. Flis-Kabulska, I., Flis, J.: Electroactivity of Ni-Fe cathodes in alkaline water electrolysis and effect of corrosion. Corros. Sci. 112, 255-263 (2016)

107. Yang, Y., Zhuang, L., Lin, R., et al.: A facile method to synthesize boron-doped $\mathrm{Ni} / \mathrm{Fe}$ alloy nano-chains as electrocatalyst for water oxidation. J. Power Sources 349, 68-74 (2017)

108. Zhu, Y., Wang, Y., Liu, S., et al.: Facile and controllable synthesis at an ionic layer level of high-performance NiFe-based nanofilm electrocatalysts for the oxygen evolution reaction in alkaline electrolyte. Electrochem. Commun. 86, 38-42 (2018)
109. Fu, Y., Yu, H.Y., Jiang, C., et al.: NiCo alloy nanoparticles decorated on $\mathrm{n}$-doped carbon nanofibers as highly active and durable oxygen electrocatalyst. Adv. Funct. Mater. 28, 1705094 (2018)

110. Du, L., Luo, L., Feng, Z., et al.: Nitrogen-doped graphitized carbon shell encapsulated NiFe nanoparticles: a highly durable oxygen evolution catalyst. Nano Energy 39, 245-252 (2017)

111. Fu, S., Song, J., Zhu, C., et al.: Ultrafine and highly disordered $\mathrm{Ni}_{2} \mathrm{Fe}$ nanofoams enabled highly efficient oxygen evolution reaction in alkaline electrolyte. Nano Energy 44, 319-326 (2018)

112. Shetty, S., Mohamed Jaffer Sadiq, M., Bhat, D.K., et al.: Electrodeposition and characterization of Ni-Mo alloy as an electrocatalyst for alkaline water electrolysis. J. Electroanal. Chem. 796, 57-65 (2017)

113. Rosalbino, F., Delsante, S., Borzone, G., et al.: Electrocatalytic activity of crystalline $\mathrm{Ni}-\mathrm{Co}-\mathrm{M}(\mathrm{M}=\mathrm{Cr}, \mathrm{Mn}, \mathrm{Cu})$ alloys on the oxygen evolution reaction in an alkaline environment. Int. J. Hydrog. Energy 38, 10170-10177 (2013)

114. Su, X., Sun, Q., Bai, J., et al.: Electrodeposition of porous $\mathrm{MoO}_{2}$-doped NiFe nanosheets for highly efficient electrocatalytic oxygen evolution reactions. Electrochim. Acta 260, 477-482 (2018)

115. Wu, L.K., Wu, W.Y., Xia, J., et al.: A nanostructured nickelcobalt alloy with an oxide layer for an efficient oxygen evolution reaction. J. Mater. Chem. A 5, 10669-10677 (2017)

116. Edison, T.N.J.I., Atchudan, R., Karthik, N., et al.: Ultrasonic synthesis, characterization and energy applications of $\mathrm{Ni}-\mathrm{B}$ alloy nanorods. J. Taiwan Inst. Chem. Eng. 80, 901-907 (2017)

117. Vishnu Prataap, R.K., Mohan, S.: Electrodeposited-hydroxide surface-covered porous nickel-cobalt alloy electrodes for efficient oxygen evolution reaction. Chem. Commun. 53, 3365-3368 (2017)

118. Hu, C.C., Wu, Y.R.: Bipolar performance of the electroplated iron-nickel deposits for water electrolysis. Mater. Chem. Phys. 82, 588-596 (2003)

119. Chen, J., Chen, J., Yu, D., et al.: Carbon nanofiber-supported $\mathrm{PdNi}$ alloy nanoparticles as highly efficient bifunctional catalysts for hydrogen and oxygen evolution reactions. Electrochim. Acta 246, 17-26 (2017)

120. Yu, J., Zhong, Y., Zhou, W., et al.: Facile synthesis of nitrogendoped carbon nanotubes encapsulating nickel cobalt alloys 3D networks for oxygen evolution reaction in an alkaline solution. J. Power Sources 338, 26-33 (2017)

121. Du, J., Zou, Z., Liu, C., et al.: Hierarchical Fe-doped $\mathrm{Ni}_{3} \mathrm{Se}_{4}$ ultrathin nanosheets as an efficient electrocatalyst for oxygen evolution reaction. Nanoscale 10, 5163-5170 (2018)

122. Xu, Y.Z., Yuan, C.Z., Chen, X.P.: Co-doped NiSe nanowires on nickel foam via a cation exchange approach as efficient electrocatalyst for enhanced oxygen evolution reaction. RSC Adv. 6, 106832-106836 (2016)

123. Hao, J., Yang, W., Hou, J., et al.: Nitrogen doped $\mathrm{NiS}_{2}$ nanoarrays with enhanced electrocatalytic activity for water oxidation. J. Mater. Chem. A 5, 17811-17816 (2017)

124. Feng, L.L., Yu, G., Wu, Y., et al.: High-index faceted $\mathrm{Ni}_{3} \mathrm{~S}_{2}$ nanosheet arrays as highly active and ultrastable electrocatalysts for water splitting. Chem. Soc. Rev. 137, 14023-14026 (2015)

125. Zhou, W., Wu, X.J., Cao, X., et al.: $\mathrm{Ni}_{3} \mathrm{~S}_{2}$ nanorods/Ni foam composite electrode with low overpotential for electrocatalytic oxygen evolution. Energy Environ. Sci. 6, 2921-2924 (2013)

126. Li, X., Han, G.Q., Liu, Y.R., et al.: NiSe@NiOOH core-shell hyacinth-like nanostructures on nickel foam synthesized by in situ electrochemical oxidation as an efficient electrocatalyst for the oxygen evolution reaction. ACS Appl. Mater. Interfaces 8, 20057-20066 (2016) 
127. Koza, J.A., He, Z., Miller, A.S., et al.: Electrodeposition of crystalline $\mathrm{Co}_{3} \mathrm{O}_{4}$-a catalyst for the oxygen evolution reaction. Chem. Mater. 24, 3567-3573 (2012)

128. Casella, I.G.: Electrodeposition of cobalt oxide films from carbonate solutions containing Co(II)-tartrate complexes. J. Electroanal. Chem. 520, 119-125 (2002)

129. Sun, Y., Gao, S., Lei, F., et al.: Atomically-thin non-layered cobalt oxide porous sheets for highly efficient oxygen-evolving electrocatalysts. Chem. Sci. 5, 3976-3982 (2014)

130. Ranaweera, C.K., Zhang, C., Bhoyate, S., et al.: Flower-shaped cobalt oxide nano-structures as an efficient, flexible and stable electrocatalyst for the oxygen evolution reaction. Mater. Chem. Front. 1, 1580-1584 (2017)

131. Wang, X., Li, T.T., Zheng, Y.Q.: $\mathrm{Co}_{3} \mathrm{O}_{4}$ nanosheet arrays treated by defect engineering for enhanced electrocatalytic water oxidation. Int. J. Hydrog. Energy 43, 2009-2017 (2018)

132. Natarajan, S., Anantharaj, S., Tayade, R.J., et al.: Recovered spinel $\mathrm{MnCo}_{2} \mathrm{O}_{4}$ from spent lithium-ion batteries for enhanced electrocatalytic oxygen evolution in alkaline medium. Dalton Trans. 46, 14382-14392 (2017)

133. Sagu, J.S., Mehta, D., Wijayantha, K.G.U.: Electrocatalytic activity of $\mathrm{CoFe}_{2} \mathrm{O}_{4}$ thin films prepared by AACVD towards the oxygen evolution reaction in alkaline media. Electrochem. Commun. 87, 1-4 (2018)

134. AlShehri, S., Ahmed, J., Ahamad, T., et al.: Bifunctional electrocatalytic performances of $\mathrm{CoWO}_{4}$ nanocubes for water redox reactions (OER/ORR). RSC Adv. 7, 45615-45623 (2017)

135. Zhu, G., Ge, R., Qu, F., et al.: In situ surface derivation of an $\mathrm{Fe}-\mathrm{Co}-\mathrm{Bi}$ layer on an $\mathrm{Fe}$-doped $\mathrm{Co}_{3} \mathrm{O}_{4}$ nanoarray for efficient water oxidation electrocatalysis under near-neutral conditions. J. Mater. Chem. A 5, 6388-6392 (2017)

136. Zhang, L., Yang, C., Xie, Z., et al.: Cobalt manganese spinel as an effective cocatalyst for photocatalytic water oxidation. Appl. Catal. B Environ. 224, 886-894 (2018)

137. Xu, W., Lyu, F., Bai, Y., et al.: Porous cobalt oxide nanoplates enriched with oxygen vacancies for oxygen evolution reaction. Nano Energy 43, 110-116 (2018)

138. Deng, S., Shen, S., Zhong, Y., et al.: Assembling $\mathrm{Co}_{9} \mathrm{~S}_{8}$ nanoflakes on $\mathrm{Co}_{3} \mathrm{O}_{4}$ nanowires as advanced core/shell electrocatalysts for oxygen evolution reaction. J. Energy Chem. 26, $1203-$ 1209 (2017)

139. Zhang, J., Zhang, D., Yang, Y., et al.: Facile synthesis of $\mathrm{ZnCo}_{2} \mathrm{O}_{4}$ mesoporous structures with enhanced electrocatalytic oxygen evolution reaction properties. RSC Adv. 6, 92699-92704 (2016)

140. Suryanto, B.H.R., Lu, X., Zhao, C.: Layer-by-layer assembly of transparent amorphous $\mathrm{Co}_{3} \mathrm{O}_{4}$ nanoparticles/graphene composite electrodes for sustained oxygen evolution reaction. J. Mater. Chem. A 1, 12726-12731 (2013)

141. Sun, X., Gao, L., Guo, C., et al.: Sulfur incorporated $\mathrm{CoFe}_{2} \mathrm{O}_{4} /$ multiwalled carbon nanotubes toward enhanced oxygen evolution reaction. Electrochim. Acta 247, 843-850 (2017)

142. Hu, W., Wang, Q., Wu, S., et al.: Facile one-pot synthesis of a nitrogen-doped mesoporous carbon architecture with cobalt oxides encapsulated in graphitic layers as a robust bicatalyst for oxygen reduction and evolution reactions. J. Mater. Chem. A 4, 16920-16927 (2016)

143. Zhang, L., Mi, T., Ziaee, M.A., et al.: Hollow POM@MOF hybrid-derived porous $\mathrm{Co}_{3} \mathrm{O}_{4} / \mathrm{CoMoO}_{4}$ nanocages for enhanced electrocatalytic water oxidation. J. Mater. Chem. A 6, 16391647 (2018)

144. Zhang, Y.X., Guo, X., Zhai, X., et al.: Diethylenetriamine (DETA)-assisted anchoring of $\mathrm{Co}_{3} \mathrm{O}_{4}$ nanorods on carbon nanotubes as efficient electrocatalysts for the oxygen evolution reaction. J. Mater. Chem. A 3, 1761-1768 (2015)
145. Qi, C., Zhang, L., Xu, G., et al.: Co@ $\mathrm{Co}_{3} \mathrm{O}_{4}$ nanoparticle embedded nitrogen-doped carbon architectures as efficient bicatalysts for oxygen reduction and evolution reactions. Appl. Surf. Sci. 427, 319-327 (2018)

146. Long, J., Gong, Y., Lin, J.: Metal-organic framework-derived $\mathrm{Co}_{9} \mathrm{~S}_{8} @ \mathrm{CoS} @ \mathrm{CoO} @ \mathrm{C}$ nanoparticles as efficient electro- and photo-catalysts for the oxygen evolution reaction. J. Mater. Chem. A 5, 10495-10509 (2017)

147. Wei, Y., Ren, X., Ma, H., et al.: $\mathrm{CoC}_{2} \mathrm{O}_{4} \cdot 2 \mathrm{H}_{2} \mathrm{O}$ derived $\mathrm{Co}_{3} \mathrm{O}_{4}$ nanorods array: a high-efficiency $1 \mathrm{D}$ electrocatalyst for alkaline oxygen evolution reaction. Chem. Commun. 54, 1533$1536(2018)$

148. Liu, M., Li, J.: Cobalt phosphide hollow polyhedron as efficient bifunctional electrocatalysts for the evolution reaction of hydrogen and oxygen. ACS Appl. Mater. Interfaces 8, 21582165 (2016)

149. Dutta, A., Samantara, A.K., Dutta, S.K., et al.: Surface-oxidized dicobalt phosphide nanoneedles as a nonprecious, durable, and efficient OER catalyst. ACS Energy Lett. 1, 169-174 (2016)

150. Jin, Z., Li, P., Xiao, D.: Metallic $\mathrm{Co}_{2} \mathrm{P}$ ultrathin nanowires distinguished from $\mathrm{CoP}$ as robust electrocatalysts for overall watersplitting. Green Chem. 18, 1459-1464 (2016)

151. Huang, Z., Chen, Z., Chen, Z., et al.: Cobalt phosphide nanorods as an efficient electrocatalyst for the hydrogen evolution reaction. Nano Energy 9, 373-382 (2014)

152. Pu, Z., Liu, Q., Jiang, P., et al.: CoP nanosheet arrays supported on a Ti Plate: an efficient cathode for electrochemical hydrogen evolution. Chem. Mater. 26, 4326-4329 (2014)

153. Tian, J., Liu, Q., Asiri, A.M., et al.: Self-supported nanoporous cobalt phosphide nanowire arrays: an efficient 3D hydrogenevolving cathode over the wide range of $\mathrm{pH} 0-14$. Chem. Soc. Rev. 136, 7587-7590 (2014)

154. Fu, S., Zhu, C., Song, J., et al.: Highly ordered mesoporous bimetallic phosphides as efficient oxygen evolution electrocatalysts. ACS Energy Lett. 1, 792-796 (2016)

155. Cao, Z., Zhou, T., Xi, W., et al.: Bimetal metal-organic frameworks derived $\mathrm{Co}_{0.4} \mathrm{Fe}_{0.28} \mathrm{P}$ and $\mathrm{Co}_{0.37} \mathrm{Fe}_{0.26} \mathrm{~S}$ nanocubes for enhanced oxygen evolution reaction. Electrochim. Acta 263, 576-584 (2018)

156. Yin, D., Jin, Z., Liu, M., et al.: Microwave-assisted synthesis of the cobalt-iron phosphates nanosheets as an efficient electrocatalyst for water oxidation. Electrochim. Acta 260, 420-429 (2018)

157. Li, D., Baydoun, H., Verani, C.N., et al.: Efficient water oxidation using CoMnP nanoparticles. Chem. Soc. Rev. 138, 4006-4009 (2016)

158. Wang, J., Yang, W., Liu, J.: $\mathrm{CoP}_{2}$ nanoparticles on reduced graphene oxide sheets as a super-efficient bifunctional electrocatalyst for full water splitting. J. Mater. Chem. A 4, 4686-4690 (2016)

159. Bai, Y., Zhang, H., Feng, Y., et al.: Sandwich-like CoP/C nanocomposites as efficient and stable oxygen evolution catalysts. J. Mater. Chem. A 4, 9072-9079 (2016)

160. Xiong, X., Ji, Y., Xie, M., et al.: $\mathrm{MnO}_{2}-\mathrm{CoP}_{3}$ nanowires array: an efficient electrocatalyst for alkaline oxygen evolution reaction with enhanced activity. Electrochem. Commun. 86, 161165 (2018)

161. Jiang, H., Li, C., Shen, H., et al.: Supramolecular gel-assisted synthesis $\mathrm{Co}_{2} \mathrm{P}$ particles anchored in multielement co-doped graphene as efficient bifunctional electrocatalysts for oxygen reduction and evolution. Electrochim. Acta 231, 344-353 (2017)

162. Wu, R., Wang, D.P., Zhou, K., et al.: Porous cobalt phosphide/ graphitic carbon polyhedral hybrid composites for efficient oxygen evolution reactions. J. Mater. Chem. A 4, 13742-13745 (2016) 
163. Zhao, X., Jiang, J., Xue, Z., et al.: An ambient temperature, $\mathrm{CO}_{2}$-assisted solution processing of amorphous cobalt sulfide in a thiol/amine based quasi-ionic liquid for oxygen evolution catalysis. Chem. Commun. 53, 9418-9421 (2017)

164. Guo, M., Xu, K., Qu, Y., et al.: Porous $\mathrm{Co}_{3} \mathrm{O}_{4} / \mathrm{CoS}_{2}$ nanosheetassembled hierarchical microspheres as superior electrocatalyst towards oxygen evolution reaction. Electrochim. Acta 268, 10-19 (2018)

165. Wu, C., Zhang, Y., Dong, D., et al.: $\mathrm{Co}_{9} \mathrm{~S}_{8}$ nanoparticles anchored on nitrogen and sulfur dual-doped carbon nanosheets as highly efficient bifunctional electrocatalyst for oxygen evolution and reduction reactions. Nanoscale 9, 12432-12440 (2017)

166. Chen, P., Xu, K., Tong, Y., et al.: Cobalt nitrides as a class of metallic electrocatalysts for the oxygen evolution reaction. Inorg. Chem. Front. 3, 236-242 (2016)

167. Gao, T., Jin, Z., Zhang, Y., et al.: Coupling cobalt-iron bimetallic nitrides and $\mathrm{N}$-doped multi-walled carbon nanotubes as high-performance bifunctional catalysts for oxygen evolution and reduction reaction. Electrochim. Acta 258, 51-60 (2017)

168. Sun, Y., Zhang, T., Li, X., et al.: Mn doped porous cobalt nitride nanowires with high activity for water oxidation under both alkaline and neutral conditions. Chem. Commun. 53, 13237-13240 (2017)

169. Xue, Y., Ren, Z., Xie, Y., et al.: $\operatorname{CoSe}_{x}$ nanocrystalline-dotted CoCo layered double hydroxide nanosheets: a synergetic engineering process for enhanced electrocatalytic water oxidation. Nanoscale 9, 16256-16263 (2017)

170. Li, J., Liu, G., Liu, B., et al.: Fe-doped $\mathrm{CoSe}_{2}$ nanoparticles encapsulated in $\mathrm{N}$-doped bamboo-like carbon nanotubes as an efficient electrocatalyst for oxygen evolution reaction. Electrochim. Acta 265, 577-585 (2018)

171. Zhou, Y., Luo, M., Zhang, Z., et al.: Iron doped cobalt sulfide derived boosted electrocatalyst for water oxidation. Appl. Surf. Sci. 448, 9-15 (2018)

172. Yang, J., Yang, Z., Li, L.H., et al.: Highly efficient oxygen evolution from $\mathrm{CoS}_{2} / \mathrm{CNT}$ nanocomposites via a one-step electrochemical deposition and dissolution method. Nanoscale $\mathbf{9}$, 6886-6894 (2017)

173. Luo, X.F., Wang, J., Liang, Z.S., et al.: Manganese oxide with different morphology as efficient electrocatalyst for oxygen evolution reaction. Int. J. Hydrog. Energy 42, 7151-7157 (2017)

174. Indra, A., Menezes, P.W., Zaharieva, I., et al.: Active mixedvalent $\mathrm{MnO}_{x}$ water oxidation catalysts through partial oxidation (corrosion) of nanostructured $\mathrm{MnO}$ particles. Angew. Chem. Int. Ed. 52, 13206-13210 (2013)

175. Kölbach, M., Fiechter, S., van de Krol, R., et al.: Evaluation of electrodeposited $\alpha-\mathrm{Mn}_{2} \mathrm{O}_{3}$ as a catalyst for the oxygen evolution reaction. Catal. Today 290, 2-9 (2017)

176. Hazarika, K.K., Goswami, C., Saikia, H., et al.: Cubic $\mathrm{Mn}_{2} \mathrm{O}_{3}$ nanoparticles on carbon as bifunctional electrocatalyst for oxygen reduction and oxygen evolution reactions. Mol. Catal. 451, 153-160 (2018)

177. Lian, S., Browne, M.P., Dominguez, C., et al.: Template-free synthesis of mesoporous manganese oxides with catalytic activity in the oxygen evolution reaction. Sustain. Energy Fuels 1, 780-788 (2017)

178. Meng, Y., Song, W., Huang, H., et al.: Structure-property relationship of bifunctional $\mathrm{MnO}_{2}$ nanostructures: highly efficient, ultra-stable electrochemical water oxidation and oxygen reduction reaction catalysts identified in alkaline media. Chem. Soc. Rev. 136, 11452-11464 (2014)

179. Bhandary, N., Ingole, P.P., Basu, S.: Electrosynthesis of Mn-Fe oxide nanopetals on carbon paper as bi-functional electrocatalyst for oxygen reduction and oxygen evolution reaction. Int. J. Hydrog. Energy 43, 3165-3171 (2018)
180. Maruthapandian, V., Pandiarajan, T., Saraswathy, V., et al.: Oxygen evolution catalytic behaviour of $\mathrm{Ni}$ doped $\mathrm{Mn}_{3} \mathrm{O}_{4}$ in alkaline medium. RSC Adv. 6, 48995-49002 (2016)

181. Song, X., Yang, T., Du, H., et al.: New binary $\mathrm{Mn}$ and $\mathrm{Cr}$ mixed oxide electrocatalysts for the oxygen evolution reaction. J. Electroanal. Chem. 760, 59-63 (2016)

182. Hosseini-Benhangi, P., Kung, C.H., Alfantazi, A., et al.: Controlling the interfacial environment in the electrosynthesis of $\mathrm{MnO}_{x}$ nanostructures for high-performance oxygen reduction/evolution electrocatalysis. ACS Appl. Mater. Interfaces 9, 26771-26785 (2017)

183. Zhang, J.H., Feng, J.Y., Zhu, T., et al.: Pd-doped urchin-like $\mathrm{MnO}_{2}$-carbon sphere three-dimensional (3D) material for oxygen evolution reaction. Electrochim. Acta 196, 661-669 (2016)

184. Seitz, L.C., Hersbach, T.J.P., Nordlund, D., et al.: Enhancement effect of noble metals on manganese oxide for the oxygen evolution reaction. J. Phys. Chem. Lett. 6, 4178-4183 (2015)

185. Qian, M., Liu, X., Cui, S., et al.: Copper oxide nanosheets prepared by molten salt method for efficient electrocatalytic oxygen evolution reaction with low catalyst loading. Electrochim. Acta 263, 318-327 (2018)

186. Yan, Y., Zhao, B., Yi, S.C., et al.: Assembling pore-rich FeP nanorods on the CNT backbone as an advanced electrocatalyst for oxygen evolution. J. Mater. Chem. A 4, 13005-13010 (2016)

187. Li, X., Li, C., Yoshida, A., et al.: Facile fabrication of $\mathrm{CuO}$ microcube@ $\mathrm{Fe}-\mathrm{Co}_{3} \mathrm{O}_{4}$ nanosheet array as a high-performance electrocatalyst for the oxygen evolution reaction. J. Mater. Chem. A 5, 21740-21749 (2017)

188. Zhang, X., Zhang, B., Liu, S., et al.: RGO modified Ni doped FeOOH for enhanced electrochemical and photoelectrochemical water oxidation. Appl. Surf. Sci. 436, 974-980 (2018)

189. Zhang, R., Zhang, C., Chen, W.: FeP embedded in N, P dualdoped porous carbon nanosheets: an efficient and durable bifunctional catalyst for oxygen reduction and evolution reactions. J. Mater. Chem. A 4, 18723-18729 (2016)

190. Siracusano, S., Van Dijk, N., Payne-Johnson, E., et al.: Nanosized $\mathrm{IrO}_{x}$ and $\mathrm{IrRuO}_{x}$ electrocatalysts for the $\mathrm{O}_{2}$ evolution reaction in PEM water electrolysers. Appl. Catal. B Environ. 164, 488-495 (2015)

191. Song, S., Zhang, H., Xiaoping, M., et al.: Electrochemical investigation of electrocatalysts for the oxygen evolution reaction in PEM water electrolyzers. Int. J. Hydrog. Energy 33, 4955-4961 (2008)

192. Slavcheva, E., Radev, I., Bliznakov, S., et al.: Sputtered iridium oxide films as electrocatalysts for water splitting via PEM electrolysis. Electrochim. Acta 52, 3889-3894 (2007)

193. Siracusano, S., Baglio, V., Grigoriev, S.A., et al.: The influence of iridium chemical oxidation state on the performance and durability of oxygen evolution catalysts in PEM electrolysis. J. Power Sources 366, 105-114 (2017)

194. Li, G., Yu, H., Yang, D., et al.: Iridium-tin oxide solid-solution nanocatalysts with enhanced activity and stability for oxygen evolution. J. Power Sources 325, 15-24 (2016)

195. Kadakia, K.S., Jampani, P.H., Velikokhatnyi, O.I., et al.: Nanostructured $\mathrm{F}$ doped $\mathrm{IrO}_{2}$ electro-catalyst powders for PEM based water electrolysis. J. Power Sources 269, 855-865 (2014)

196. Kadakia, K.S., Jampani, P.H., Velikokhatnyi, O.I., et al.: Study of fluorine doped $(\mathrm{Nb}, \mathrm{Ir}) \mathrm{O}_{2}$ solid solution electro-catalyst powders for proton exchange membrane based oxygen evolution reaction. Mater. Sci. Eng. B 212, 101-108 (2016)

197. Kadakia, K., Datta, M.K., Velikokhatnyi, O.I., et al.: High performance fluorine doped $(\mathrm{Sn}, \mathrm{Ru}) \mathrm{O}_{2}$ oxygen evolution reaction electro-catalysts for proton exchange membrane based water electrolysis. J. Power Sources 245, 362-370 (2014) 
198. Mayousse, E., Maillard, F., Fouda-Onana, F., et al.: Synthesis and characterization of electrocatalysts for the oxygen evolution in PEM water electrolysis. Int. J. Hydrog. Energy 36, 10474-10481 (2011)

199. Kadakia, K., Datta, M.K., Velikokhatnyi, O.I., et al.: Novel (Ir, $\mathrm{Sn}, \mathrm{Nb}) \mathrm{O}_{2}$ anode electrocatalysts with reduced noble metal content for PEM based water electrolysis. Int. J. Hydrog. Energy 37, 3001-3013 (2012)

200. Puthiyapura, V.K., Mamlouk, M., Pasupathi, S., et al.: Physical and electrochemical evaluation of ATO supported $\mathrm{IrO}_{2}$ catalyst for proton exchange membrane water electrolyser. J. Power Sources 269, 451-460 (2014)

201. Marshall, A.T., Sunde, S., Tsypkin, M., et al.: Performance of a PEM water electrolysis cell using $\mathrm{Ir}_{x} \mathrm{Ru}_{y} \mathrm{Ta}_{z} \mathrm{O}_{2}$ electrocatalysts for the oxygen evolution electrode. Int. J. Hydrog. Energy 32, 2320-2324 (2007)

202. Wu, X., Tayal, J., Basu, S., et al.: Nano-crystalline $\mathrm{Ru}_{x} \mathrm{Sn}_{1-x} \mathrm{O}_{2}$ powder catalysts for oxygen evolution reaction in proton exchange membrane water electrolysers. Int. J. Hydrog. Energy 36, 14796-14804 (2011)

203. Fernández, J.L., Gennero De Chialvo, M.R., Chialvo, A.C.: Preparation and electrochemical characterization of $\mathrm{Ti} / \mathrm{Ru}_{x} \mathrm{Mn}_{1-x} \mathrm{O}_{2}$ electrodes. J. Appl. Electrochem. 32, 513-520 (2002)

204. Wu, X., Scott, K.: $\mathrm{RuO}_{2}$ supported on Sb-doped $\mathrm{SnO}_{2}$ nanoparticles for polymer electrolyte membrane water electrolysers. Int. J. Hydrog. Energy 36, 5806-5810 (2011)

205. Slavcheva, E., Borisov, G., Lefterova, E., et al.: Ebonex supported iridium as anode catalyst for PEM water electrolysis. Int. J. Hydrog. Energy 40, 11356-11361 (2015)

206. Stoyanova, A., Borisov, G., Lefterova, E., et al.: Oxygen evolution on Ebonex-supported Pt-based binary compounds in PEM water electrolysis. Int. J. Hydrog. Energy 37, 16515-16521 (2012)

207. Xu, J., Liu, G., Li, J., et al.: The electrocatalytic properties of an $\mathrm{IrO}_{2} / \mathrm{SnO}_{2}$ catalyst using $\mathrm{SnO}_{2}$ as a support and an assisting reagent for the oxygen evolution reaction. Electrochim. Acta 59, 105-112 (2012)

208. Karimi, F., Peppley, B.A.: Metal carbide and oxide supports for iridium-based oxygen evolution reaction electrocatalysts for polymer-electrolyte-membrane water electrolysis. Electrochim. Acta 246, 654-670 (2017)

209. Polonský, J., Petrushina, I.M., Christensen, E., et al.: Tantalum carbide as a novel support material for anode electrocatalysts in polymer electrolyte membrane water electrolysers. Int. J. Hydrog. Energy 37, 2173-2181 (2012)

210. Ye, F., Li, J., Wang, X., et al.: Electrocatalytic properties of Ti/ $\mathrm{Pt}-\mathrm{IrO}_{2}$ anode for oxygen evolution in PEM water electrolysis. Int. J. Hydrog. Energy 35, 8049-8055 (2010)

211. Lagarteira, T., Han, F., Morawietz, T., et.al.: Highly active screen-printed $\mathrm{IrTi}_{4} \mathrm{O}_{7}$ anodes for proton exchange membrane electrolyzers. In: Hyceltec 2017-VI Symposium on Hydrogen, Fuel Cells and Advanced Batteries, Porto, Portugal, 19-23 June 2017

212. Erning, J.W., Hauber, T., Stimming, U., et al.: Catalysis of the electrochemical processes on solid oxide fuel cell cathodes. J. Power Sources 61, 205-211 (1996)

213. Sahibzada, M., Benson, S.J., Rudkin, R.A., et al.: Pd-promoted $\mathrm{La}_{0.6} \mathrm{Sr}_{0.4} \mathrm{Co}_{0.2} \mathrm{Fe}_{0.8} \mathrm{O}_{3}$ cathodes. Solid State Ion. 113-115, 285290 (1998)

214. Haanappel, V.A.C., Rutenbeck, D., Mai, A., et al.: The influence of noble-metal-containing cathodes on the electrochemical performance of anode-supported SOFCs. J. Power Sources 130, 119-128 (2004)

215. Yu, B., Zhang, W., Xu, J. et al.: Microstructural characterization and electrochemical properties of $\mathrm{Ba}_{0.5} \mathrm{Sr}_{0.5} \mathrm{Co}_{0.8} \mathrm{Fe}_{0.2} \mathrm{O}_{3-\delta}$ and its application for anode of SOEC. Int. J. Hydrog. Energy 33, 6873-6877 (2008)

216. Chrzan, A., Karczewski, J., Gazda, M., et al.: $\mathrm{La}_{0.6} \mathrm{Sr}_{0.4} \mathrm{Co}_{0.2} \mathrm{Fe}_{0.8} \mathrm{O}_{3-\delta}$ oxygen electrodes for solid oxide cells prepared by polymer precursor and nitrates solution infiltration into gadolinium doped ceria backbone. J. Eur. Ceram. Soc. 37, 3559-3564 (2017)

217. Gao, C., Liu, Y., Xi, K., et al.: Improve the catalytic property of $\mathrm{La}_{0.6} \mathrm{Sr}_{0.4} \mathrm{Co}_{0.2} \mathrm{Fe}_{0.8} \mathrm{O}_{3} / \mathrm{Ce}_{0.9} \mathrm{Gd}_{0.1} \mathrm{O}_{2}$ (LSCF/CGO) cathodes with $\mathrm{CuO}$ nanoparticles infiltration. Electrochim. Acta 246, 148-155 (2017)

218. Kim, S.J., Kim, K.J., Dayaghi, A.M., et al.: Polarization and stability of $\mathrm{La}_{2} \mathrm{NiO}_{4+\delta}$ in comparison with $\mathrm{La}_{0.6} \mathrm{Sr}_{0.4} \mathrm{Co}_{0.2} \mathrm{Fe}_{0.8} \mathrm{O}_{3-\delta}$ as air electrode of solid oxide electrolysis cell. Int. J. Hydrog. Energy 41, 14498-14506 (2016)

219. Fan, H., Keane, M., Li, N., et al.: Electrochemical stability of $\mathrm{La}_{0.6} \mathrm{Sr}_{0.4} \mathrm{Co}_{0.2} \mathrm{Fe}_{0.8} \mathrm{O}_{3-\delta}$ infiltrated YSZ oxygen electrode for reversible solid oxide fuel cells. Int. J. Hydrog. Energy 39, 14071-14078 (2014)

220. Meng, X., Shen, Y., Xie, M., et al.: Novel solid oxide cells with $\mathrm{SrCo}_{0.8} \mathrm{Fe}_{0.1} \mathrm{Ga}_{0.1} \mathrm{O}_{3-\delta}$ oxygen electrode for flexible power generation and hydrogen production. J. Power Sources 306, 226-232 (2016)

221. Boulfrad, S., Cassidy, M., Djurado, E., et al.: Pre-coating of LSCM perovskite with metal catalyst for scalable high performance anodes. Int. J. Hydrog. Energy 38, 9519-9524 (2013)

222. Chrzan, A., Ovtar, S., Jasinski, P., et al.: High performance $\mathrm{LaNi}_{1-x} \mathrm{Co}_{x} \mathrm{O}_{3-\delta}(x=0.4-0.7)$ infiltrated oxygen electrodes for reversible solid oxide cells. J. Power Sources 353, 67-76 (2017)

223. Egger, A., Schrödl, N., Gspan, C., et al.: $\mathrm{La}_{2} \mathrm{NiO}_{4+\delta}$ as electrode material for solid oxide fuel cells and electrolyzer cells. Solid State Ion. 299, 18-25 (2017)

224. Ai, N., Li, N., He, S., et al.: Highly active and stable $\mathrm{Er}_{0.4} \mathrm{Bi}_{1.6} \mathrm{O}_{3}$ decorated $\mathrm{La}_{0.76} \mathrm{Sr}_{0.19} \mathrm{MnO}_{3+\sigma}$ nanostructured oxygen electrodes for reversible solid oxide cells. J. Mater. Chem. A 5, 1214912157 (2017)

225. Tan, Y., Wang, A., Jia, L., et al.: High-performance oxygen electrode for reversible solid oxide cells with power generation and hydrogen production at intermediate temperature. Int. J. Hydrog. Energy 42, 4456-4464 (2017)

226. Zhou, N., Yin, Y.M., Li, J., et al.: A robust high performance cobalt-free oxygen electrode $\mathrm{La}_{0.5} \mathrm{Sr}_{0.5} \mathrm{Fe}_{0.8} \mathrm{Cu}_{0.15} \mathrm{Nb}_{0.05} \mathrm{O}_{3-\delta}$ for reversible solid oxide electrochemical cell. J. Power Sources 340, 373-379 (2017)

227. Mahata, A., Datta, P., Basu, R.N.: Synthesis and characterization of $\mathrm{Ca}$ doped $\mathrm{LaMnO}_{3}$ as potential anode material for solid oxide electrolysis cells. Ceram. Int. 43, 433-438 (2017)

228. Chen, K., Ai, N., Jiang, S.P.: Enhanced electrochemical performance and stability of $(\mathrm{La}, \mathrm{Sr}) \mathrm{MnO}_{3}-(\mathrm{Gd}, \mathrm{Ce}) \mathrm{O}_{2}$ oxygen electrodes of solid oxide electrolysis cells by palladium infiltration. Int. J. Hydrog. Energy 37, 1301-1310 (2012)

229. Tong, X., Zhou, F., Yang, S., et al.: Performance and stability of Ruddlesden-Popper $\mathrm{La}_{2} \mathrm{NiO}_{4+\delta}$ oxygen electrodes under solid oxide electrolysis cell operation conditions. Ceram. Int. 43, 10927-10933 (2017)

230. Yan, J., Zhao, Z., Shang, L., et al.: Co-synthesized Y-stabilized $\mathrm{Bi}_{2} \mathrm{O}_{3}$ and $\mathrm{Sr}$-substituted $\mathrm{LaMnO}_{3}$ composite anode for high performance solid oxide electrolysis cell. J. Power Sources 319, 124-130 (2016)

231. Cheng, X., Li, Y., Zheng, L., et al.: Highly active, stable oxidized platinum clusters as electrocatalysts for the hydrogen evolution reaction. Energy Environ. Sci. 10, 2450-2458 (2017)

232. Lima, D.W., Fiegenbaum, F., Trombetta, F., et al.: PtNi and PtMo nanoparticles as efficient catalysts using TEA-PS. $\mathrm{BF}_{4}$ ionic 
liquid as electrolyte towards HER. Int. J. Hydrog. Energy 42, 5676-5683 (2017)

233. Ren, F., Zhou, W., Du, Y., et al.: High efficient electrocatalytic oxidation of formic acid at $\mathrm{Pt}$ dispersed on porous poly(o-methoxyaniline). Int. J. Hydrog. Energy 36, 6414-6421 (2011)

234. Zheng, J.: Binary platinum alloy electrodes for hydrogen and oxygen evolutions by seawater splitting. Appl. Surf. Sci. 413, 72-82 (2017)

235. Gabler, A., Müller, C.I., Rauscher, T., et al.: Ultrashort-pulse laser structured titanium surfaces with sputter-coated platinum catalyst as hydrogen evolution electrodes for alkaline water electrolysis. Int. J. Hydrog. Energy 43, 7216-7226 (2018)

236. Luo, B., Yan, X., Chen, J., et al.: PtFe nanotubes/graphene hybrid: facile synthesis and its electrochemical properties. Int. J. Hydrog. Energy 38, 13011-13016 (2013)

237. Ma, R., Zhou, Y., Wang, F., et al.: Efficient electrocatalysis of hydrogen evolution by ultralow-Pt-loading bamboo-like nitrogendoped carbon nanotubes. Mater. Today 6, 173-180 (2017)

238. Deng, J., Ren, P., Deng, D., et al.: Highly active and durable nonprecious-metal catalysts encapsulated in carbon nanotubes for hydrogen evolution reaction. Energy Environ. Sci. 7, 1919-1923 (2014)

239. Wang, Z.L., Hao, X.F., Jiang, Z., et al.: $\mathrm{C}$ and $\mathrm{N}$ hybrid coordination derived $\mathrm{Co}-\mathrm{C}-\mathrm{N}$ complex as a highly efficient electrocatalyst for hydrogen evolution reaction. Chem. Soc. Rev. 137, 15070-15073 (2015)

240. Guan, H., Lin, J., Qiao, B., et al.: Catalytically active Rh subnanoclusters on $\mathrm{TiO}_{2}$ for $\mathrm{CO}$ oxidation at cryogenic temperatures. Angew. Chem. Int. Ed. 55, 2820-2824 (2016)

241. Wang, S., Gao, X., Hang, X., et al.: Ultrafine pt nanoclusters confined in a calixarene-based $\mathrm{Ni}_{24}$ coordination cage for highefficient hydrogen evolution reaction. J. Am. Chem. Soc. 138, 16236-16239 (2016)

242. Fang, M., Gao, W., Dong, G., et al.: Hierarchical NiMo-based 3D electrocatalysts for highly-efficient hydrogen evolution in alkaline conditions. Nano Energy 27, 247-254 (2016)

243. Sun, T., Cao, J., Dong, J., et al.: Ordered mesoporous NiCo alloys for highly efficient electrocatalytic hydrogen evolution reaction. Int. J. Hydrog. Energy 42, 6637-6645 (2017)

244. Guo, H., Youliwasi, N., Zhao, L., et al.: Carbon-encapsulated nickel-cobalt alloys nanoparticles fabricated via new post-treatment strategy for hydrogen evolution in alkaline media. Appl. Surf. Sci. 435, 237-246 (2018)

245. Schalenbach, M., Speck, F.D., Ledendecker, M., et al.: Nickelmolybdenum alloy catalysts for the hydrogen evolution reaction: activity and stability revised. Electrochim. Acta 259, 1154-1161 (2018)

246. Rauscher, T., Müller, C.I., Schmidt, A., et al.: Ni-Mo-B alloys as cathode material for alkaline water electrolysis. Int. J. Hydrog. Energy 41, 2165-2176 (2016)

247. Yüce, A.O., Döner, A., Kardaş, G.: NiMn composite electrodes as cathode material for hydrogen evolution reaction in alkaline solution. Int. J. Hydrog. Energy 38, 4466-4473 (2013)

248. Yang, Q., Lv, C., Huang, Z., et al.: Amorphous film of ternary $\mathrm{NiCoP}$ alloy on Ni foam for efficient hydrogen evolution by electroless deposition. Int. J. Hydrog. Energy 43, 7872-7880 (2018)

249. Wang, X., Su, R., Aslan, H., et al.: Tweaking the composition of NiMoZn alloy electrocatalyst for enhanced hydrogen evolution reaction performance. Nano Energy 12, 9-18 (2015)

250. Zhu, Y., Zhang, X., Song, J., et al.: Microstructure and hydrogen evolution catalytic properties of $\mathrm{Ni}-\mathrm{Sn}$ alloys prepared by electrodeposition method. Appl. Catal. A Gen. 500, 51-57 (2015)

251. He, X.D., Xu, F., Li, F., et al.: Composition-performance relationship of $\mathrm{Ni}_{x} \mathrm{Cu}_{y}$ nanoalloys as hydrogen evolution electrocatalyst. J. Electroanal. Chem. 799, 235-241 (2017)
252. Hong, S.H., Ahn, S.H., Choi, J., et al.: High-activity electrodeposited NiW catalysts for hydrogen evolution in alkaline water electrolysis. Appl. Surf. Sci. 349, 629-635 (2015)

253. Yin, Z., Chen, F.: A facile electrochemical fabrication of hierarchically structured nickel-copper composite electrodes on nickel foam for hydrogen evolution reaction. J. Power Sources 265, 273-281 (2014)

254. Zhang, J., Baro, M.D., Pellicer, E., et al.: Electrodeposition of magnetic, superhydrophobic, non-stick, two-phase $\mathrm{Cu}-\mathrm{Ni}$ foam films and their enhanced performance for hydrogen evolution reaction in alkaline water media. Nanoscale 6, 12490-12499 (2014)

255. Wu, Y., He, H.: Direct-current electrodeposition of Ni-S-Fe alloy for hydrogen evolution reaction in alkaline solution. Int. J. Hydrog. Energy 43, 1989-1997 (2018)

256. McArthur, M.A., Jorge, L., Coulombe, S., et al.: Synthesis and characterization of 3D Ni nanoparticle/carbon nanotube cathodes for hydrogen evolution in alkaline electrolyte. J. Power Sources 266, 365-373 (2014)

257. Damian, A., Omanovic, S.: Ni and NiMo hydrogen evolution electrocatalysts electrodeposited in a polyaniline matrix. J. Power Sources 158, 464-476 (2006)

258. Bai, Y., Zhang, H., Li, X., et al.: Novel peapod-like $\mathrm{Ni}_{2} \mathrm{P}$ nanoparticles with improved electrochemical properties for hydrogen evolution and lithium storage. Nanoscale 7, 1446-1453 (2015)

259. Jiang, P., Liu, Q., Sun, X.: $\mathrm{NiP}_{2}$ nanosheet arrays supported on carbon cloth: an efficient 3D hydrogen evolution cathode in both acidic and alkaline solutions. Nanoscale 6, 13440-13445 (2014)

260. Jeoung, S., Seo, B., Hwang, J.M., et al.: Direct conversion of coordination compounds into $\mathrm{Ni}_{2} \mathrm{P}$ nanoparticles entrapped in $3 \mathrm{D}$ mesoporous graphene for an efficient hydrogen evolution reaction. Mater. Chem. Front. 1, 973-978 (2017)

261. $\mathrm{Pu}, \mathrm{Z}$., Liu, Q., Tang, C., et al.: $\mathrm{Ni}_{2} \mathrm{P}$ nanoparticle films supported on a Ti plate as an efficient hydrogen evolution cathode. Nanoscale 6, 11031-11034 (2014)

262. Hansen, M.H., Stern, L.A., Feng, L., et al.: Widely available active sites on $\mathrm{Ni}_{2} \mathrm{P}$ for electrochemical hydrogen evolutioninsights from first principles calculations. Phys. Chem. Chem. Phys. 17, 10823-10829 (2015)

263. Wang, X., Zhou, H., Zhang, D., et al.: Mn-doped $\mathrm{NiP}_{2}$ nanosheets as an efficient electrocatalyst for enhanced hydrogen evolution reaction at all $\mathrm{pH}$ values. J. Power Sources 387, 1-8 (2018)

264. Ma, Z., Li, R., Wang, M., et al.: Self-supported porous Ni-Fe-P composite as an efficient electrocatalyst for hydrogen evolution reaction in both acidic and alkaline medium. Electrochim. Acta 219, 194-203 (2016)

265. Ledendecker, M., Krick Calderon, S., Papp, C., et al.: The synthesis of nanostructured Ni5P4 films and their use as a nonnoble bifunctional electrocatalyst for full water splitting. Angew. Chem. 54, 12538-12542 (2015)

266. Zhang, J., Cui, R., Li, X.A., et al.: A nanohybrid consisting of $\mathrm{NiPS}_{3}$ nanoparticles coupled with defective graphene as a pHuniversal electrocatalyst for efficient hydrogen evolution. J. Mater. Chem. A 5, 23536-23542 (2017)

267. Jin, Z., Li, P., Huang, X., et al.: Three-dimensional amorphous tungsten-doped nickel phosphide microsphere as an efficient electrocatalyst for hydrogen evolution. J. Mater. Chem. A 2, 18593-18599 (2014)

268. Li, Y., Jiang, Z., Huang, J., et al.: Template-synthesis and electrochemical properties of urchin-like NiCoP electrocatalyst for hydrogen evolution reaction. Electrochim. Acta 249, 301-307 (2017)

269. Wu, J., Ge, X., Li, Z., et al.: Highly dispersed NiCoP nanoparticles on carbon nanotubes modified nickel foam for efficient electrocatalytic hydrogen production. Electrochim. Acta 252, 101-108 (2017) 
270. Liu, T., Yan, X., Xi, P., et al.: Nickel-cobalt phosphide nanowires supported on Ni foam as a highly efficient catalyst for electrochemical hydrogen evolution reaction. Int. J. Hydrog. Energy 42, 14124-14132 (2017)

271. Tang, C., $\mathrm{Pu}, \mathrm{Z}$., Liu, Q., et al.: $\mathrm{NiS}_{2}$ nanosheets array grown on carbon cloth as an efficient 3D hydrogen evolution cathode. Electrochim. Acta 153, 508-514 (2015)

272. Yang, C., Gao, M.Y., Zhang, Q.B., et al.: In-situ activation of self-supported 3D hierarchically porous $\mathrm{Ni}_{3} \mathrm{~S}_{2}$ films grown on nanoporous copper as excellent $\mathrm{pH}$-universal electrocatalysts for hydrogen evolution reaction. Nano Energy 36, 85-94 (2017)

273. Ouyang, C., Wang, X., Wang, C., et al.: Hierarchically porous $\mathrm{Ni}_{3} \mathrm{~S}_{2}$ nanorod array foam as highly efficient electrocatalyst for hydrogen evolution reaction and oxygen evolution reaction. Electrochim. Acta 174, 297-301 (2015)

274. Tao, K., Gong, Y., Lin, J.: Low-temperature synthesis of NiS/ $\mathrm{MoS}_{2} / \mathrm{C}$ nanowires/nanoflakes as electrocatalyst for hydrogen evolution reaction in alkaline medium via calcining/sulfurizing metal-organic frameworks. Electrochim. Acta 274, 74-83 (2018)

275. Liu, Z.Z., Shang, X., Dong, B., et al.: Triple Ni-Co-Mo metal sulfides with one-dimensional and hierarchical nanostructures towards highly efficient hydrogen evolution reaction. J. Catal. 361, 204-213 (2018)

276. Shang, X., Yan, K.L., Rao, Y., et al.: In situ cathodic activation of V-incorporated $\mathrm{Ni}_{x} \mathrm{~S}_{y}$ nanowires for enhanced hydrogen evolution. Nanoscale 9, 12353-12363 (2017)

277. Du, H., Liu, Q., Cheng, N., et al.: Template-assisted synthesis of CoP nanotubes to efficiently catalyze hydrogen-evolving reaction. J. Mater. Chem. A 2, 14812-14816 (2014)

278. Gu, S., Du, H., Asiri, A.M., et al.: Three-dimensional interconnected network of nanoporous $\mathrm{CoP}$ nanowires as an efficient hydrogen evolution cathode. Phys. Chem. Chem. Phys. 16, 16909-16913 (2014)

279. Luo, P., Zhang, H., Liu, L., et al.: Targeted synthesis of unique nickel sulfide ( $\mathrm{NiS}, \mathrm{NiS}_{2}$ ) microarchitectures and the applications for the enhanced water splitting system. ACS Appl. Mater. Interfaces 9, 2500-2508 (2017)

280. Kuang, P., Tong, T., Fan, K., et al.: In situ fabrication of Ni-Mo bimetal sulfide hybrid as an efficient electrocatalyst for hydrogen evolution over a wide $\mathrm{pH}$ range. ACS Catal. 7, 6179-6187 (2017)

281. Yu, X.Y., Feng, Y., Jeon, Y., et al.: Formation of Ni-Co-MoS nanoboxes with enhanced electrocatalytic activity for hydrogen evolution. Adv. Mater. 28, 9006-9011 (2016)

282. Zhu, H., Zhang, J., Ruoping, Y., et al.: When cubic cobalt sulfide meets layered molybdenum disulfide: a core-shell system toward synergetic electrocatalytic water splitting. Adv. Mater. 27, 47524759 (2015)

283. Wu, Z., Guo, J., Wang, J., et al.: Hierarchically porous electrocatalyst with vertically aligned defect-rich CoMoS nanosheets for the hydrogen evolution reaction in an alkaline medium. ACS Appl. Mater. Interfaces 9, 5288-5294 (2017)

284. Yan, X.Y., Devaramani, S., Chen, J., et al.: Self-supported rectangular $\mathrm{CoP}$ nanosheet arrays grown on a carbon cloth as an efficient electrocatalyst for the hydrogen evolution reaction over a variety of pH values. New J. Chem. 41, 2436-2442 (2017)

285. Lin, Y., Pan, Y., Zhang, J.: CoP nanorods decorated biomass derived N, P co-doped carbon flakes as an efficient hybrid catalyst for electrochemical hydrogen evolution. Electrochim. Acta 232, 561-569 (2017)

286. Jin, J., Zhu, Y., Liu, Y., et al.: CoP nanoparticles combined with $\mathrm{WS}_{2}$ nanosheets as efficient electrocatalytic hydrogen evolution reaction catalyst. Int. J. Hydrog. Energy 42, 3947-3954 (2017)

287. Jiang, P., Liu, Q., Ge, C., et al.: CoP nanostructures with different morphologies: synthesis, characterization and a study of their electrocatalytic performance toward the hydrogen evolution reaction. J. Mater. Chem. A 2, 14634-14640 (2014)

288. Popczun, E.J., Read, C.G., Roske, C.W., et al.: Highly active electrocatalysis of the hydrogen evolution reaction by cobalt phosphide nanoparticles. Angew. Chem. Int. Ed. 53, 5427-5430 (2014)

289. Yang, H., Zhang, Y., Hu, F., et al.: Urchin-like CoP nanocrystals as hydrogen evolution reaction and oxygen reduction reaction dual-electrocatalyst with superior stability. Nano Lett. 15, 7616-7620 (2015)

290. Zhou, D., He, L., Zhu, W., et al.: Interconnected urchin-like cobalt phosphide microspheres film for highly efficient electrochemical hydrogen evolution in both acidic and basic media. J. Mater. Chem. A 4, 10114-10117 (2016)

291. Li, M., Liu, X., Xiong, Y., et al.: Facile synthesis of various highly dispersive CoP nanocrystal embedded carbon matrices as efficient electrocatalysts for the hydrogen evolution reaction. J. Mater. Chem. A 3, 4255-4265 (2015)

292. Zhang, R., Ren, X., Hao, S., et al.: Selective phosphidation: an effective strategy toward $\mathrm{CoP} / \mathrm{CeO}_{2}$ interface engineering for superior alkaline hydrogen evolution electrocatalysis. J. Mater. Chem. A 6, 1985-1990 (2018)

293. Jintao, Z., Liangti, Q., Gaoquan, S., et al.: N, P-codoped carbon networks as efficient metal-free bifunctional catalysts for oxygen reduction and hydrogen evolution reactions. Angew. Chem. 128, 2270-2274 (2016)

294. Zhou, W., Jia, J., Lu, J., et al.: Recent developments of carbonbased electrocatalysts for hydrogen evolution reaction. Nano Energy 28, 29-43 (2016)

295. Yan, D., Dou, S., Tao, L., et al.: Electropolymerized supermolecule derived $\mathrm{N}, \mathrm{P}$ co-doped carbon nanofiber networks as a highly efficient metal-free electrocatalyst for the hydrogen evolution reaction. J. Mater. Chem. A 4, 13726-13730 (2016)

296. Ma, L., Shen, X., Zhou, H., et al.: CoP nanoparticles deposited on reduced graphene oxide sheets as an active electrocatalyst for the hydrogen evolution reaction. J. Mater. Chem. A 3, 5337-5343 (2015)

297. Qian, L., Jingqi, T., Wei, C., et al.: Carbon nanotubes decorated with CoP nanocrystals: a highly active non-noble-metal nanohybrid electrocatalyst for hydrogen evolution. Angew. Chem. Int. Ed. 53, 6710-6714 (2014)

298. Li, M., Zhou, H., Yang, W., et al.: $\mathrm{Co}_{9} \mathrm{~S}_{8}$ nanoparticles embedded in a $\mathrm{N}, \mathrm{S}$ co-doped graphene-unzipped carbon nanotube composite as a high performance electrocatalyst for the hydrogen evolution reaction. J. Mater. Chem. A 5, 1014-1021 (2017)

299. Zhou, X., Yang, X., Hedhili, M.N., et al.: Symmetrical synergy of hybrid $\mathrm{Co}_{9} \mathrm{~S}_{8}-\mathrm{MoS}_{x}$ electrocatalysts for hydrogen evolution reaction. Nano Energy 32, 470-478 (2017)

300. Kim, J.Y., Han, S., Bang, J.H.: Cobalt disulfide nano-pine-tree array as a platinum alternative electrocatalyst for hydrogen evolution reaction. Mater. Lett. 189, 97-100 (2017)

301. Ansovini, D., Jun Lee, C.J., Chua, C.S., et al.: A highly active hydrogen evolution electrocatalyst based on a cobalt-nickel sulfide composite electrode. J. Mater. Chem. A 4, 9744-9749 (2016)

302. Wang, K., Xi, D., Zhou, C., et al.: $\mathrm{CoSe}_{2}$ necklace-like nanowires supported by carbon fiber paper: a 3D integrated electrode for the hydrogen evolution reaction. J. Mater. Chem. A 3, 9415-9420 (2015)

303. Gong, K., Du, F., Xia, Z., et al.: Nitrogen-doped carbon nanotube arrays with high electrocatalytic activity for oxygen reduction. Science 323, 760 (2009)

304. Dai, L., Xue, Y., Qu, L., et al.: Metal-free catalysts for oxygen reduction reaction. Chem. Rev. 115, 4823-4892 (2015) 
305. Xie, J., Zhang, H., Li, S., et al.: Defect-rich $\mathrm{MoS}_{2}$ ultrathin nanosheets with additional active edge sites for enhanced electrocatalytic hydrogen evolution. Adv. Mater. 25, 5807-5813 (2013)

306. Yan, Y., Xia, B., Ge, X., et al.: Ultrathin $\mathrm{MoS}_{2}$ nanoplates with rich active sites as highly efficient catalyst for hydrogen evolution. ACS Appl. Mater. Interfaces 5, 12794-12798 (2013)

307. Xia, X., Zheng, Z., Zhang, Y., et al.: Synthesis of $\mathrm{MoS}_{2}$-carbon composites with different morphologies and their application in hydrogen evolution reaction. Int. J. Hydrog. Energy 39, 9638-9650 (2014)

308. Wang, F., Sun, Y., He, Y., et al.: Highly efficient and durable MoNiNC catalyst for hydrogen evolution reaction. Nano Energy 37, 1-6 (2017)

309. Shi, J., Hu, J.: Molybdenum sulfide nanosheet arrays supported on Ti plate: an efficient hydrogen-evolving cathode over the whole $\mathrm{pH}$ range. Electrochim. Acta 168, 256-260 (2015)

310. Qian, X., Ding, J., Zhang, J., et al.: Ultrathin molybdenum disulfide/carbon nitride nanosheets with abundant active sites for enhanced hydrogen evolution. Nanoscale 10, 1766-1773 (2018)

311. Guo, M., Wu, Q., Yu, M., et al.: One-step liquid phase chemical method to prepare carbon-based amorphous molybdenum sulfides: as the effective hydrogen evolution reaction catalysts. Electrochim. Acta 236, 280-287 (2017)

312. Cao, P., Peng, J., Li, J., et al.: Highly conductive carbon black supported amorphousmolybdenum disulfide for efficient hydrogen evolution reaction. J. Power Sources 347, 210-219 (2017)

313. Li, R., Yang, L., Xiong, T., et al.: Nitrogen doped $\mathrm{MoS}_{2}$ nanosheets synthesized via a low-temperature process as electrocatalysts with enhanced activity for hydrogen evolution reaction. J. Power Sources 356, 133-139 (2017)

314. Mak, K.F., He, K., Lee, C., et al.: Tightly bound trions in monolayer $\mathrm{MoS}_{2}$. Nat. Mater. 12, 207 (2012)

315. Joensen, P., Frindt, R.F., Morrison, S.R.: Single-layer $\mathrm{MoS}_{2}$. Mater. Res. Bull. 21, 457-461 (1986)

316. Eda, G., Yamaguchi, H., Voiry, D., et al.: Photoluminescence from chemically exfoliated $\mathrm{MoS}_{2}$. Nano Lett. 11, 5111-5116 (2011)

317. Liu, K.K., Zhang, W., Lee, Y.H., et al.: Growth of large-area and highly crystalline $\mathrm{MoS}_{2}$ thin layers on insulating substrates. Nano Lett. 12, 1538-1544 (2012)

318. Wang, X., Feng, H., Wu, Y., et al.: Controlled synthesis of highly crystalline $\mathrm{MoS}_{2}$ flakes by chemical vapor deposition. Chem. Soc. Rev. 135, 5304-5307 (2013)

319. Yongjie, Z., Zheng, L., Sina, N., et al.: Large-area vapor-phase growth and characterization of $\mathrm{MoS}_{2}$ atomic layers on a $\mathrm{SiO}_{2}$ substrate. Small 8, 966-971 (2012)

320. Xie, J., Zhang, J., Li, S., et al.: Controllable disorder engineering in oxygen-incorporated $\mathrm{MoS}_{2}$ ultrathin nanosheets for efficient hydrogen evolution. Chem. Soc. Rev. 135, 17881-17888 (2013)

321. Li, Y., Wang, H., Xie, L., et al.: $\mathrm{MoS}_{2}$ nanoparticles grown on graphene: an advanced catalyst for the hydrogen evolution reaction. Chem. Soc. Rev. 133, 7296-7299 (2011)

322. Merki, D., Fierro, S., Vrubel, H., et al.: Amorphous molybdenum sulfide films as catalysts for electrochemical hydrogen production in water. Chem. Sci. 2, 1262-1267 (2011)

323. Ojha, K., Sharma, M., Kolev, H., et al.: Reduced graphene oxide and MoP composite as highly efficient and durable electrocatalyst for hydrogen evolution in both acidic and alkaline media. Catal. Sci. Technol. 7, 668-676 (2017)
324. $\mathrm{Pu}, \mathrm{Z}$., Saana Amiinu, I., Wang, M., et al.: Semimetallic $\mathrm{MoP}_{2}$ : an active and stable hydrogen evolution electrocatalyst over the whole pH range. Nanoscale 8, 8500-8504 (2016)

325. Deng, C., Xie, J., Xue, Y., et al.: Synthesis of MoP decorated carbon cloth as a binder-free electrode for hydrogen evolution. RSC Adv. 6, 68568-68573 (2016)

326. Xiao, P., Sk, M.A., Thia, L., et al.: Molybdenum phosphide as an efficient electrocatalyst for the hydrogen evolution reaction. Energy Environ. Sci. 7, 2624-2629 (2014)

327. Deng, C., Ding, F., Li, X., et al.: Templated-preparation of a three-dimensional molybdenum phosphide sponge as a high performance electrode for hydrogen evolution. J. Mater. Chem. A 4 59-66 (2016)

328. Pu, Z., Wei, S., Chen, Z., et al.: Flexible molybdenum phosphide nanosheet array electrodes for hydrogen evolution reaction in a wide pH range. Appl. Catal. B Environ. 196, 193-198 (2016)

329. Chen, X., Qi, J., Wang, P., et al.: Polyvinyl alcohol protected $\mathrm{Mo}_{2} \mathrm{C} / \mathrm{Mo}_{2} \mathrm{~N}$ multicomponent electrocatalysts with controlled morphology for hydrogen evolution reaction in acid and alkaline medium. Electrochim. Acta 273, 239-247 (2018)

330. Lv, C., Huang, Z., Yang, Q., et al.: Nanocomposite of $\mathrm{MoO}_{2}$ and $\mathrm{MoC}$ loaded on porous carbon as an efficient electrocatalyst for hydrogen evolution reaction. Inorg. Chem. Front. 5, 446-453 (2018)

331. Xie, X., Lin, L., Liu, R.Y., et al.: The synergistic effect of metallic molybdenum dioxide nanoparticle decorated graphene as an active electrocatalyst for an enhanced hydrogen evolution reaction. J. Mater. Chem. A 3, 8055-8061 (2015)

332. Bukola, S., Merzougui, B., Creager, S.E., et al.: Nanostructured cobalt-modified molybdenum carbides electrocatalysts for hydrogen evolution reaction. Int. J. Hydrog. Energy 41, 22899-22912 (2016)

333. Liu, X., Zhang, L., Lan, X., et al.: Paragenesis of $\mathrm{Mo}_{2} \mathrm{C}$ nanocrystals in mesoporous carbon nanofibers for electrocatalytic hydrogen evolution. Electrochim. Acta 274, 23-30 (2018)

334. Wang, H., Sun, C., Cao, Y., et al.: Molybdenum carbide nanoparticles embedded in nitrogen-doped porous carbon nanofibers as a dual catalyst for hydrogen evolution and oxygen reduction reactions. Carbon 114, 628-634 (2017)

335. Jing, S., Zhang, L., Luo, L., et al.: N-doped porous molybdenum carbide nanobelts as efficient catalysts for hydrogen evolution reaction. Appl. Catal. B Environ. 224, 533-540 (2018)

336. Jiang, R., Fan, J., Hu, L., et al.: Electrochemically synthesized $\mathrm{N}$-doped molybdenum carbide nanoparticles for efficient catalysis of hydrogen evolution reaction. Electrochim. Acta 261, 578587 (2018)

337. Jin, Y., Shen, P.K.: Nanoflower-like metallic conductive $\mathrm{MoO}_{2}$ as a high-performance non-precious metal electrocatalyst for the hydrogen evolution reaction. J. Mater. Chem. A 3, 20080-20085 (2015)

338. Grigoriev, S.A., Mamat, M.S., Dzhus, K.A., et al.: Platinum and palladium nano-particles supported by graphitic nano-fibers as catalysts for PEM water electrolysis. Int. J. Hydrog. Energy 36, 4143-4147 (2011)

339. Grigoriev, S.A., Millet, P., Fateev, V.N.: Evaluation of carbonsupported Pt and Pd nanoparticles for the hydrogen evolution reaction in PEM water electrolysers. J. Power Sources 177, 281-285 (2008)

340. Su, D.S., Centi, G.: A perspective on carbon materials for future energy application. J. Energy Chem. 22, 151-173 (2013)

341. Pushkarev, A.S., Pushkareva, I.V., Grigoriev, S.A., et al.: Electrocatalytic layers modified by reduced graphene oxide for PEM fuel cells. Int. J. Hydrog. Energy 40, 14492-14497 (2015) 
342. Terrones, M., Ajayan, P.M., Banhart, F., et al.: N-doping and coalescence of carbon nanotubes: synthesis and electronic properties. Appl. Phys. A 74, 355-361 (2002)

343. Esposito, D.V., Hunt, S.T., Kimmel, Y.C., et al.: A new class of electrocatalysts for hydrogen production from water electrolysis: metal monolayers supported on low-cost transition metal carbides. Chem. Soc. Rev. 134, 3025-3033 (2012)

344. Nikiforov, A.V., Petrushina, I.M., Christensen, E., et al.: WC as a non-platinum hydrogen evolution electrocatalyst for high temperature PEM water electrolysers. Int. J. Hydrog. Energy 37, 18591-18597 (2012)

345. Kelly, T.G., Hunt, S.T., Esposito, D.V., et al.: Monolayer palladium supported on molybdenum and tungsten carbide substrates as low-cost hydrogen evolution reaction (HER) electrocatalysts. Int. J. Hydrog. Energy 38, 5638-5644 (2013)

346. Esposito, D.V., Hunt, S.T., Stottlemyer, A.L., et al.: Low-cost hydrogen-evolution catalysts based on monolayer platinum on tungsten monocarbide substrates. Angew. Chem. Int. Ed. 49, 9859-9862 (2010)

347. Meyer, S., Nikiforov, A.V., Petrushina, I.M., et al.: Transition metal carbides ( $\mathrm{WC}, \mathrm{Mo}_{2} \mathrm{C}, \mathrm{TaC}, \mathrm{NbC}$ ) as potential electrocatalysts for the hydrogen evolution reaction (HER) at medium temperatures. Int. J. Hydrog. Energy 40, 2905-2911 (2015)

348. Tang, C., Sun, A., Xu, Y., et al.: High specific surface area $\mathrm{Mo}_{2} \mathrm{C}$ nanoparticles as an efficient electrocatalyst for hydrogen evolution. J. Power Sources 296, 18-22 (2015)

349. Ramakrishna, S.U.B., Srinivasulu Reddy, D., Shiva Kumar, S., et al.: Nitrogen doped CNTs supported palladium electrocatalyst for hydrogen evolution reaction in PEM water electrolyser. Int. J. Hydrog. Energy 41, 20447-20454 (2016)

350. Sedlak, J.M., Lawrance, R.J., Enos, J.F.: Advances in oxygen evolution catalysis in solid polymer electrolyte water electrolysis. Int. J. Hydrog. Energy 6, 159-165 (1981)

351. Takenaka, H., Torikai, E., Kawami, Y., et al.: Solid polymer electrolyte water electrolysis. Int. J. Hydrog. Energy 7, 397-403 (1982)

352. Millet, P., Durand, R., Pineri, M.: Preparation of new solid polymer electrolyte composites for water electrolysis. Int. J. Hydrog. Energy 15, 245-253 (1990)

353. Pantani, O., Anxolabéhère-Mallart, E., Aukauloo, A., et al.: Electroactivity of cobalt and nickel glyoximes with regard to the electro-reduction of protons into molecular hydrogen in acidic media. Electrochem. Commun. 9, 54-58 (2007)

354. Cheng, J., Zhang, H., Ma, H., et al.: Study of carbon-supported $\mathrm{IrO}_{2}$ and $\mathrm{RuO}_{2}$ for use in the hydrogen evolution reaction in a solid polymer electrolyte electrolyzer. Electrochim. Acta 55, 1855-1861 (2010)

355. Yan, J., Chen, H., Dogdibegovic, E., et al.: High-efficiency intermediate temperature solid oxide electrolyzer cells for the conversion of carbon dioxide to fuels. J. Power Sources 252, 79-84 (2014)

356. Zhan, Z., Zhao, L.: Electrochemical reduction of $\mathrm{CO}_{2}$ in solid oxide electrolysis cells. J. Power Sources 195, 7250-7254 (2010)

357. Singh, V., Muroyama, H., Matsui, T., et al.: Feasibility of alternative electrode materials for high temperature $\mathrm{CO}_{2}$ reduction on solid oxide electrolysis cell. J. Power Sources 293, 642-648 (2015)

358. Cao, Z., Zhang, Y., Miao, J., et al.: Titanium-substituted lanthanum strontium ferrite as a novel electrode material for symmetrical solid oxide fuel cell. Int. J. Hydrog. Energy 40, 16572-16577 (2015)

359. Yu, X., Long, W., Jin, F., et al.: Cobalt-free perovskite cathode materials $\mathrm{SrFe}_{1-x} \mathrm{Ti}_{x} \mathrm{O}_{3-\delta}$ and performance optimization for intermediate-temperature solid oxide fuel cells. Electrochim. Acta 123, 426-434 (2014)

360. Liu, Q., Dong, X., Xiao, G., et al.: A novel electrode material for symmetrical SOFCs. Adv. Mater. 22, 5478-5482 (2010)

361. Yang, Z., Xu, N., Han, M., et al.: Performance evaluation of $\mathrm{La}_{0.4} \mathrm{Sr}_{0.6} \mathrm{Co}_{0.2} \mathrm{Fe}_{0.7} \mathrm{Nb}_{0.1} \mathrm{O}_{3-\delta}$ as both anode and cathode material in solid oxide fuel cells. Int. J. Hydrog. Energy 39, 7402-7406 (2014)

362. Yang, Z., Chen, Y., Jin, C., et al.: $\mathrm{La}_{0.7} \mathrm{Sr}_{0.3} \mathrm{Fe}_{0.7} \mathrm{Ga}_{0.3} \mathrm{O}_{3-\sigma}$ as electrode material for a symmetrical solid oxide fuel cell. RSC Adv. 5, 2702-2705 (2015)

363. Lai, B.K., Kerman, K., Ramanathan, S.: Nanostructured $\mathrm{La}_{0.6} \mathrm{Sr}_{0.4} \mathrm{Co}_{0.8} \mathrm{Fe}_{0.2} \mathrm{O}_{3} / \mathrm{Y}_{0.08} \mathrm{Zr}_{0.92} \mathrm{O}_{1.96} / \mathrm{La}_{0.6} \mathrm{Sr}_{0.4} \mathrm{Co}_{0.8} \mathrm{Fe}_{0.2} \mathrm{O}_{3}$ (LSCF/YSZ/LSCF) symmetric thin film solid oxide fuel cells. J. Power Sources 196, 1826-1832 (2011)

364. Liu, L., Sun, K., Li, X., et al.: A novel doped $\mathrm{CeO}_{2}-\mathrm{LaFeO}_{3}$ composite oxide as both anode and cathode for solid oxide fuel cells. Int. J. Hydrog. Energy 37, 12574-12579 (2012)

365. Fernández-Ropero, A.J., Porras-Vázquez, J.M., Cabeza, A., et al.: High valence transition metal doped strontium ferrites for electrode materials in symmetrical SOFCs. J. Power Sources 249, 405-413 (2014)

366. Zhou, Q., Yuan, C., Han, D., et al.: Evaluation of $\mathrm{LaSr}_{2} \mathrm{Fe}_{2} \mathrm{CrO}_{9-\delta}$ as a potential electrode for symmetrical solid oxide fuel cells. Electrochim. Acta 133, 453-458 (2014)

367. Yaremchenko, A.A., Patrício, S.G., Frade, J.R.: Thermochemical behavior and transport properties of Pr-substituted $\mathrm{SrTiO}_{3}$ as potential solid oxide fuel cell anode. J. Power Sources 245, 557-569 (2014)

368. Wang, X., Zhang, C., Zang, G., et al.: Effect of doping content of $\mathrm{Pr}$ ions on oxygen vacancies in $\mathrm{SrTiO}_{3}$ films. J. Alloys Compd. 637, 277-280 (2015)

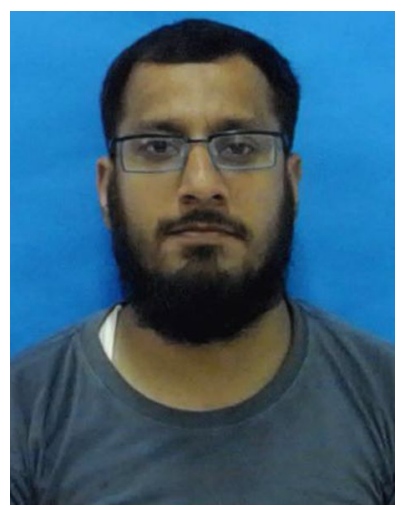

Muhammad Arif Khan received his Bachelor's degree in physical chemistry from the Institute of Chemical Sciences, University of Peshawar, Pakistan, and M.Phil. in physical chemistry from the NCE, University of Peshawar, Pakistan. Currently, he is working as a Ph.D. scholar under the supervision of associate Professor Hongbin Zhao at Shanghai University. His research interests are focused on electrode materials for energy storage devices and electrocatalysis. 


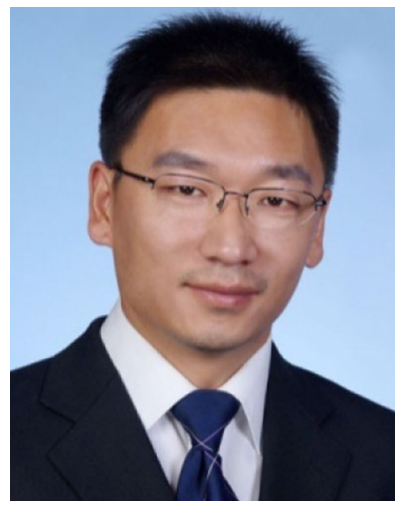

Hongbin Zhao received his Ph.D. from Shanghai Jiaotong University in 2009 and completed his postdoctoral research in Shanghai University between 2009 and 2011. Since 2011, he has remained at Shanghai University in addition to working for a year in the Department of Chemical Engineering at the University of Waterloo, Canada, from 2014 to 2015 as a visiting scholar (Shanghai Pujiang Talent). He is currently an associate professor at Shanghai University, and his research interests focus on electrode materials for fuel cells, lithium-ion batteries, lithium-sulphur batteries and supercapacitors. He was awarded the "Shanghai Pujiang Talent" award and has published more than 70 academic papers, 1 edited book, 2 book chapters and 6 patents. In addition, he has also organized more than 5 academic research projects and one application project.

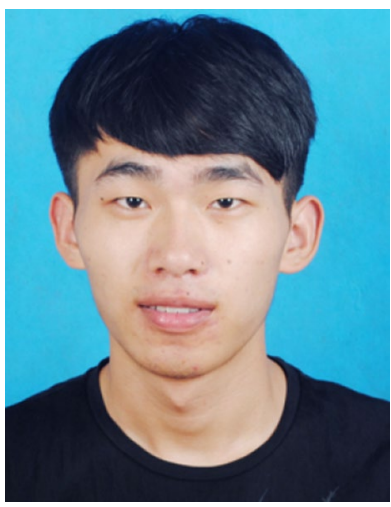

Wenwen Zou received his B.Sc. from the College of Engineering, Huzhou University, in 2017 and is currently a M.S. student at the College of Sciences, Shanghai University. His research interests include the synthesis of nonnoble metal catalysts and their application in fuel cells and solid polymer electrolyte water-splitting techniques.

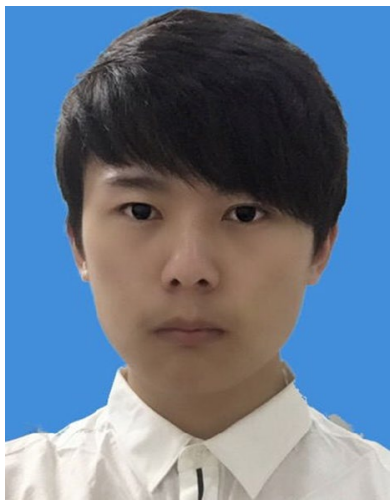

Zhe Chen received his B.Sc. from the College of Sciences, Shanghai University, in 2017 and is currently a M.S. student at the College of Sciences, Shanghai University. His research interests include the synthesis of nonnoble metal catalysts and their application in fuel cells and solid polymer electrolyte water-splitting techniques.

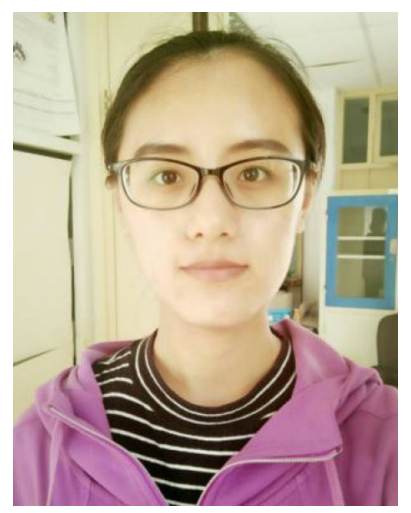

Wenjuan Cao received her B.Sc. in 2016 majoring in chemical engineering and technology from the Zhengzhou University of Light Industry. Currently, she is pursuing her M.S. in the Department of Chemistry, Shanghai University. Her research interests focus on electrode materials for lithium-ion batteries, water-splitting catalysts and fuel cells.

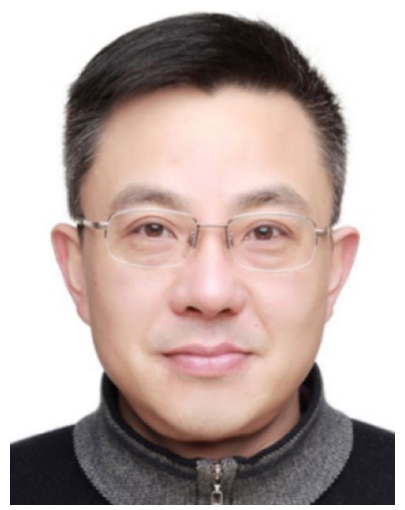

Jianhui Fang started his career at the Shanghai University of Science and Technology in 1986 and received his Ph.D. from Shanghai University in 2006. Currently, he is a professor and supervisor at Shanghai University and his research field mainly involves the innovation and application of material chemistry, electrochemistry and water treatment technologies.

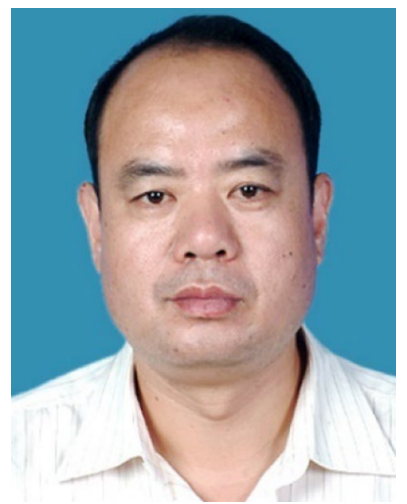

Jiaqiang $\mathrm{Xu}$ is professor and vice dean of the Department of Chemistry at Shanghai University. His research interests include controllable synthesis of nanostructured materials and their application in sensing, energy and environment. His accomplishments include over 200 peerreviewed journal publications with 5700 citations and 42 H-Index, along with 6 provincial science and technology achievement awards and tens of patents. Currently, Jiaqiang $\mathrm{Xu}$ is also a director at the Special Committee on Gas and Humidity Sensor Technologies within China Electronics Society and an academic leader in the field of nanostructured materials and devices belonging to the Nanomaterials Chemistry Key Discipline of Shanghai Municipal Education Commission. He also is a member of the Council of Sensors and Actuators Technical Committee, China Instrument and Control Society and China Sensors Alliance. 


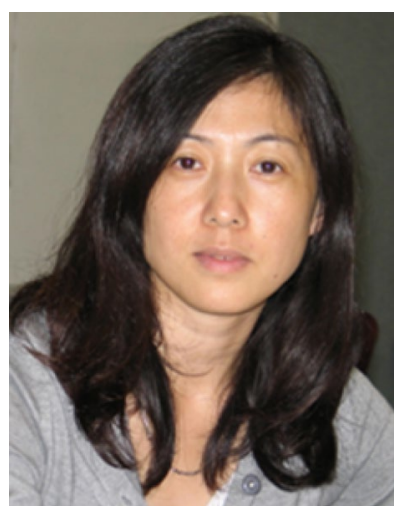

Lei Zhang is a senior research officer at the National Research Council Canada (NRC), a Fellow of the Royal Society of Chemistry (FRSC), an adjunct professor at Shanghai University, and the vice president of the International Academy of Electrochemical Energy Science (IAOEES). In 2004, she joined NRC to initiate the PEM Fuel Cell program and has also carried out R\&D into other electrochemical energy technologies, such as supercapacitors, metal-air batteries and hybrid batteries. She has coauthored more than 170 publications (> 13000 citations), including over 80 referenced journal papers, 3 edited books, 4 book chapters, 5 patents and applications and over 50 technical reports. She is also a member of the NSERC Industrial R\&D Fellowships College of Reviewers in Canada and an editorial board member of Electrochemical Energy Reviews (EER), Springer Nature. In addition, she is an active member of the Royal Society of Chemistry (RSC), the Canadian Society for Chemistry (CSC), the Canadian Society for Chemical Engineering (CSChE) and the International Academy of Electrochemical Energy Science (IAOEES).

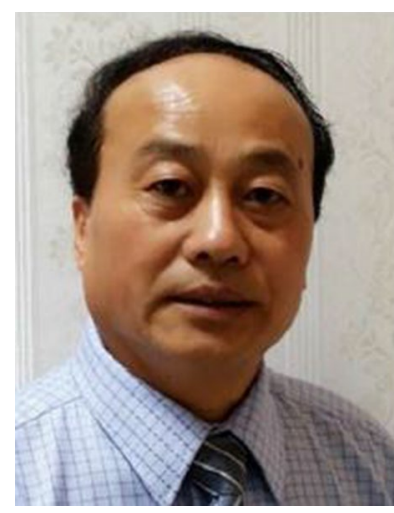

Jiujun Zhang is a professor at Shanghai University and a principal research officer (Emeritus) and technical core competency leader at the National Research Council of Canada Energy (NRC). Dr. Zhang received his B.S. and M.Sc. in electrochemistry from Peking University in 1982 and 1985, respectively, and his $\mathrm{Ph} . \mathrm{D}$. in electrochemistry from Wuhan University in 1988. He then carried out three terms of postdoctoral research at the California Institute of Technology, York University, and the

University of British Columbia. Dr. Zhang has over 30 years of scientific research experience, particularly in electrochemical energy storage and conversion. In addition, he is also an adjunct professor at the University of British Columbia and the University of Waterloo. 